\title{
Quantifying the impact of forest management intensity and tree species diversity on individual tree shape and three-dimensional stand structure
}

\author{
Dissertation \\ zur Erlangung des Doktorgrades (Dr. rer. nat.) \\ der Fakultät für Forstwissenschaften und Waldökologie \\ der Georg-August-Universität Göttingen \\ vorgelegt von \\ Dipl.-Biol. Julia Juchheim \\ geboren am 23.03.1982 in Blaubeuren
}

Göttingen, Oktober 2020 

Erstgutachter: $\quad$ Prof. Dr. Christian Ammer

Abteilung Waldbau und Waldökologie der gemäßigten Zonen

Fakultät für Forstwissenschaften und Waldökologie

Georg-August-Universität Göttingen

Büsgenweg 1, 37077 Göttingen

Zweitgutachter: $\quad$ Prof. Dr. Dirk Hölscher

Abteilung Waldbau und Waldökologie der Tropen

Fakultät für Forstwissenschaften und Waldökologie

Georg-August-Universität Göttingen

Büsgenweg 1, 37077 Göttingen

Tag der mündlichen Prüfung: 18.09.2020 



\section{Table of contents}

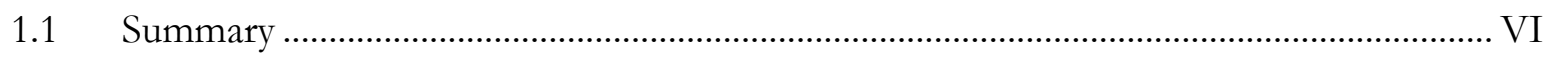

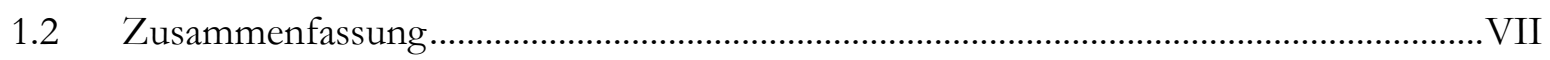

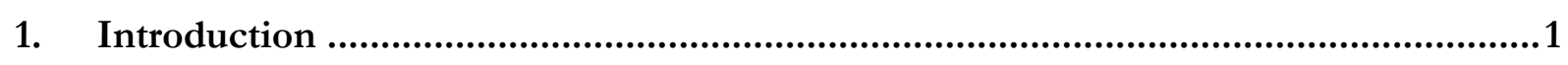

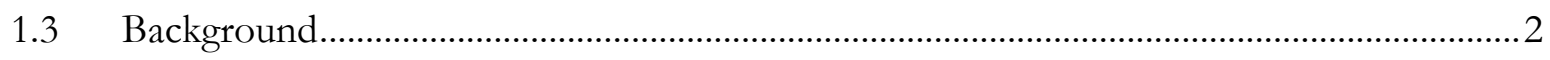

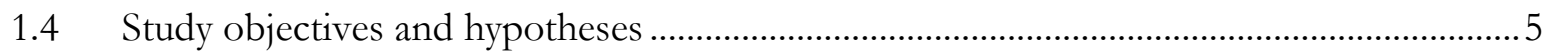

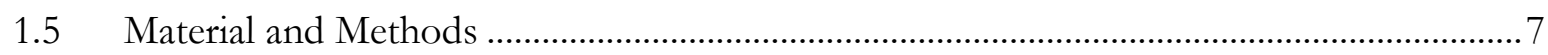

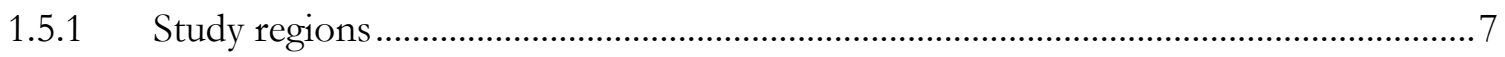

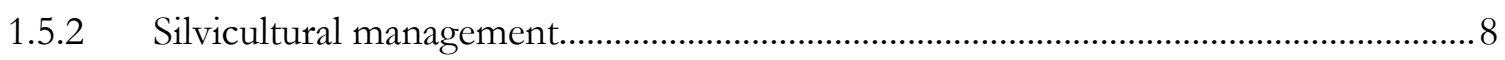

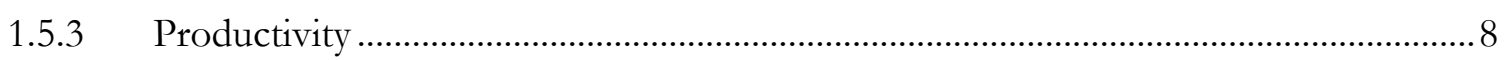

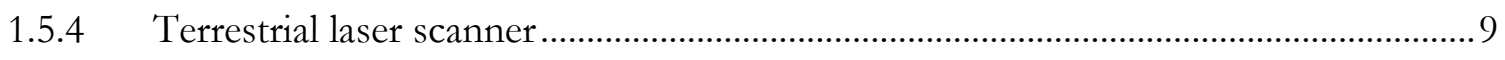

1.5.5 Data acquisition and computation of TLS-based structural measures ......................10

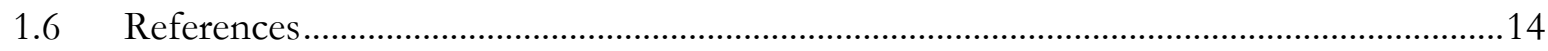

2. How management intensity and neighborhood composition affect the structure of

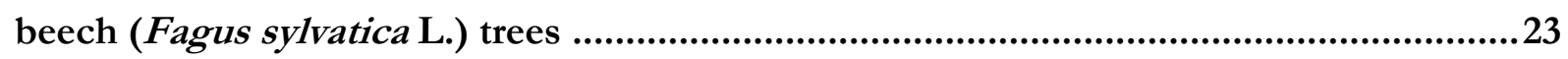

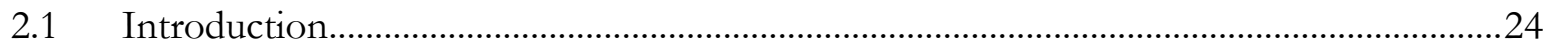

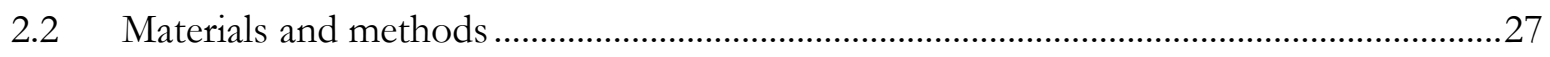

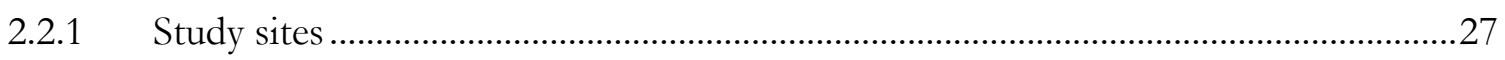

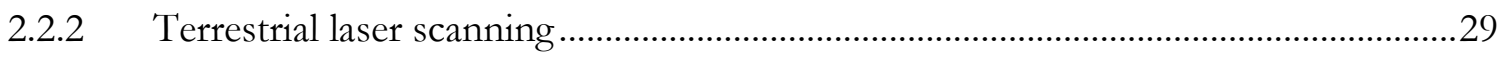

2.2.3 Point cloud pre-processing …………..........................................................................

2.2.4 Point cloud post-processing ………………...................................................................30

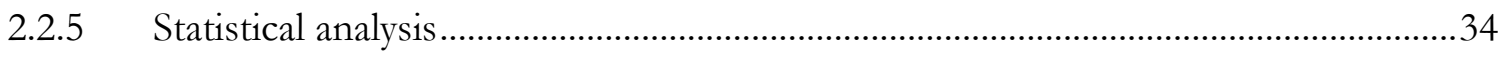

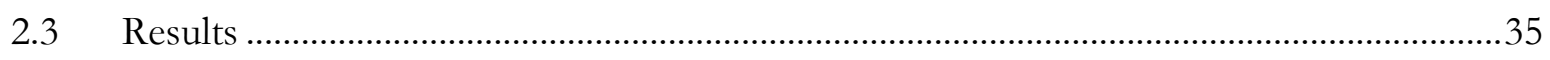

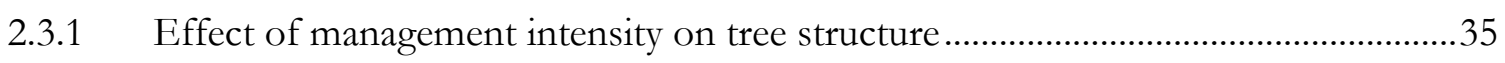

2.3.2 Effect of stand composition on tree structure................................................................ 36

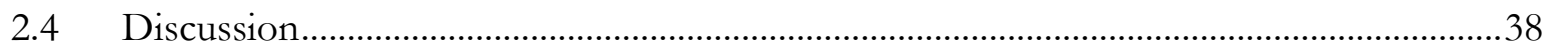

2.4.1 Effect of management intensity on tree structure .........................................................38

2.4.2 Effect of stand composition on tree structure.............................................................. 39 


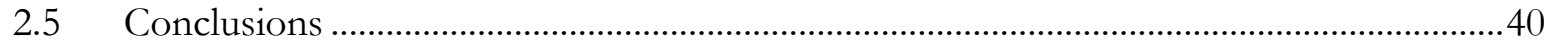

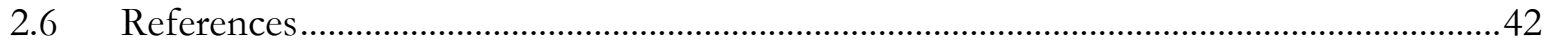

3. Canopy space filling rather than conventional measures of structural diversity explains

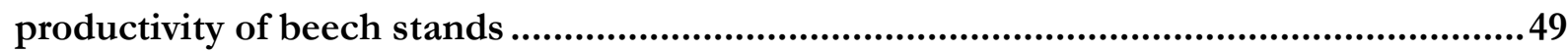

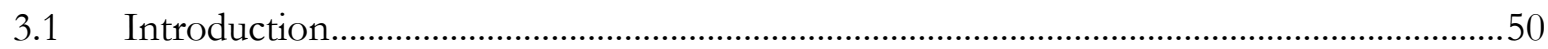

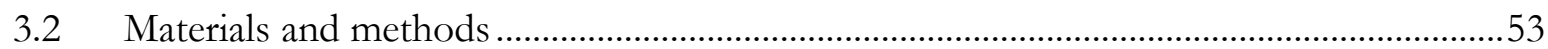

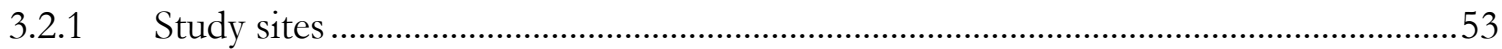

3.2.2 Terrestrial laser scanning and sampling design ............................................................54

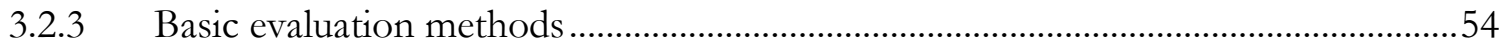

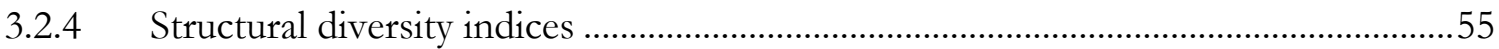

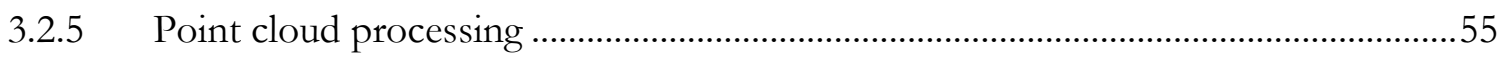

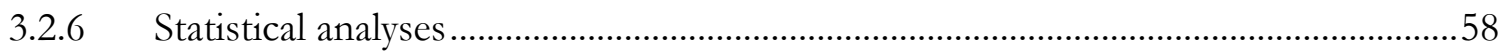

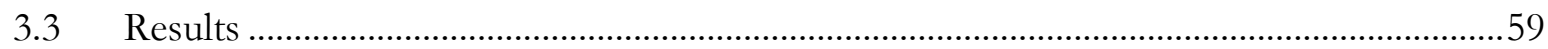

3.3.1 Effect of SMI on productivity, space filling and structural diversity .........................59

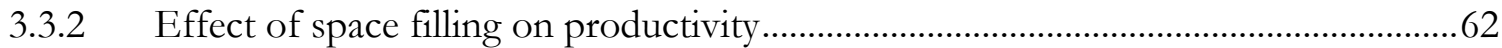

3.3.3 Effect of structural diversity on productivity .................................................................64

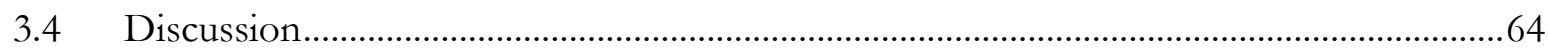

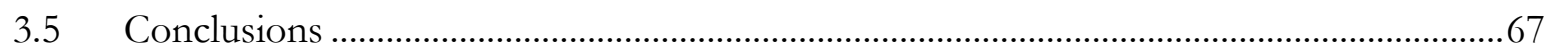

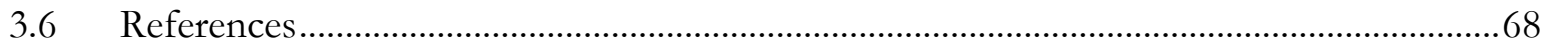

4. Effect of tree species mixing on stand structural complexity ..................................73

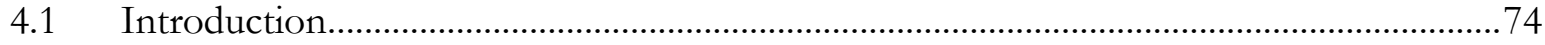

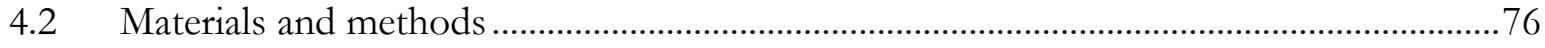

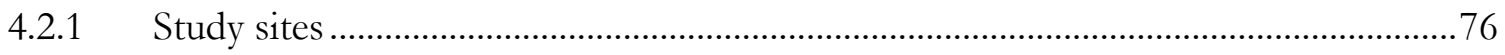

4.2.2 Data acquisition and computation of single-scan based structural measures............79

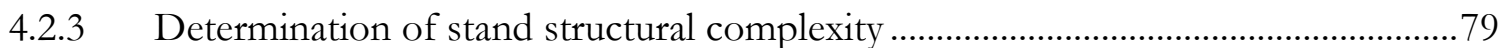

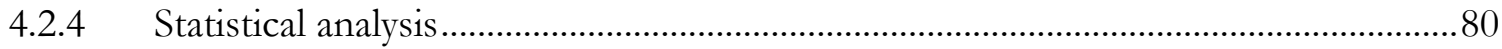

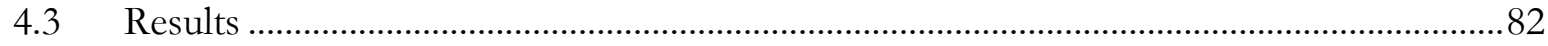

4.3.1 Effect of increasing tree species diversity on stand structural complexity ................82 
4.3.2 Effect of an increasing PBL on stand structural complexity of coniferous stands .84

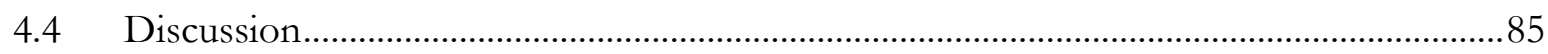

4.4.1 Effect of increasing tree species diversity on stand structural complexity ……........85

4.4.2 Effect of an increasing PBL on stand structural complexity of coniferous stands 87

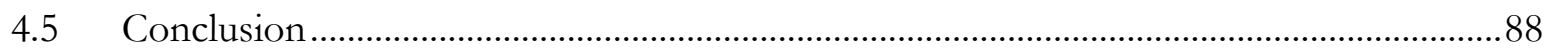

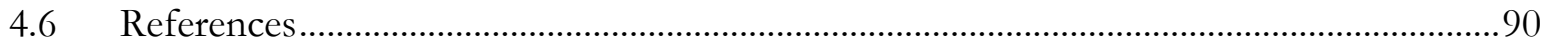

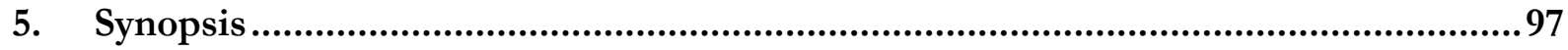

5.1 Effect of silvicultural management intensity on tree and stand structure ........................ 98

5.2 Effect of forest structure on stand productivity ……......................................................... 101

5.3 Effect of tree species mixing on tree and stand structure ..............................................103

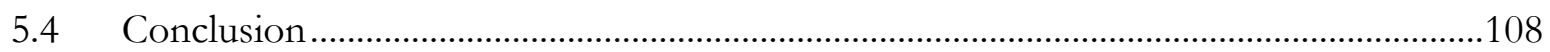

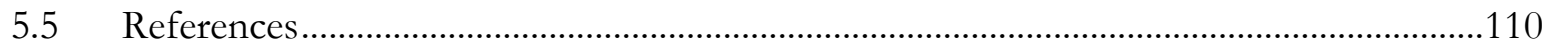

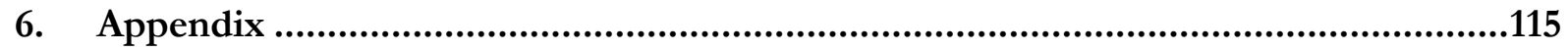

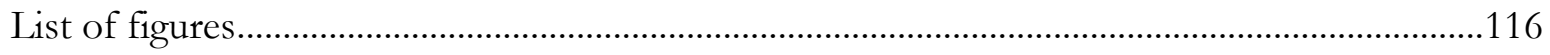

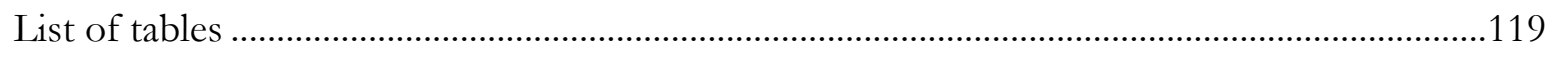

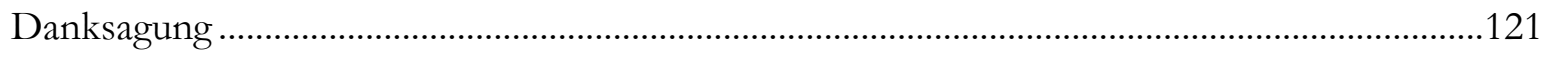

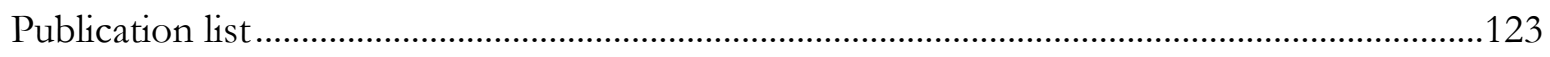

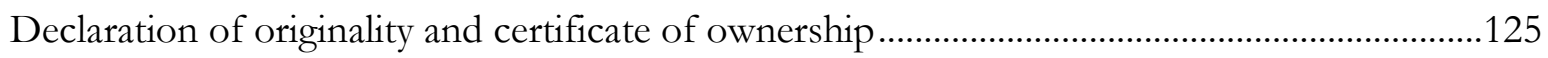





\subsection{Summary}

The three-dimensional distribution of trees and their crowns is an essential characteristic of forest ecosystems that is directly related to several ecosystem functions and services. Silvicultural interventions modify the stand structure and thus have a major impact on the ecological and economical value of a forest stand.

In the past, it was challenging to obtain quantitative data on the effects of different silvicultural treatments on tree architecture and three-dimensional stand structure. Comprehensive manual measurements of crown characteristics in mature stands were labor-intensive, time-consuming and, because of the complexity of the canopy, difficult to realize on a large-scale. In recent years, terrestrial laser scanning (TLS) allowed great advances in measuring the three-dimensional forest structure with reasonable effort and high accuracy. Terrestrial laser scanning is a ground-based active remote sensing technique that measures the distance between a laser scanner device and an object by transmitting laser energy. The distance to the target is calculated either by the phase difference between the transmitted and the received laser light or by the laser return time. Spatial data on the scanned objects is then available in form of three-dimensional point clouds.

In the present work, we used terrestrial laser scanning data to quantify the impact of forest management intensity and tree species diversity on individual tree shape and three-dimensional stand structure. We conducted our studies within the framework of the Biodiversity Exploratories, a long-dated and large-scaled project which addresses the relationship between land-use intensity and biodiversity. The research plots are located in three different regions of Germany: the Swabian Alb in southwest Germany, the Hainich-Dün in central Germany, and the Schorfheide-Chorin in northeast Germany.

In our first study we identified that structural attributes of European beech trees, such as crown and trunk shape or branching patterns, were significantly influenced by silvicultural management intensity and stand composition. Our findings demonstrate the high plasticity of beech and indicate an increasing competition with decreasing management intensity and a higher competitive pressure for beech trees growing in pure stands than for beech trees surrounded by valuable hardwoods.

Our second study showed that an increasing management intensity in beech stands led to a vertically more even distribution of aboveground biomass. The regularly thinned stands showed a higher canopy space filling compared to the unmanaged stands, despite the removal of trees. In addition, our results revealed that a higher space filling, particularly in the shaded canopy, positively affected stand productivity. 
In our third study we could show that an increasing tree species diversity enhanced the complexity of the stand structure. Furthermore, we found that an increasing share of broadleaved trees increased the structural complexity of coniferous stands.

The presented results contribute to a better understanding of how different management approaches modify tree and stand structure and provide insights to promote certain ecosystem functions and services of forests.

\subsection{Zusammenfassung}

Die dreidimensionale Verteilung von Bäumen und ihren Kronen ist ein wesentliches Charakteristikum von Waldökosystemen, welche in direktem Zusammenhang mit verschiedenen Ökosystemfunktionen und -dienstleistungen steht. Waldbauliche Eingriffe verändern die Bestandesstruktur und haben somit einen großen Einfluss auf den ökologischen und ökonomischen Wert eines Waldes.

In der Vergangenheit war es schwierig quantitative Daten über die Auswirkungen verschiedener Managementansätze auf die Baumarchitektur und die dreidimensionale Bestandesstruktur zu erhalten. Umfassende manuelle Messungen von Kronenmerkmalen in Altbeständen waren arbeitsintensiv, zeitaufwendig und aufgrund der Komplexität des Kronendaches im großen Maßstab schwierig zu realisieren. In den letzten Jahren wurden bedeutende Fortschritte bei der Messung der dreidimensionalen Struktur mittels terrestrischem Laserscanning (TLS) bei vertretbarem Aufwand und hoher Genauigkeit erzielt.

Das terrestrische Laserscanning ist eine bodengestützte aktive Fernerkundungstechnik, die den Abstand zwischen einem Laserscanner und einem Objekt durch das Aussenden von Laserstrahlen misst. Die Entfernung zum Ziel wird entweder durch die Phasendifferenz zwischen ausgesendetem und empfangenem Signal oder über die Signallaufzeit berechnet. Die räumlichen Daten der gescannten Objekte werden dann verwendet, um dreidimensionale Punktwolken zu erzeugen.

In der vorliegenden Arbeit haben wir terrestrische Laserscandaten verwendet, um den Einfluss der Waldbewirtschaftungsintensität und der Baumartenvielfalt auf die Architektur einzelner Bäume sowie auf die dreidimensionale Bestandesstruktur zu quantifizieren. Die Studien wurden im Rahmen der Biodiversitäts-Exploratorien durchgeführt. Hierbei handelt es sich um ein langfristig und groß angelegtes Projekt zur Erforschung der Beziehung zwischen Landnutzungsintensität und Biodiversität. Die Untersuchungsflächen befinden sich in drei verschiedenen Regionen in Deutschland: auf der Schwäbischen Alb in Südwestdeutschland, in der Hainich-Dün Region in Mitteldeutschland und in der Schorfheide-Chorin in Nordostdeutschland. 
In unserer ersten Studie konnten wir zeigen, dass verschiedene Strukturmerkmale der Rotbuche (Fagus sylvatica L.), wie beispielsweise Kronen- und Stammform oder Verzweigungsmuster durch die waldbauliche Bewirtschaftungsintensität und die Bestandeszusammensetzung signifikant beeinflusst wurden. Unsere Ergebnisse verdeutlichen die hohe Plastizität der Rotbuche und weisen auf eine zunehmende Konkurrenz mit abnehmender Bewirtschaftungsintensität und auf einen höheren Konkurrenzdruck für Buchen in Reinbeständen im Vergleich zu Mischbeständen mit Edellaubhölzern hin.

Unsere zweite Studie zeigte, dass eine zunehmende Intensität der Bewirtschaftung in Buchenbeständen zu einer vertikal gleichmäßigeren Verteilung der oberirdischen Biomasse führte. Die regelmäßig durchforsteten Bestände wiesen, verglichen mit den unbewirtschafteten Beständen, trotz der Entnahme von Bäumen, eine höhere Raumbesetzung auf. Unsere Ergebnisse zeigten darüber hinaus, dass eine höhere Raumbefüllung insbesondere in der Schattenkrone die Bestandesproduktivität positiv beeinflusst.

In unserer dritten Studie stellten wir fest, dass eine zunehmende Baumartendiversität zu einer höheren Komplexität der Bestandesstruktur führt. Weiterhin konnten wir zeigen, dass ein zunehmender Laubbaumanteil die strukturelle Komplexität von Nadelbaumbeständen erhöht.

Die vorgestellten Ergebnisse tragen zu einem besseren Verständnis darüber bei, wie verschiedene Bewirtschaftungsansätze die Baum- und Bestandesstruktur verändern und liefern Erkenntnisse, um bestimmte Ökosystemfunktionen und -dienstleistungen von Wäldern zu fördern. 



\section{Chapter 1}

\section{Introduction}




\subsection{Background}

The condition of many forests today is the result of the constantly changing needs of humans that reflect the political, economic and ecological dynamics of society (von Gadow, 2005; Puettmann et al., 2012; Messier et al., 2015).

Until the $18^{\text {th }}$ and $19^{\text {th }}$ centuries European beech forests (Fagus sylvatica L.) were traditionally managed as coppice and coppice-with-standards or were used as pasture for livestock (Peters, 1997). During the $19^{\text {th }}$ century after a long period of forest devastation and soil degradation by exploitation, grazing and litter extraction, great efforts were undertaken to meet the increasing wood demand in Central Europe (Zerbe, 2002). As a result, large areas that had been naturally dominated by European beech were afforested or converted to even-aged conifer monocultures of Norway spruce (Picea abies L. H. KARST) or Scots pine (Pinus sylvestris L.) (Augusto et al., 2002; Verstraeten, 2013). In addition, most of the remaining beech forests experienced significant changes in forest structure through the introduction of shelterwood management (Emanuelsson, 2009).

Nowadays, increasing concerns about climate change, the loss of biodiversity as well as the high susceptibility of pure coniferous stands to disturbances, have led to a paradigm shift in forestry (Spiecker, 2003; Verstraeten, 2013; Raum and Potter, 2015). In this context, managing forests to promote structural heterogeneity (also termed 'structural diversity' or 'structural complexity') has become a major objective of sustainable forestry in many European countries (del Río et al., 2016; Pretzsch and Zenner, 2017). Consequently, silvicultural management practices changed from focusing on conifer monocultures towards more broadleaved-dominated stands and from evenaged towards uneven-aged forest management (O'Hara, 2016). In many cases, beech is involved in this transformation process, as without human intervention beech would dominate large parts of Central European forest area (Pretzsch et al., 2013; Leuschner and Ellenberg, 2017).

Structurally heterogeneous and species-rich forest stands are supposed to have a higher ecological stability than mono-layered and single-species stands regarding abiotic and biotic stress (Knoke et al., 2008; Jactel et al., 2009; Thurm et al., 2016). Moreover, they are presumed to provide many ecosystem goods and services, such as carbon storage capacity (Hulvey et al., 2013), productivity (Dănescu et al., 2016; Liang et al., 2016a; Ammer, 2019), nutrient use-efficiency (Schwarz et al., 2014) or habitat quality (Tews et al., 2004; Jung et al., 2012) to a greater degree than structurally less complex and species-poor stands.

The positive effect of structurally and compositionally diverse forests on ecosystem functioning is usually attributed to a more efficient use of resources through complementary niche exploitations (del Río et al., 2014; Forrester and Bauhus, 2016). Beneficial complementary effects can arise when 
tree species with different morphological (e.g. shallow and deep-rooting, deciduous and evergreen species) or physiological traits (e.g. light-demanding and shade-tolerant species) are mixed (Pretzsch, 2014; Forrester and Pretzsch, 2015; Forrester et al., 2018). Complementarity can also arise in monocultures, for example, between shade-tolerant beech saplings and light demanding beech overstorey trees. If complementary effects exist, this may result in an increased vertical stratification., which is often accompanied by more heterogeneous stand structures (Jucker et al., 2015).

Since structure and functioning of forests are closely linked to each other, an improved knowledge on how silvicultural interventions, such as the intensity and frequency of tree harvests as well as the identity of tree species that are cultivated, modify tree and stand structure is therefore of particular importance.

The structure of forest stands can be defined "as the distribution of tree elements in space and their variability in size, arrangement, consistency, and time" (Schall et al., 2018). Stand structure is often described by the horizontal and vertical distribution pattern of trees, stand density, stand age or tree species diversity (del Río et al., 2016). Various spatial and non-spatial indices have been developed to characterize and compare stand structures, such as the Clark and Evans index of aggregation (Clark and Evans, 1954), Reineke's stand density index (Reineke, 1933) or the Gini coefficient of diameters (e.g. Dănescu et al., 2016). In addition, stand structural complexity indices (e.g. complexity index by Holdridge et al., 1967; structural complexity index by Zenner and Hibbs, 2000), which are often a combination of different stand structural attributes have been proposed (McElhinny et al., 2005). However, most structural attributes, such as tree height or stem diameter are obtained by conventional field measurements and only indirectly reflect the complex threedimensional canopy structure of forests, which plays an important role in ecosystem function and biodiversity (Ishii et al., 2004; Dănescu et al., 2016). Detailed direct measurements of crown characteristics in mature stands are labor-intensive, time-consuming and difficult to realize on a large-scale (Andersen et al., 2006; Seidel et al., 2011a). In the past, the sheer size, inaccessibility and complexity of the canopy hindered a detailed quantification (Lovell et al., 2003; van der Zande et al., 2006; Côté et al., 2018).

Today, LiDAR (Light Detection and Ranging) offers new opportunities to measure forest structure and the three-dimensional distribution of plant canopies non-destructively with reasonable effort and high accuracy (Dassot et al., 2011; Calders et al., 2015). LiDAR is an active remote sensing technique that directly measures the distance between the target's surface and the sensor by emitting laser light (Lim et al., 2003; Diaz et al., 2017). Differences in wavelengths or laser return times are then utilized to create three-dimensional point clouds of the scanned objects (Dassot et al., 2011; Disney, 2019). Depending on the respective application area, LiDAR sensors 
can be mounted on a tripod, vehicle, airborne or satellite platform (Chen et al., 2018; Cheng et al., 2018). Whereas the use of airborne LiDAR (ALS) for forestry started in the 1980's, the first commercial terrestrial LiDAR system (TLS) was built in the late 1990s and the earliest studies related to forest inventory were conducted around 2000 (Bauwens et al., 2016; Michez et al., 2016). ALS-systems are able to capture forest structure over large areas but suffer from occlusion in the lower canopy parts (Dassot et al., 2011; Kelbe, 2015). However, the below-canopy data (for example stem shape and quality) are often of special interest for foresters. The ground-based perspective of TLS in contrast, allows a detailed measurement of the lower forest areas with occlusion only occurring at the upper treetops (Newnham et al., 2015; Liu et al., 2018; Disney, 2019). In several studies, characteristics of individual trees as well as stand parameters, such as aboveground biomass (Seidel et al., 2012; Kankare et al., 2013; Abd et al., 2017), canopy gap fraction (Danson et al., 2007; Zhao et al., 2012; Ramirez et al., 2013; Cifuentes et al., 2014), leaf area distribution (Béland et al., 2011), leaf orientation (Bailey and Mahaffee, 2017) and detailed crown parameters (Seidel et al., 2011b; Bayer et al., 2013; Barbeito et al., 2017) have efficiently been determined from TLS data.

However, little is known about the impact of forest management intensity and tree species diversity on the three-dimensional stand structure. Moreover, there is still a limited knowledge on alterations in tree structure due to management activities and different neighborhood compositions, especially if single tree attributes, such as branching pattern, crown shapes or crown dimensions are considered. 


\subsection{Study objectives and hypotheses}

The aim of this thesis was to contribute to a deeper understanding of the effects of forest management intensity and tree species composition on tree and stand structure by using threedimensional data obtained by terrestrial laser scanning. We focused our investigations on European beech, which is the most common deciduous tree species in Central Europe. Due to its high importance from both an ecological and an economic standpoint, beech is also one of the most favored hardwood tree species for silvicultural management. In addition, beech is known for its high crown plasticity and its superior ability to occupy canopy space (Schröter et al., 2012; Pretzsch, 2014).

Based on novel TLS-derived structural measures we analyzed in our first study the architecture of beech trees that grew in either unmanaged pure beech or unmanaged mixed broadleaved stands, or on pure beech stands that covered a gradient of management intensity (chapter 2).

In our second study we investigated the relationship between silvicultural management intensity, three-dimensional space filling and productivity of beech stands (chapter 3). The selected stands represented frequently occurring management types of beech forests and included unmanaged, as well as managed uneven-aged and even-aged forests.

In our third study, we examined the effect of an increasing tree species diversity on the complexity of stand structure and analyzed how an increasing share of broadleaved trees affects the structural complexity of coniferous forests (chapter 4). For this investigation, we chose commercially important tree species compositions, that are widely distributed across Central Europe. These were, firstly, managed even-aged beech stands with different proportions of other broadleaves and, secondly managed even-aged stands of Norway spruce and Scots pine comprising an increasing share of beech and other broadleaved tree species.

\section{The main objectives of the dissertation can be summarized as follows:}

- investigating how neighborhood composition affects the structural dimensions and architecture of beech trees

- identifying to what extent forest management of different intensities modifies structural attributes of beech trees

- quantifying the effect of silvicultural management intensity and tree species diversity on the three-dimensional stand structure and

- analyzing the influence of the three-dimensional stand structure on the productivity of beech stands 


\section{The following main hypotheses were tested:}

(i) structural attributes of beech trees vary significantly between trees exposed to intra- or interspecific competition and

(ii) are significantly affected by different levels of silvicultural management intensity (chapter 2).

(iii) the three-dimensional space filling of beech stands is influenced by an increasing silvicultural management intensity (chapter 3).

(iv) the productivity of beech stands increases with space filling (chapter 3).

(v) the complexity of the three-dimensional stand structure increases with increasing tree species diversity (chapter 4).

(vi) an increasing proportion of broadleaved trees positively affects the stand structural complexity of coniferous stands (chapter 4). 


\subsection{Material and Methods}

\subsubsection{Study regions}

The studies were conducted within the framework of the Biodiversity Exploratories and were funded by the German Research Foundation (DFG). The Biodiversity Exploratories are a longdated and large-scaled project for biodiversity research and comprise three study regions across Germany, namely the Swabian Alb, the Hainich-Dün and the Schorfheide-Chorin (see http://www.biodiversity-exploratories.de and Fischer et al., 2010; Figure 1.1).

The UNESCO Biosphere Reserve Swabian Alb is situated in the low mountain area in southwest Germany and is characterized by a strongly fragmented forest landscape. The forests mainly consist of beech and, to a smaller proportion, of spruce stands (Müller et al., 2015). The National Park Hainich and the surrounding Hainich-Dün region are situated in central Germany and comprise the largest coherent deciduous forest in Germany. The UNESCO Biosphere Reserve Schorfheide-Chorin, located in the lowlands of northeast Germany, is one of the driest regions in Germany and is dominated by pine, beech and oak forests. (Fischer et al., 2010). The three areas differ in climate as well as topography and are situated along a gradient of increasing temperature and decreasing precipitation and elevation from southwest to northeast Germany (Boch et al., 2013). In each region 50 forest plots (each $100 \times 100 \mathrm{~m}$ in size) with different silvicultural management intensities were established (Schall et al., 2018).

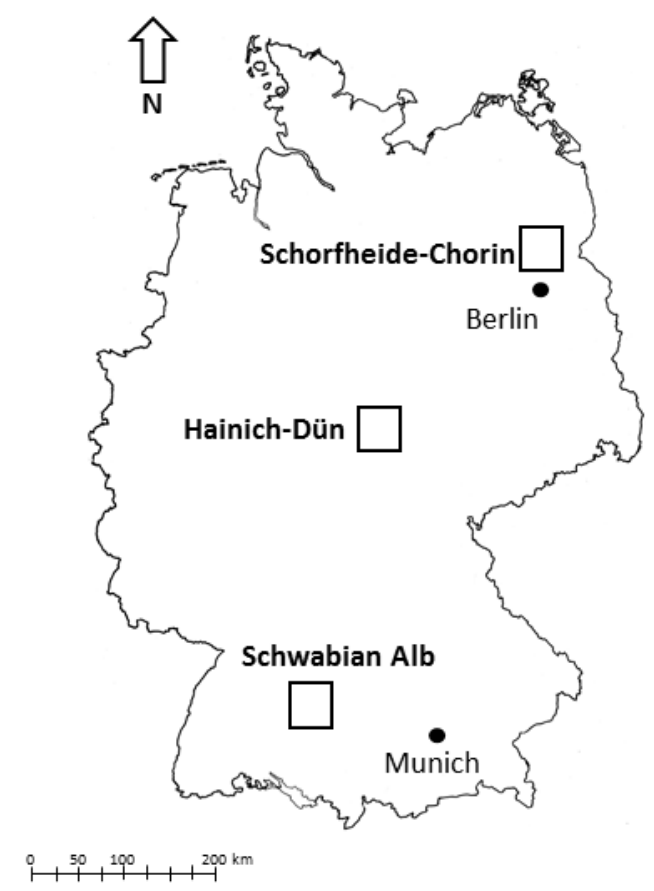

Figure 1.1: Geographic location of the three study areas in Germany. 


\subsubsection{Silvicultural management}

The studied forest stands cover a management intensity gradient ranging from unmanaged stands to intensively managed monocultures. Forests with European beech as main tree species were situated in each of the three study regions. Norway spruce-dominated stands were located in the Swabian Alb and Hainich, while stands with Scots pine as main tree species occurred in Schorfheide-Chorin.

Age-class forests with even-aged stands of beech, spruce or pine were predominantly in the mature timber stage. Thinning operations take place every 5-10 years and the rotation period is around 80-120 years. Spruce and pine stands had been planted in the past, while beech stands naturally regenerated after repeated shelterwood cuttings under the canopy of the remaining trees.

Uneven-aged beech forests were restricted to the Hainich region and are managed by singletree selection cutting. Silvicultural interventions are carried out every 5 years and primarily focus on trees with a diameter at breast height $>50 \mathrm{~cm}$ (Schall et al., 2018).

The unmanaged forests were mature broadleaved stands, which were mainly dominated by European beech. These forests were limited to nature reserves and national parks and silvicultural management was ceased between 20 to 70 years ago (Schall et al., 2020).

In order to quantify the intensity of forest management, we used the silvicultural management intensity indicator (SMI; Schall and Ammer, 2013). The indicator combines tree species, aboveground woody biomass and stand age as the three essential stand characteristics. It consists of a density component which relates the existing stand biomass to the biomass carrying capacity of the forest site and a risk component which describes the probability of stand loss. Both components are tree species and age-dependent and represent the main silvicultural management decisions: the choice of tree species that are cultivated and its silvicultural treatment (Schall and Ammer, 2013). The SMI scales from 0 to 1 and increases with increasing management intensity.

\subsubsection{Productivity}

Stand productivity of the beech forests was quantified by the periodic annual increment (PAI; $\mathrm{m}^{2}$ $\left.* \mathrm{ha}^{-1} * \mathrm{a}^{-1}\right)$. For the calculation of the average annual increment (incl. the basal area removed through thinning and natural mortality) we used the forest inventory data collected between 2008-2011 and between 2015-2016. At each forest plot, the diameter at breast height (DBH) of all tree stems greater or equal $7 \mathrm{~cm}$ in diameter was measured. Plot basal area was then calculated as the sum of the cross-sectional areas of all measured tree stems. 


\subsubsection{Terrestrial laser scanner}

In our studies, all laser scans were conducted with a Faro Focus 3D 120 (Faro Technologies Inc., Lake Mary, FL, USA) terrestrial laser scanner. The device covers a field of view of 300 degrees in vertical and 360 degrees in horizontal direction and was mounted on a tripod at $1.3 \mathrm{~m}$ height (Figure 1.2). With an angular step width of 0.035 degrees the scanner emits a laser beam into a vertical rotating mirror which is then deflected towards the environment being scanned. While the rotating mirror defines the vertical direction of the laser beam, the horizontal instrument rotation ensures the coverage of all azimuthal directions. To measure the distance to the surrounding objects the scanner uses the phase-shift principle (FARO, 2013). Laser scanning systems that are based on phase-shift technology calculate the range by measuring the phase-difference between the emitted and the reflected laser pulse (Pfeifer et al., 2007; van Dijk et al., 2016), whereas instruments that apply the time-of flight principle measure the elapsed time between the transmission of a laser pulse and the detection of the reflection of that pulse (Liang et al., 2016b). Distance, vertical and horizontal angle of each point determine a polar coordinate $(\delta, \alpha, \beta)$, which is then converted to a cartesian coordinate $(x, y, z)(F A R O, 2013)$. The result is a point cloud, a three-dimensional representation of the scanner's environment composed of millions of points.

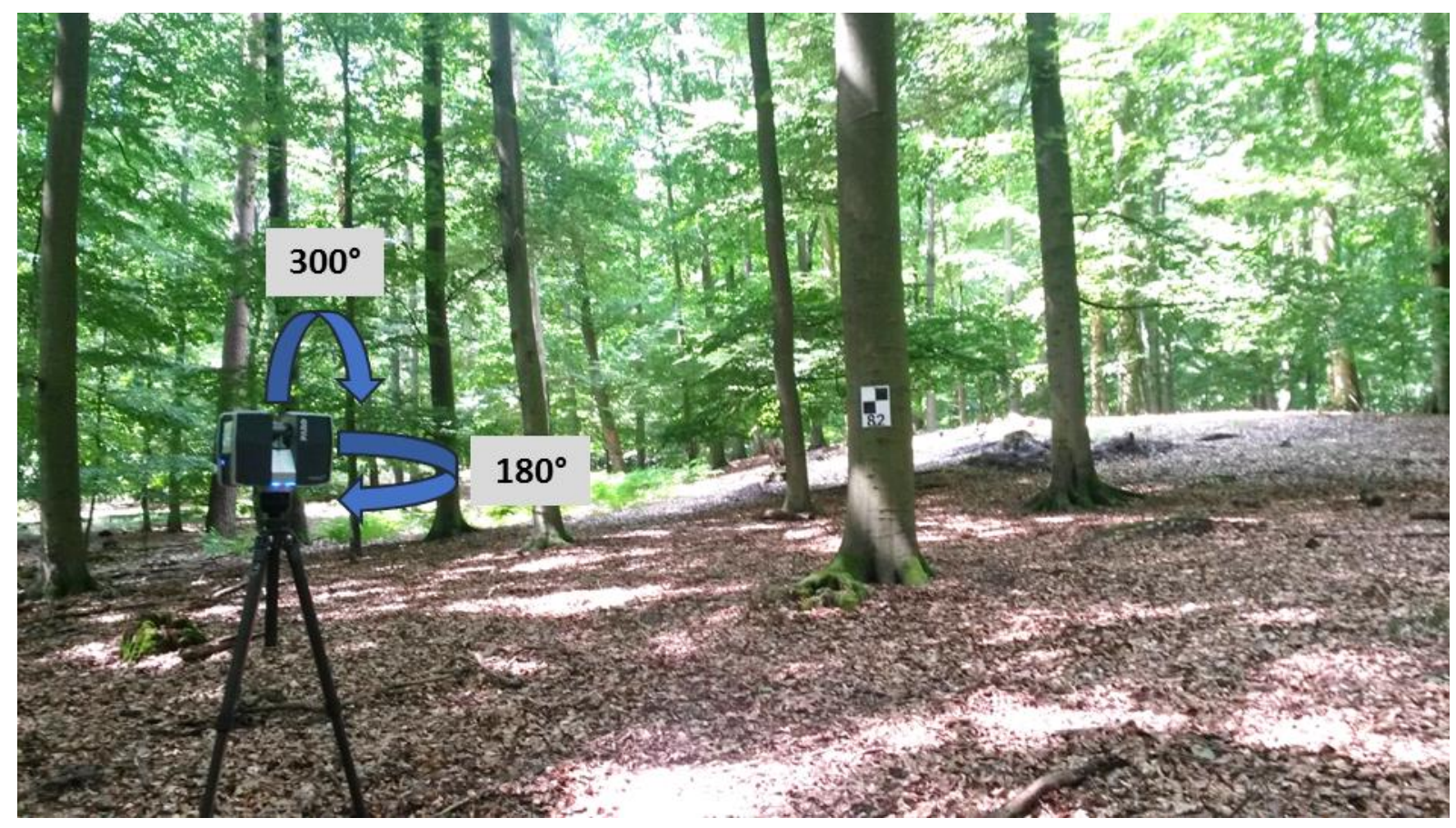

Figure 1.2: The principle of terrestrial laser scanning: the scanner is mounted on a tripod and turns 180 degrees in horizontal direction and 300 in vertical direction, providing a field of view of $360 \times 300$ degrees. 


\subsubsection{Data acquisition and computation of TLS-based structural measures}

\section{Single-scan approach and calculation of stand structural complexity index (SSCI)}

Two different scanning approaches can be distinguished to acquire TLS data: single scans and multiple scans. In the single-scan approach, the laser scanner is positioned at a single location and only one scan is conducted. This method has a fast data acquisition and does not require time consuming post-processing. A single scan position, however, does only provide information of one side of the scanned forest scene and distant objects are often occluded by plant elements (e.g. stems, branches or leaves) in the foreground (Lovell et al., 2003; Dassot et al., 2011; Liang et al., 2016b; see Figure 1.3).
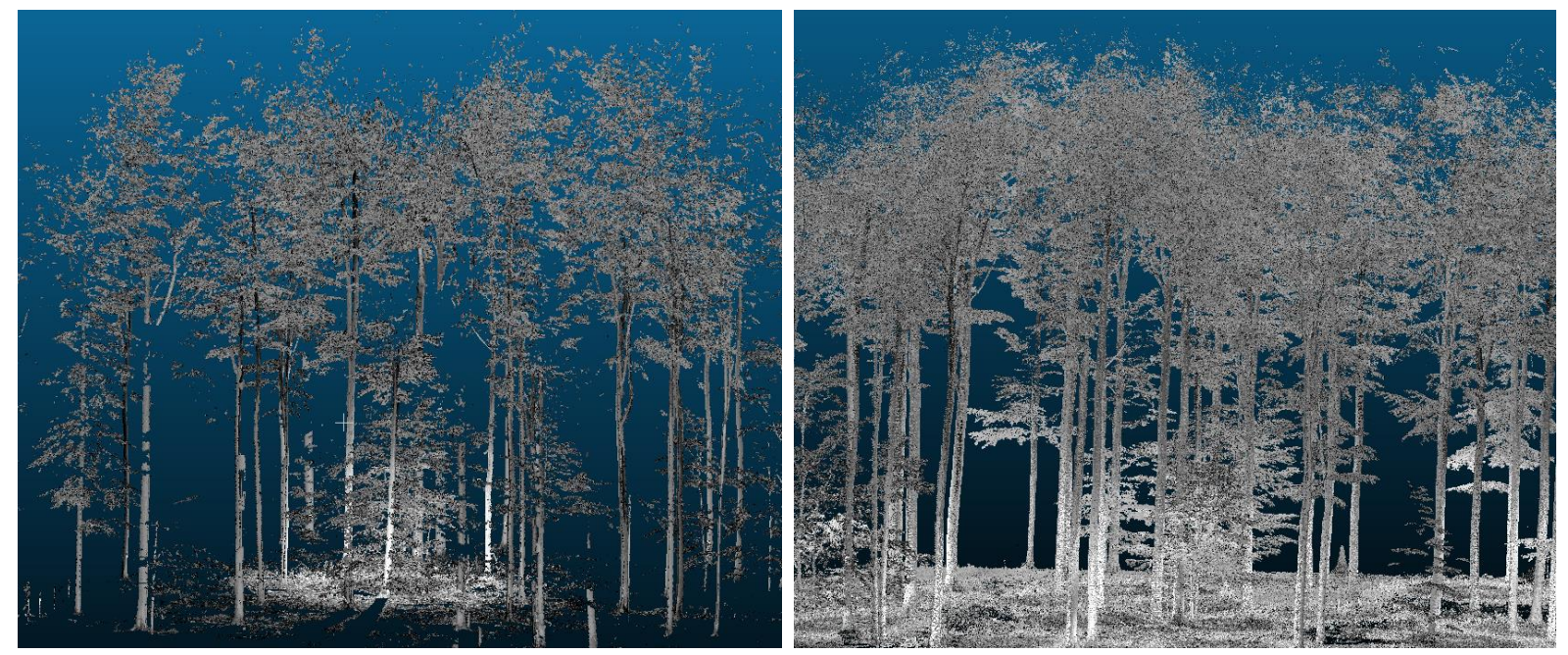

Figure 1.3: Point clouds of forest plots from single- (left) and multi-scan data (right). The left point cloud shows a shadowing effect behind the tree trunks due to the lack of information from only one perspective in the single-scan approach. The more laborious multi-scan approach allows an almost complete capture of the forest plot.

We used a single-scan approach to analyze the effect of an increasing proportion of broadleaved trees on the structural complexity of coniferous stands. We also made single scans to investigate the relationship between tree species diversity and stand structural complexity (SSCI; chapter 4). This allowed us to increase the sample size and to investigate a broader range of tree species mixtures. Scans were conducted under leaf-on conditions in summer 2014. Nine systematically distributed single scans were made at each of the 60 plots (see Figure 1.4). All scans were then imported to FARO Scene and exported as xyz-files. We used an algorithm written in Mathematica to calculate the SSCI as described in Ehbrecht et al. (2017). The index quantifies structural 
complexity on the basis of the three-dimensional spatial distribution of all visible plant material and consists of two components, the effective number of layers (ENL, see Ehbrecht et al., 2016) and the mean fractal dimension (MeanFrac, see Ehbrecht et al., 2017). Further details related to data acquisition using the single-scan approach and to the calculation of the SSCI can be found in Ehbrecht et al. (2017 and 2019).

Single-scan approach

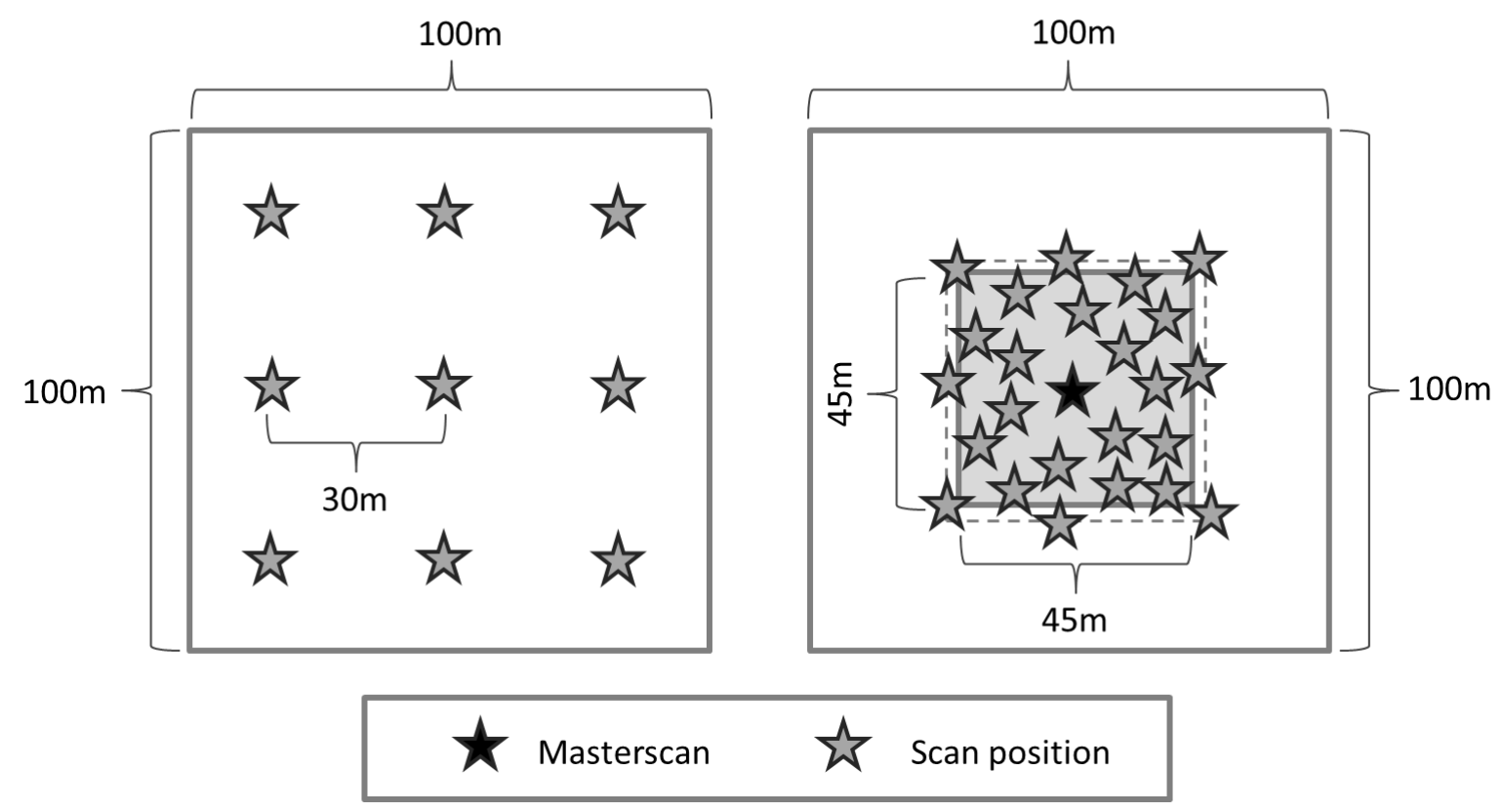

Multi-scan approach

Figure 1.4: Draft of the single-scan (left) and multi-scan design (right). Scanner positions are indicated with a star. The masterscan (filled black) is located in the center of the plot.

\section{Multi-scan approach and calculation of space filling}

In the multi-scan approach, the respective tree or forest stand is scanned from several positions. This method requires more field measurement time and, due to the registration of the different scans, more effort in the data processing. However, it reduces the amount of occluded space and has the capability to provide full coverage of the forest scene of interest (Astrup et al., 2014; Newnham et al., 2015; see Figure 1.3).

We applied a multi-scan approach to analyze the relationship between management intensity, three-dimensional space filling and productivity of beech stands (chapter 3). We defined space filling as the occupation of foliage and woody components relative to the total volume of the forest plot. In order to obtain data in leaf-on and leaf-off condition of the forest stands, we scanned 35 plots in summer 2014 and 35 plots in winter 2014/15. In both seasons, the same forest plots and 
scan settings were used. We started with a master scan in the center of the plot, followed by 20 to 30 additional scans from various surrounding standpoints (see Figure 1.4). Prior to scanning, artificial checkerboard targets were evenly distributed over the area to register the scans to the local coordinate system of the master scan. Each scan position was subjectively selected to better respond to the variability in the understory vegetation. On every plot, an area of $45 \mathrm{~m}$ by $45 \mathrm{~m}$ was scanned. To ensure full coverage of the plant elements within the study area, some scans were made in the outer area.

After scanning, we imported all data files to Faro Scene Software (Faro Technologies Inc., Lake Mary, FL, USA) to remove erroneous points and to conduct a semi-automatic registration of all scans taken at a plot. The unified point clouds were then imported as a single point cloud (.pts-file) to Leica Cyclone 8 (Leica Geosystems AG, Heerbrugg, Switzerland). Subsequently, the point cloud of each stand was exported as xyz-file to compute the space filling with an algorithm written in Mathematica (Version 9, Wolfram Research, Champaign, USA). The algorithm selected a horizontal extent of 40 by $40 \mathrm{~m}$ from the point cloud and converted it into a voxel grid with voxels of $20 \mathrm{~cm}$ edge length. We only kept voxels that contained at least one point, empty voxels were not processed any further. To account for uneven terrain, we corrected the elevation and calculated the volume of the total forest plot by its base area $\left(40 \mathrm{x} 40 \mathrm{~m}=1600 \mathrm{~m}^{2}\right.$ for all plots) times stand height. Space filling was then calculated as the percentage of the total plot volume filled with voxels. We also determined the percentage of filled volume for the vertical layers, each $10 \%$ of total stand height in thickness, starting from $0-10 \%, 10-20 \%, 20-30 \%$ and so forth.

\section{Multi- scan approach and calculation of tree architectural attributes}

To investigate how management intensity and tree species composition influence structural attributes of beech trees, we also applied a multi-scan approach (chapter 2). Scans were conducted in winter 2014/15 under leaf-off conditions. We scanned 12 plots and used the same data acquisition and sampling design as above mentioned. After the registration of the scans in Faro Scene, the point cloud of each plot was imported to Cyclone 9.0 (Leica Geosystems AG, Heerbrugg, Switzerland) to manually extract beech trees with a diameter at breast height between 35 and $60 \mathrm{~cm}$ (see Figure 1.5). We then exported every manually isolated tree as a single point cloud (.xyz-file) for further processing and the calculation of two sets of structural measures.

The first set was computed on the basis of the Cartesian coordinates of all points belonging to the point cloud of a tree. In this approach, we calculated architectural characteristics that can be derived from the geometry such as crown volume, crown surface area or the height of the maximal horizontal crown. The second set of structural measures such as mean branch length or the mean 
branch angle was based on quantitative structural models (QSM; for further details see Raumonen et al. (2013) and Calders et al. (2015)).

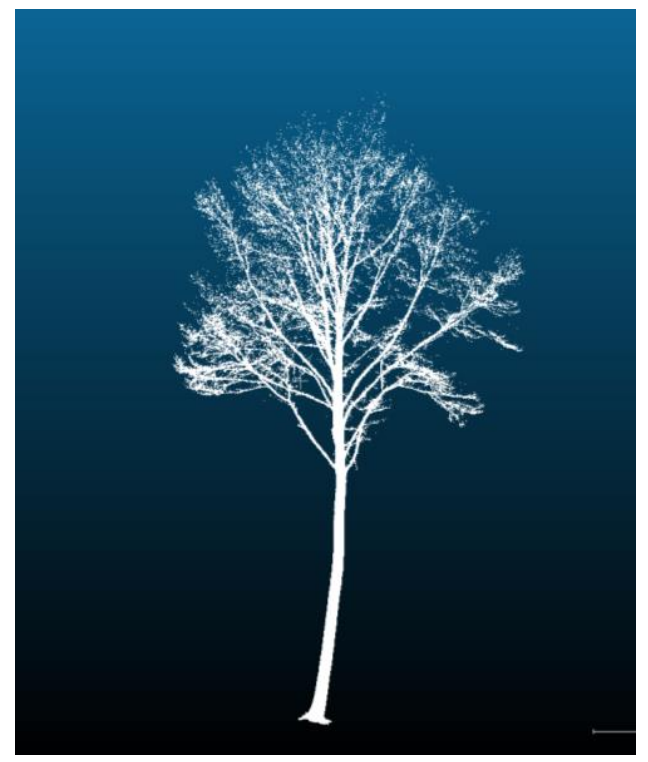

Figure 1.5: Point cloud of a manually selected beech tree. 


\subsection{References}

Abd Rahman, M., Abu Bakar, M., Razak, K., Rasib, A., Kanniah, K., Wan Kadir, W., ... \& Abd Latif, Z. (2017). Non-destructive, laser-based individual tree aboveground biomass estimation in a tropical rainforest. Forests, 8(3), 86.

Ammer, C. (2019). Diversity and forest productivity in a changing climate. New Phytologist, 221(1), $50-66$.

Andersen, H. E., Reutebuch, S. E., \& McGaughey, R. J. (2006). Active remote sensing. In Computer applications in sustainable forest management (pp. 43-66). Springer, Dordrecht.

Astrup, R., Ducey, M. J., Granhus, A., Ritter, T., \& von Lüpke, N. (2014). Approaches for estimating stand-level volume using terrestrial laser scanning in a single-scan mode. Canadian journal of forest research, 44(6), 666-676.

Augusto, L., Ranger, J., Binkley, D., \& Rothe, A. (2002). Impact of several common tree species of European temperate forests on soil fertility. Annals of forest science, 59(3), 233-253.

Bailey, B. N., \& Mahaffee, W. F. (2017). Rapid measurement of the three-dimensional distribution of leaf orientation and the leaf angle probability density function using terrestrial LiDAR scanning. Remote sensing of environment, 194, 63-76.

Barbeito, I., Dassot, M., Bayer, D., Collet, C., Drössler, L., Löf, M., ... \& Pretzsch, H. (2017). Terrestrial laser scanning reveals differences in crown structure of Fagus sylvatica in mixed vs. pure European forests. Forest Ecology and Management, 405, 381-390.

Bauwens, S., Bartholomeus, H., Calders, K., \& Lejeune, P. (2016). Forest inventory with terrestrial LiDAR: A comparison of static and hand-held mobile laser scanning. Forests, 7(6), 127.

Bayer, D., Seifert, S., \& Pretzsch, H. (2013). Structural crown properties of Norway spruce (Picea abies [L.] Karst.) and European beech (Fagus sylvatica [L.]) in mixed versus pure stands revealed by terrestrial laser scanning. Trees, 27(4), 1035-1047.

Béland, M., Widlowski, J. L., Fournier, R. A., Côté, J. F., \& Verstraete, M. M. (2011). Estimating leaf area distribution in savanna trees from terrestrial LiDAR measurements. Agricultural and Forest Meteorology, 151(9), 1252-1266 
Boch, S., Prati, D., Hessenmöller, D., Schulze, E. D., \& Fischer, M. (2013). Richness of lichen species, especially of threatened ones, is promoted by management methods furthering stand continuity. PloS one, 8(1), e55461.

Calders, K., Newnham, G., Burt, A., Murphy, S., Raumonen, P., Herold, M., ... \& Kaasalainen, M. (2015). Nondestructive estimates of above-ground biomass using terrestrial laser scanning. Methods in Ecology and Evolution, 6(2), 198-208.

Chen, Y., Liu, X., Yao, M., Cheng, L., \& Li, M. (2018, August). Fine Registration of Mobile and Airborne LiDAR Data Based on Common Ground Points. In 2018 10th IAPR Workshop on Pattern Recognition in Remote Sensing (PRRS) (pp. 1-6). IEEE.

Cheng, L., Chen, S., Liu, X., Xu, H., Wu, Y., Li, M., \& Chen, Y. (2018). Registration of laser scanning point clouds: A review. Sensors, 18(5), 1641.

Cifuentes, R., Van der Zande, D., Farifteh, J., Salas, C., \& Coppin, P. (2014). Effects of voxel size and sampling setup on the estimation of forest canopy gap fraction from terrestrial laser scanning data. Agricultural and forest meteorology, 194, 230-240.

Clark, P. J., \& Evans, F. C. (1954). Distance to nearest neighbor as a measure of spatial relationships in populations. Ecology, 35(4), 445-453.

Côté, J. F., Fournier, R. A., Luther, J. E., \& van Lier, O. R. (2018). Fine-scale three-dimensional modeling of boreal forest plots to improve forest characterization with remote sensing. Remote sensing of environment, 219, 99-114.

Dănescu, A., Albrecht, A. T., \& Bauhus, J. (2016). Structural diversity promotes productivity of mixed, uneven-aged forests in southwestern Germany. Oecologia, 182(2), 319-333.

Danson, F. M., Hetherington, D., Morsdorf, F., Koetz, B., \& Allgower, B. (2007). Forest canopy gap fraction from terrestrial laser scanning. IEEE Geoscience and remote sensing letters, 4(1), 157-160.

Dassot, M., Constant, T., \& Fournier, M. (2011). The use of terrestrial LiDAR technology in forest science: application fields, benefits and challenges. Annals of forest science, 68(5), 959-974.

del Río, M., Condés, S., \& Pretzsch, H. (2014). Analyzing size-symmetric vs. size-asymmetric and intra-vs. inter-specific competition in beech (Fagus sylvatica L.) mixed stands. Forest Ecology and Management, 325, 90-98. 
del Río, M., Pretzsch, H., Alberdi, I., Bielak, K., Bravo, F., Brunner, A., ... \& Pach, M. (2016). Characterization of the structure, dynamics, and productivity of mixed-species stands: review and perspectives. European journal of forest research, 135(1), 23-49.

Diaz J.C.F., Carter W.E., Shrestha R.L., Glennie C.L. (2017). LiDAR Remote Sensing. In: Pelton J., Madry S., Camacho-Lara S. (eds) Handbook of Satellite Applications. Springer, Cham

Disney, M. (2019). Terrestrial LiDAR: a three-dimensional revolution in how we look at trees. New Phytologist, 222(4), 1736-1741.

Ehbrecht, M., Schall, P., Juchheim, J., Ammer, C., \& Seidel, D. (2016). Effective number of layers: a new measure for quantifying three-dimensional stand structure based on sampling with terrestrial LiDAR. Forest Ecology and Management, 380, 212-223.

Ehbrecht, M., Schall, P., Ammer, C., \& Seidel, D. (2017). Quantifying stand structural complexity and its relationship with forest management, tree species diversity and microclimate. Agricultural and Forest Meteorology, 242, 1-9.

Ehbrecht, M., Schall, P., Ammer, C., Fischer, M., \& Seidel, D. (2019). Effects of structural heterogeneity on the diurnal temperature range in temperate forest ecosystems. Forest ecology and management, 432, 860-867.

Emanuelsson, U. (2009). The rural landscapes of Europe. How man has shaped European nature. Stockholm: The Swedish Research Council Formas.

FARO. (2013). Available online at http://www.faro.com. Last accessed 28 December 2019.

Fischer, M., Bossdorf, O., Gockel, S., Hänsel, F., Hemp, A., Hessenmöller, D., ... \& Renner, S. (2010). Implementing large-scale and long-term functional biodiversity research: The Biodiversity Exploratories. Basic and Applied Ecology, 11(6), 473-485.

Forrester, D. I., \& Pretzsch, H. (2015). Tamm Review: On the strength of evidence when comparing ecosystem functions of mixtures with monocultures. Forest Ecology and Management, 356, 41-53.

Forrester, D. I., \& Bauhus, J. (2016). A review of processes behind diversity-productivity relationships in forests. Current Forestry Reports, 2(1), 45-61. 
Forrester, D. I., Ammer, C., Annighöfer, P. J., Barbeito, I., Bielak, K., Bravo-Oviedo, A., ... \& Hurt, V. (2018). Effects of crown architecture and stand structure on light absorption in mixed and monospecific Fagus sylvatica and Pinus sylvestris forests along a productivity and climate gradient through Europe. journal of ecology, 106(2), 746-760.

von Gadow, K. (2005). Forsteinrichtung: Analyse und Entwurf der Waldentwicklung. Universitätsverlag Göttingen.

Holdridge, L. R. (1967). Life zone ecology. Tropical Science Center: San Jose, Costa Rica.

Hulvey, K. B., Hobbs, R. J., Standish, R. J., Lindenmayer, D. B., Lach, L., \& Perring, M. P. (2013). Benefits of tree mixes in carbon plantings. Nature Climate Change, 3(10), 869-874.

Ishii, H. T., Tanabe, S. I., \& Hiura, T. (2004). Exploring the relationships among canopy structure, stand productivity, and biodiversity of temperate forest ecosystems. Forest Science, 50(3), 342-355.

Jactel, H., Nicoll, B. C., Branco, M., Gonzalez-Olabarria, J. R., Grodzki, W., Långström, B., ... \& Santos, H. (2009). The influences of forest stand management on biotic and abiotic risks of damage. Annals of forest science, 66(7), 701-701.

Jucker, T., Bouriaud, O., \& Coomes, D. A. (2015). Crown plasticity enables trees to optimize canopy packing in mixed-species forests. Functional Ecology, 29(8), 1078-1086.

Jung, K., Kaiser, S., Böhm, S., Nieschulze, J., \& Kalko, E. K. (2012). Moving in three dimensions: effects of structural complexity on occurrence and activity of insectivorous bats in managed forest stands. Journal of Applied Ecology, 49(2), 523-531.

Kankare, V., Holopainen, M., Vastaranta, M., Puttonen, E., Yu, X., Hyyppä, J., ... \& Alho, P. (2013). Individual tree biomass estimation using terrestrial laser scanning. ISPRS Journal of Photogrammetry and Remote Sensing, 75, 64-75.

Kelbe, D. (2015). Forest structure from terrestrial laser scanning in support of remote sensing calibration/validation and operational inventory. $\mathrm{PhD}$ thesis, Rochester Institute of Technology

Knoke, T., Ammer, C., Stimm, B., \& Mosandl, R. (2008). Admixing broadleaved to coniferous tree species: a review on yield, ecological stability and economics. European journal of forest research, 127(2), 89-101. 
Leuschner, C., \& Ellenberg, H. (2017). Ecology of Central European forests: vegetation ecology of Central Europe (Vol. 1). Springer.

Liang, J., Crowther, T. W., Picard, N., Wiser, S., Zhou, M., Alberti, G., ... \& De-Miguel, S. (2016a). Positive biodiversity-productivity relationship predominant in global forests. Science, 354(6309), aaf8957.

Liang, X., Kankare, V., Hyyppä, J., Wang, Y., Kukko, A., Haggrén, H., ... \& Holopainen, M. (2016b). Terrestrial laser scanning in forest inventories. ISPRS Journal of Photogrammetry and Remote Sensing, 115, 63-77.

Lim, K., Treitz, P., Wulder, M., St-Onge, B., \& Flood, M. (2003). LiDAR remote sensing of forest structure. Progress in physical geography, 27(1), 88-106.

Liu, G., Wang, J., Dong, P., Chen, Y., \& Liu, Z. (2018). Estimating Individual Tree Height and Diameter at Breast Height (DBH) from Terrestrial Laser Scanning (TLS) Data at Plot Level. Forests, 9(7), 398.

Lovell, J. L., Jupp, D. L., Culvenor, D. S., \& Coops, N. C. (2003). Using airborne and ground-based ranging lidar to measure canopy structure in Australian forests. Canadian Journal of Remote Sensing, 29(5), 607-622.

McElhinny, C., Gibbons, P., Brack, C., \& Bauhus, J. (2005). Forest and woodland stand structural complexity: its definition and measurement. Forest Ecology and Management, 218(1-3), 124.

Messier, C., Puettmann, K., Chazdon, R., Andersson, K. P., Angers, V. A., Brotons, L., ... \& Levin, S. A. (2015). From management to stewardship: viewing forests as complex adaptive systems in an uncertain world. Conservation Letters, 8(5), 368-377.

Michez, A., Bauwens, S., Bonnet, S., \& Lejeune, P. (2016). Characterization of forests with lidar technology. In Land Surface Remote Sensing in Agriculture and Forest (pp. 331-362). Elsevier.

Müller, J., Wende, B., Strobl, C., Eugster, M., Gallenberger, I., Floren, A., ... \& Gossner, M. M. (2015). Forest management and regional tree composition drive the host preference of saproxylic beetle communities. Journal of Applied Ecology, 52(3), 753-762. 
Newnham, G. J., Armston, J. D., Calders, K., Disney, M. I., Lovell, J. L., Schaaf, C. B., ... \& Danson, F. M. (2015). Terrestrial laser scanning for plot-scale forest measurement. Current Forestry Reports, 1(4), 239-251.

O'Hara, K. L. (2016). What is close-to-nature silviculture in a changing world?. Forestry: An International Journal of Forest Research, 89(1), 1-6.

Peters, R. (1997). Beech forests. Geobotany, Vol 24. Kluwer Academic, Dordrecht.

Pfeifer, N., \& Briese, C. (2007, April). Laser scanning-principles and applications. In GeoSiberia 2007-International Exhibition and Scientific Congress.

Pretzsch, H., Schütze, G., \& Uhl, E. (2013). Resistance of European tree species to drought stress in mixed versus pure forests: evidence of stress release by inter-specific facilitation. Plant Biology, 15(3), 483-495.

Pretzsch, H. (2014). Canopy space filling and tree crown morphology in mixed-species stands compared with monocultures. Forest Ecology and Management, 327, 251-264.

Pretzsch, H., \& Zenner, E. K. (2017). Toward managing mixed-species stands: from parametrization to prescription. Forest Ecosystems, 4(1), 19.

Puettmann, K. J., Coates, K. D., \& Messier, C. C. (2012). A critique of silviculture: managing for complexity. Island press.

Ramirez, F., Armitage, R., \& Danson, F. (2013). Testing the application of terrestrial laser scanning to measure forest canopy gap fraction. Remote Sensing, 5(6), 3037-3056.

Raum, S., \& Potter, C. (2015). Forestry paradigms and policy change: The evolution of forestry policy in Britain in relation to the ecosystem approach. Land Use Policy, 49, 462-470.

Raumonen, P., Kaasalainen, M., Åkerblom, M., Kaasalainen, S., Kaartinen, H., Vastaranta, M., ... \& Lewis, P. (2013). Fast automatic precision tree models from terrestrial laser scanner data. Remote Sensing, 5(2), 491-520.

Reineke, L. H. (1933). Perfecting a stand-density index for even-aged forests. Journal of Agricultural Research, 46, 627-638.

Schall, P., \& Ammer, C. (2013). How to quantify forest management intensity in Central European forests. European Journal of Forest Research, 132(2), 379-396. 
Schall, P., Schulze, E. D., Fischer, M., Ayasse, M., \& Ammer, C. (2018). Relations between forest management, stand structure and productivity across different types of Central European forests. Basic and Applied Ecology, 32, 39-52.

Schall, P., Heinrichs, S., Ammer, C., Ayasse, M., Boch, S., Buscot, F., ... \& Sikorski, J. (2020). Can multi-taxa diversity in European beech forest landscapes be increased by combining different management systems?. Journal of Applied Ecology.

Schröter, M., Härdtle, W., \& von Oheimb, G. (2012). Crown plasticity and neighborhood interactions of European beech (Fagus sylvatica L.) in an old-growth forest. European Journal of Forest Research, 131(3), 787-798.

Schwarz, M. T., Bischoff, S., Blaser, S., Boch, S., Schmitt, B., Thieme, L., ... \& Wilcke, W. (2014). More efficient aboveground nitrogen use in more diverse Central European forest canopies. Forest Ecology and Management, 313, 274-282.

Seidel, D., Fleck, S., Leuschner, C., \& Hammett, T. (2011a). Review of ground-based methods to measure the distribution of biomass in forest canopies. Annals of Forest Science, 68(2), 225-244.

Seidel, D., Leuschner, C., Müller, A., \& Krause, B. (2011b). Crown plasticity in mixed forestsquantifying asymmetry as a measure of competition using terrestrial laser scanning. Forest Ecology and Management, 261(11), 2123-2132.

Seidel, D., Albert, K., Fehrmann, L., \& Ammer, C. (2012). The potential of terrestrial laser scanning for the estimation of understory biomass in coppice-with-standard systems. Biomass and bioenergy, 47, 20-25.

Spiecker, H. (2003). Silvicultural management in maintaining biodiversity and resistance of forests in Europe-temperate zone. Journal of Environmental Management, 67(1), 55-65.

Tews, J., Brose, U., Grimm, V., Tielbörger, K., Wichmann, M. C., Schwager, M., \& Jeltsch, F. (2004). Animal species diversity driven by habitat heterogeneity/diversity: the importance of keystone structures. Journal of biogeography, 31(1), 79-92.

Thurm, E. A., Uhl, E., \& Pretzsch, H. (2016). Mixture reduces climate sensitivity of Douglas-fir stem growth. Forest Ecology and Management, 376, 205-220. 
Van der Zande, D., Hoet, W., Jonckheere, I., van Aardt, J., \& Coppin, P. (2006). Influence of measurement set-up of ground-based LiDAR for derivation of tree structure. Agricultural and Forest Meteorology, 141(2-4), 147-160.

van Dijk, N. P., Gamstedt, E. K., \& Bjurhager, I. (2016). Monitoring archaeological wooden structures: Non-contact measurement systems and interpretation as average strain fields. Journal of Cultural Heritage, 17, 102-113.

Verstraeten, G. (2013). Conversion of deciduous forests to spruce plantations and back: evaluation of interacting effects on soil, forest floor, earthworm and understorey communities (Doctoral dissertation, Ghent University).

Zenner, E. K., \& Hibbs, D. E. (2000). A new method for modeling the heterogeneity of forest structure. Forest Ecology and Management, 129(1-3), 75-87.

Zerbe, S. (2002). Restoration of natural broad-leaved woodland in Central Europe on sites with coniferous forest plantations. Forest Ecology and Management, 167(1-3), 27-42.

Zhao, F., Strahler, A. H., Schaaf, C. L., Yao, T., Yang, X., Wang, Z., ... \& Ni-Meister, W. (2012). Measuring gap fraction, element clumping index and LAI in Sierra Forest stands using a full-waveform ground-based lidar. Remote Sensing of Environment, 125, 73-79. 



\section{Chapter 2}

How management intensity and neighborhood composition affect the structure of beech (Fagus sylvatica L.) trees

Julia Juchheim · Peter Annighöfer · Christian Ammer · Kim Calders ·

Pasi Raumonen · Dominik Seidel

Trees 31(5) (2017), 1723-1735

DOI:10.1007/s00468-017-1581-z 


\begin{abstract}
The intensity of silvicultural interventions and the composition of tree species are important forest management decisions. Both determine tree shape and thus influence the value of a tree, be it in terms of economy (trunk form, branchiness), or in terms of ecology (microhabitats). However, our knowledge on the distinct changes in tree architecture due to silvicultural management intensity or different neighborhood diversities is still limited, especially if the focus is on single tree attributes, e.g. branching patterns or crown shapes. We used terrestrial laser scanner data to calculate 25 structural measures for 55 European beech (Fagus sylvatica L.) trees that grew either in pure stands along a gradient of management intensity or in intra or interspecific neighborhoods in unmanaged stands. We found a lower height of maximal horizontal crown extension, a higher crown surface area, and straighter trunks with increasing management intensity. Moreover, our study revealed that beech trees surrounded by valuable hardwoods showed a lower height of maximal horizontal crown extension, a lower height-diameter ratio, and longer branches with flatter branch angles than beech trees surrounded by conspecific neighbors. Our findings provide evidence of phenotypic plasticity of European beech to diverse environmental conditions. The differences in tree structure indicate an increasing crown competition with decreasing management intensity and stronger competitive pressure for beech surrounded by conspecific neighbors in comparison to alien neighbors.
\end{abstract}

Keywords: competition, crown plasticity, terrestrial laser scanning, thinning, tree architecture, quantitative structural models

\title{
2.1 Introduction
}

Forest management intends to optimize a controlled development of forest stands according to predefined management goals (e.g. Puettmann et al., 2009), using different silvicultural management tools. Thereby, the intensity of interventions, such as thinnings or final harvests, as well as the identity of the tree species that are cultivated are two basic tools of silvicultural management (e.g. Röhrig et al., 2006; Schall and Ammer, 2013). They can be used to control the ecological and economical values of a forest stand under given environmental conditions and the prevailing management objectives. Silvicultural success in achieving a certain management objective is hence strongly dependent on knowledge about the consequences of management intensity and tree neighborhood diversity on the resulting tree and stand structure and the related ecosystem functions and services (e.g. Hawley, 1946; Kimmins, 2004; Ammer and Puettmann, 2009). 
In the past, it was very difficult to derive quantitative data about the effects of different management approaches on the distinct three-dimensional shape of an individual tree. This was due to the general inaccessibility, size, and complexity of the study object, especially if the crown also has to be considered. Comprehensive in situ measurements in mature forests were almost impossible (e.g. Seidel et al., 2011a). In addition, today's large-scale forest conversion from monospecific stands into mixed-species stands further increased the variability of individual trees, as more diverse structural elements occur (Pretzsch et al., 2016). With the species-specific characteristics present in mixed stands, the effects of silvicultural interventions become even more diverse. As a result, our knowledge on the distinct changes in tree architecture due to silvicultural management intensity or different neighborhood diversities is still limited, especially if the focus is on single tree attributes, e.g. branching patterns or crown forms.

The previous research in this field mainly focused on the effects of different management intensities on simple crown dimensions such as crown diameter and crown length (e.g. Wohlfarth, 1935; Guericke, 2001; Brown et al., 2004) or on trunk volume increment (e.g. Hamilton, 1981; Pape, 1999) in pure stands. Detailed changes in tree architecture were rarely investigated. Even scarcer are studies that took the effect of neighborhood diversity on a target tree's shape and growth into account (Lang et al., 2012; Dieler and Pretzsch, 2013; Metz et al., 2013). Since mixedspecies stands are of increasing importance, a deeper understanding of the effects of neighborhood diversity on tree architecture is needed for two reasons. First, it may better explain the different growth responses of equally sized trees of the same species on a comparable site (Ishii and Asano, 2010; Dieler and Pretzsch, 2013). Second, tree shape and crown architecture are known to be attributes related to the habitat diversity required for different animal taxa (Valladares, 2003). Habitat diversity is of continuously growing interest as the goals of forest management are not restricted to growth and yield any longer (Porté and Bartelink, 2002). From the literature, it is known that tree crowns and trunks respond species-specifically to different light conditions (e.g. Umeki, 1995; Valladares, 2003), slope effects (e.g. Matsuzaki et al., 2006), or neighborhood diversity (e.g. Yoshida and Kamitani, 2000; Pretzsch and Schütze, 2009; Lang et al., 2010). Most studies used rather simple architectural measures among which tree height, crown radius, crown length, trunk diameter, and trunk base position are the most common.

Today, terrestrial laser scanning (TLS) is available as a powerful tool to measure comprehensive spatial structures in complex environments such as forests (e.g. Watt and Donoghue, 2005; Seidel et al., 2011a Newnham et al., 2015). TLS methodology permits to record simultaneously usual tree measurements as well as several crown attributes. In forest research, tree and stand characteristics, such as diameter at breast height, total height (e.g. Hopkinson et al., 2004), trunk attributes (e.g. 
Thies et al., 2004), or detailed crown parameters (e.g. Takeda et al., 2008; Seidel et al., 2011b) were successfully derived from terrestrial laser scanning data.

Modern TLS instruments can measure the three-dimensional coordinates of up to 1 million points per second with millimeter accuracy based on the emission and detection of laser light. The ground-based perspective of TLS allows for a detailed representation of the forest from the ground up to the canopy, especially if data from a large number of scan positions are combined (e.g. Danson et al., 2007; Seidel et al., 2012). This is an advantage compared to airborne laser scanning, where large below-canopy areas remain undetected due to the birds-eye perspective and a lower point spacing of the LIDAR systems. Surprisingly, TLS was rarely used to relate the architecture of adjacent trees to each other or to investigate how management intensity or neighborhood diversity of a stand alters individual tree characteristics, such as branching patterns, crown shapes, and crown dimensions, ramification patterns, or growth habitus.

A first successful approach was presented by Seidel et al. (2011b) for European beech (Fagus sylvatica L.), common ash (Fraxinus excelsior L.) and small-leaved lime (Tilia cordata Mill.) trees. Competition of 15 target trees (five of each of the three species) was quantified and crown deformations were successfully explained using a competitive pressure model. Bayer et al. (2013) investigated the architecture of beech in pure stands and in mixture with Norway spruce and found significant differences. Metz et al. (2013) were able to relate the competitive situation of beech trees to their growth performance based on crown attributes. Neighborhood diversity and target tree growth were correlated, indicating stronger effects of intra- compared to interspecific competition. Even though some general patterns for beech seem to exist, e.g. stronger effects of intraspecific competition when compared to interspecific competition, further research is needed to clarify to what extent these results are valid for other sites, different species, or with varying management intensity.

The aim of this study was to contribute to a deeper understanding of these open questions. We focused our investigation on the European beech, since it is the most common deciduous tree species in Central Europe. For our study, we used TLS data to calculate 25 structural measures, some of which were newly developed, for 55 beech tree individuals that grew in either pure or mixed neighborhoods, and on plots that cover a gradient of management intensity.

We hypothesized that (1) an increasing management intensity results in longer and wider tree crowns and straighter trunks and (2) that beech trees growing in mixed stands develop larger crowns with longer branches and flatter branch angles than beech trees growing in pure stands. 


\subsection{Materials and methods}

\subsubsection{Study sites}

This study was conducted in the vicinity of the UNESCO World Natural Heritage Site "Hainich National Park", Thuringia, Germany (51 06' N, $10^{\circ} 23^{\prime}$ E). We used 12 experimental plots (EPs) that are located in mostly beech dominated (F. sylvatica) forests and that were part of the research network of the Biodiversity Exploratories (see http://www.biodiversity-exploratories.de/ or Fischer et al. 2010). The locations of the plots used in the present study are shown in Figure 2.1.

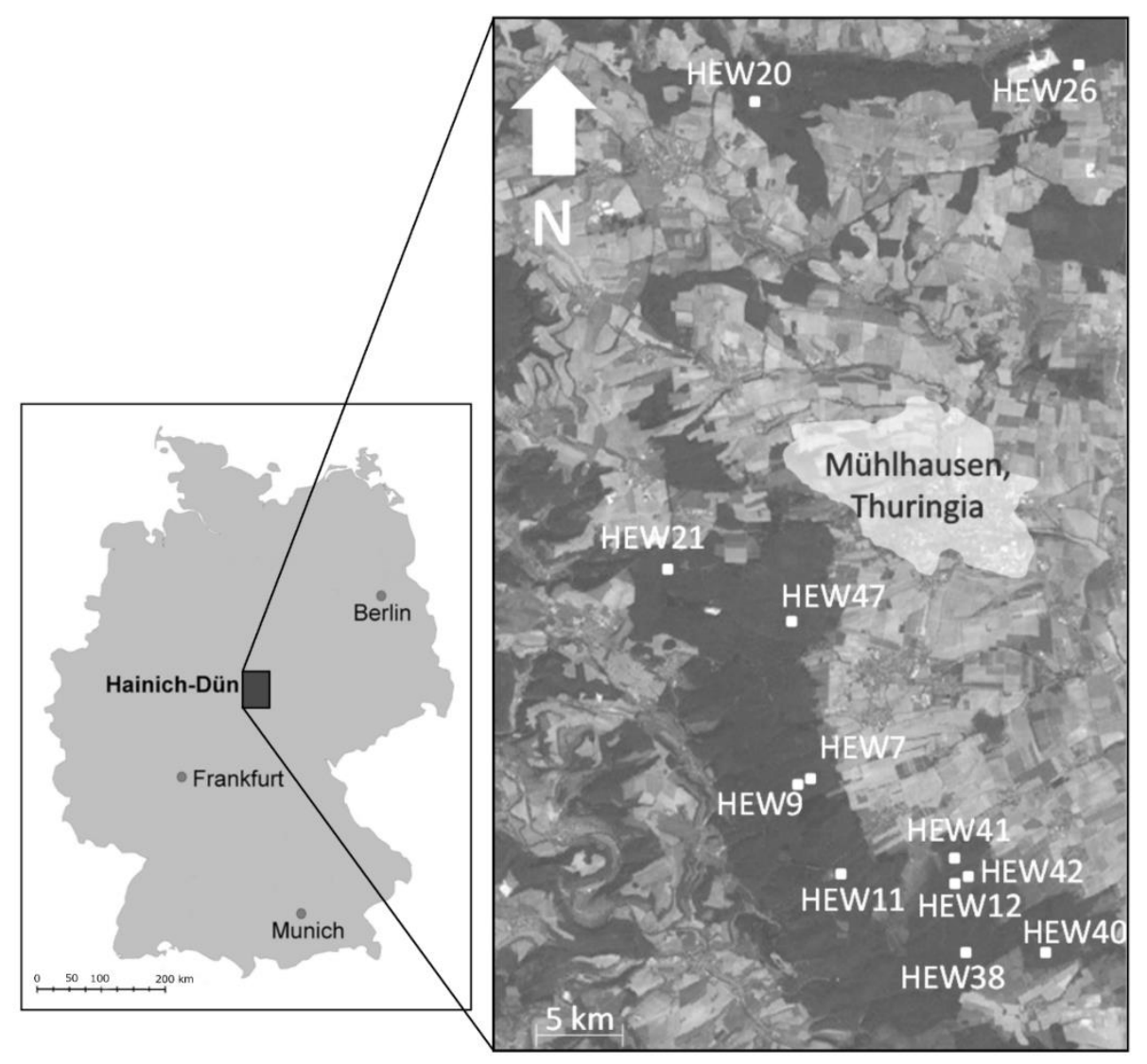

Figure 2.1: Map of the twelve study plots near the City of Mühlhausen, Thuringia, Germany. Basemap: Bing Aerial Maps.

The sites are characterized by calcic soils, mostly brown soils that developed over loess or lacustrine limestone. The climate is characterized by a mean annual temperature of $6.5-8{ }^{\circ} \mathrm{C}$ and a mean annual precipitation of 500-800 mm (Fischer et al., 2010). The plot characteristics can be found in Table 2.1. 
Table 2.1: Characterization of the study plots near the city of Mühlhausen, Germany.

\begin{tabular}{llllll}
\hline Plots & $\begin{array}{l}\text { Management } \\
\text { system }\end{array}$ & $\begin{array}{l}\text { Number } \\
\text { of sample } \\
\text { beech trees }\end{array}$ & $\begin{array}{l}\text { Age } \\
\text { in 2016 } \\
\text { (yrs) }\end{array}$ & $\begin{array}{l}\text { Stem } \\
\text { density } \\
\text { in 2016 } \\
\left(\mathbf{n o . h a}^{-1}\right)\end{array}$ & $\begin{array}{l}\text { Basal area } \\
\text { in 2016 } \\
\left.\mathbf{( m}^{\mathbf{2}} \mathbf{h a}^{-\mathbf{1}}\right)\end{array}$ \\
\hline \hline HEW7 & uneven-aged & 5 & 160 & 363 & 31.01 \\
HEW9 & uneven-aged & 5 & 171 & 284 & 27.78 \\
HEW11 & unmanaged (mixed) & 5 & 179 & 576 & 39.60 \\
HEW12 & unmanaged & 3 & 182 & 342 & 40.49 \\
HEW20 & mature even-aged & 5 & 104 & 342 & 35.06 \\
HEW21 & mature even-aged & 5 & 119 & 275 & 32.05 \\
HEW26 & uneven-aged & 5 & 186 & 227 & 31.34 \\
HEW38 & unmanaged & 3 & 178 & 397 & 39.92 \\
HEW40 & unmanaged (mixed) & 5 & 169 & 452 & 40.91 \\
HEW41 & unmanaged (mixed) & 4 & 166 & 407 & 34.82 \\
HEW42 & unmanaged & 5 & 182 & 278 & 36.53 \\
HEW47 & mature even-aged & 5 & 116 & 337 & 38.87 \\
\hline
\end{tabular}

To cover a management intensity gradient, we selected nine pure beech plots, which consisted of three mature even-aged stands, three uneven-aged stands, and three unmanaged stands. To quantify the management intensity for each plot, we used the silvicultural management intensity indicator (SMI). This indicator, which is a quantitative measure of forest management intensity, increases with increasing management intensity and consists of a risk component and a density component. The two components are determined by stand age, tree species identity, and management regime (Schall and Ammer, 2013). SMI data for all investigated plots were provided through the Biodiversity Exploratories Information System (BExIS). The effect of management intensity on tree structure was investigated, by selecting healthy trees from the point cloud data surrounded only by conspecific neighbors.

For studying the effect of intra- and interspecific competition, we chose six unmanaged stands, consisting of three mixed and three pure plots. The mixed plots comprised beech in combination with valuable broadleaves (Acerpsendoplatanus L., Fraxinus excelsior L., Quercus petraea Matt., and Tilia cordata Mill.). Stand type was defined using a limit of $80 \%$ share of F. sylvatica for pure versus mixed stands stands (pure: share F. sylvatica $\geq 80 \%$, mixed: share F. sylvatica $<80 \%$ ). The share was expressed relative to basal area (Bravo-Oviedo et al., 2014). The effect of intra- and interspecific competition was investigated by comparing structural measures of trees that had either only 
conspecific or mixed neighbor trees. The plot configuration resulted in 25 target trees located in unmanaged stands of which 11 trees were growing in pure and 14 trees were growing in mixed composition. Furthermore, a total of 41 trees (15 in even-aged stands; 15 in uneven-aged stands; 11 in unmanaged stands) growing under pure composition but along a gradient of management intensity were available. Figure 2.2 provides a graphical overview of the study design.

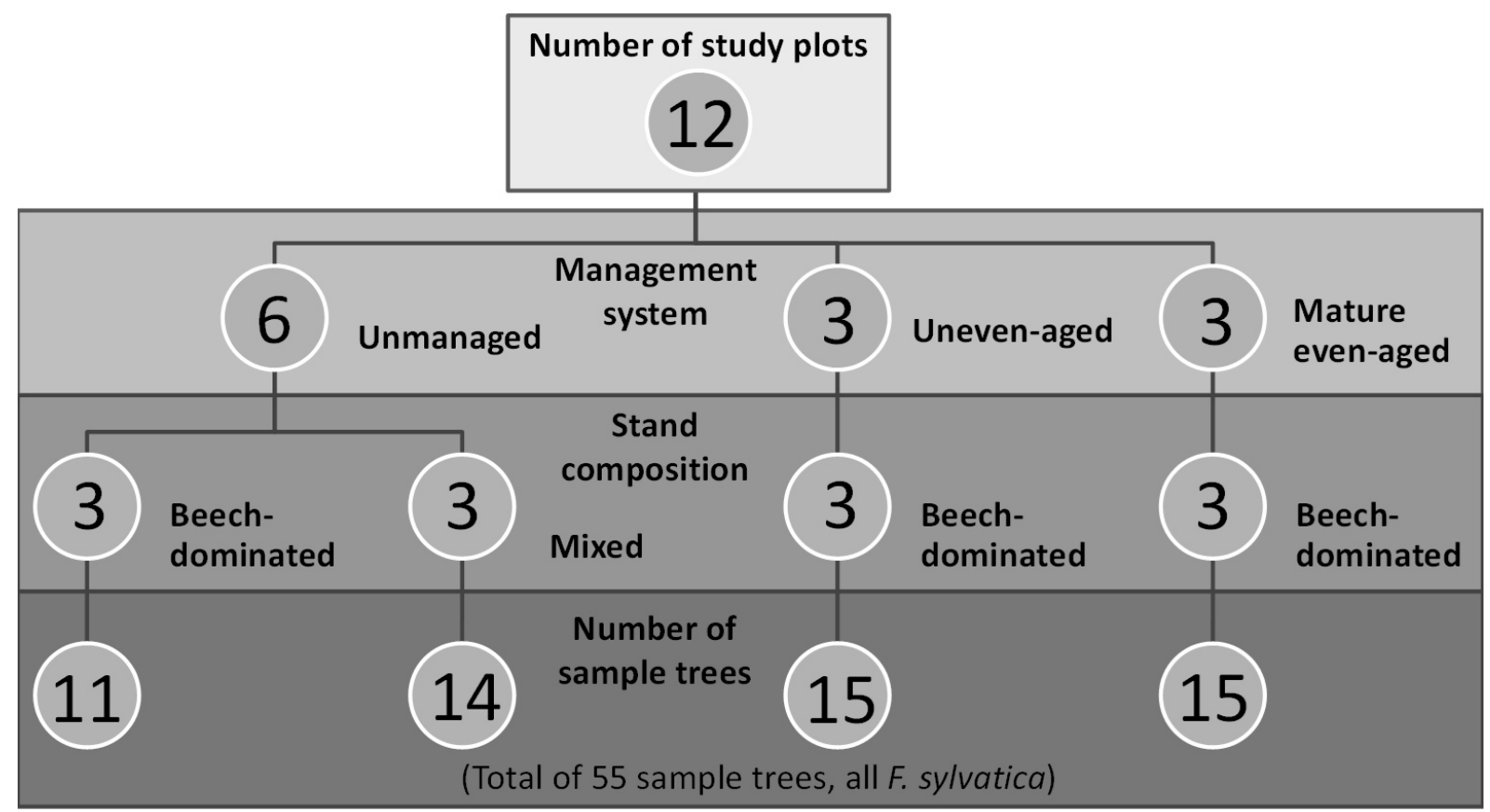

Figure 2.2: Graphical visualization of the experimental design based on 12 plots and a total of 55 tree individuals.

\subsubsection{Terrestrial laser scanning}

In February 2015, we scanned an area of $40 \mathrm{~m}$ by $40 \mathrm{~m}$ on each plot using 20-30 scans positions. Each scan position was chosen subjectively to optimize the visibility through the stand from the instruments' point of view under the given variations in understory vegetation density and irregularities in tree positions. A Faro Focus 3D 120 terrestrial laser scanner (Faro, Lake Mary, USA) was used for all scans. It was mounted on a standard tripod to operate at $1.3 \mathrm{~m}$ above ground and with identical scan settings for all scans. The near-infrared laser was set to scan a field of view of $305^{\circ}$ in vertical direction and $360^{\circ}$ in horizontal direction with an angular resolution of $0.035^{\circ}$, resulting in approximately 44.4 million measurements per scan.

We distributed artificial checker-board targets in every plot to allow for semi-automatic coregistration of all scans taken at a plot using the Faro Scene Software (Faro, Lake Mary, USA). After co-registration and application of standard filters in Faro Scene, all scans were exported as pts-files. 


\subsubsection{Point cloud pre-processing}

The scan data of each plot were imported to Cyclone 9.0 (Leica Geosystems AG, Heerbrugg, Switzerland) to manually select healthy looking tree individuals from the point cloud data. We chose beech (F. sylvatica) trees with a diameter at breast height (1.3 $\mathrm{m}$ above ground) between 35 and $60 \mathrm{~cm}$ (Table 2.2). For each manually isolated tree, a single point cloud was then exported as xyz-file for further processing. This procedure has been tested in earlier studies and provides reliable information on the trees' architecture (e.g. Seidel et al. 2011b; Metz et al. 2013).

Table 2.2: Dimensions of sample trees $(n=55)$ presented as mean ( \pm standard deviation) derived from the TLS data.

\begin{tabular}{lll}
\hline Measure & Mean $( \pm$ Std. dev. $)$ & Unit \\
\hline \hline Total tree height & $30.9( \pm 2.1)$ & $\mathrm{m}$ \\
Diameter at breast height & $46.6( \pm 6.4)$ & $\mathrm{cm}$ \\
Crown base height & $14.5( \pm 4.6)$ & $\mathrm{m}$ \\
Crown surface area & $419.9( \pm 168)$ & $\mathrm{m}^{2}$ \\
Crown volume & $319.2( \pm 212.9)$ & $\mathrm{m}^{3}$ \\
Wooden tree volume & $3.3( \pm 0.9)$ & $\mathrm{m}^{3}$ \\
\hline
\end{tabular}

\subsubsection{Point cloud post-processing}

Based on the xyz-files of each tree individual, we calculated two sets of structural measures. The first set was based on the Cartesian coordinates of all points belonging to the point cloud of a tree. In this cloud-based approach, we determined structural measures that can be derived from the geometry. Descriptions on how they were calculated from the point cloud can be found in the literature provided in Table 3. For three attributes, namely lean, sweep, and uprightness, we introduce new TLS-based definitions.

Lean was defined as the Euclidean distance between the $\mathrm{x}$ - and y-coordinates of the trunk base position (trunk center at breast height) and $\mathrm{x}$ - and $\mathrm{y}$-coordinates of the position at crown base height (trunk center at crown base height) (Figure 2.3, line a). To correct for different absolute sizes, this measure was divided by the total length (Figure 2.3, line b) of the branch free trunk, which yields the lean per meter of the trunk.

Sweep was defined as the ratio between the total lengths of the lines connecting the centers (xyzcoordinates) of trunk sections determined every $10 \mathrm{~cm}$ along the vertical axis (Figure 2.3, line d) 
between breast height and crown base height and the line connecting breast height and crown base height directly (Figure 2.3, line c).

Uprightness was defined as the ratio between the lengths of two lines. The first was the total length of the lines connecting the centers (xy-coordinates) of trunk sections taken every $10 \mathrm{~cm}$ along the vertical trunk axis between breast height and crown base height (Figure 2.3, line d). The second was the length of the line describing the horizontal displacement between the trunk section at breast height and its pendant at crown base height (Figure 2.3, line a). Each trunk section was $10 \mathrm{~cm}$ in thickness and the xy-coordinates of the points representing it were used to define the section's center based on QR decomposition (Gentle, 1998) as described in Seidel and Ammer (2014).

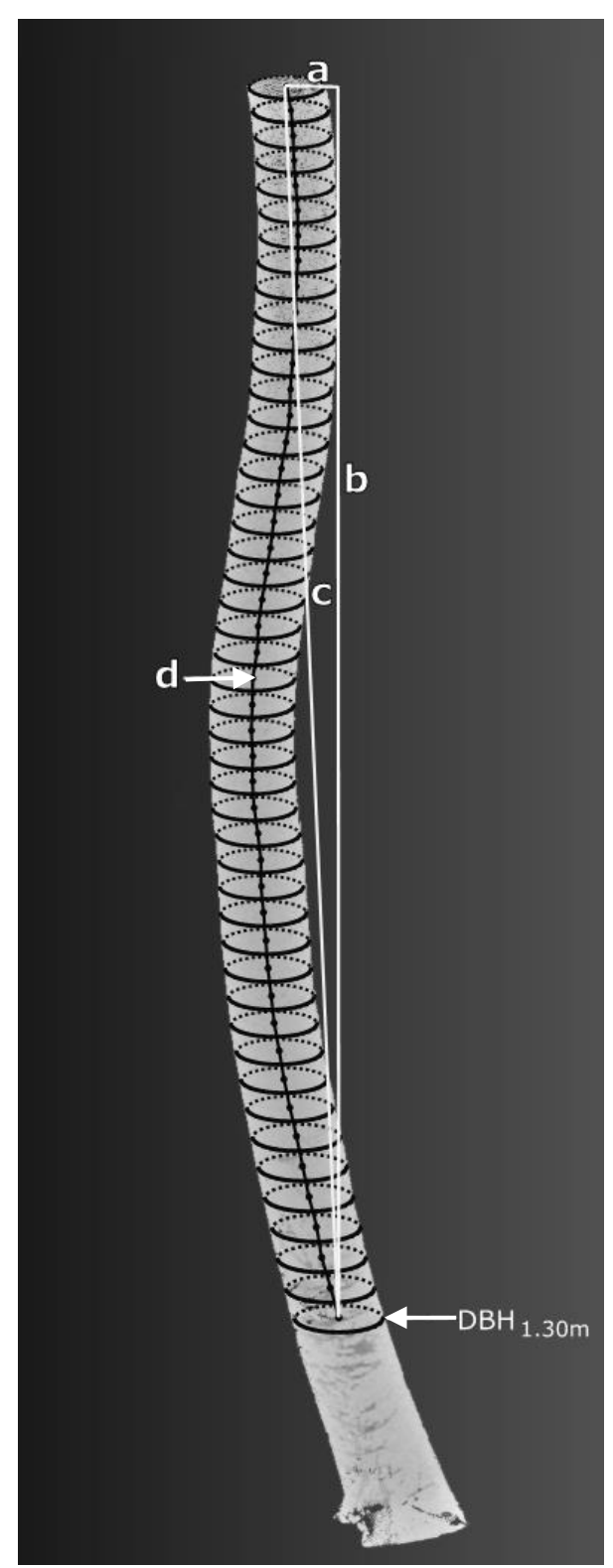

Figure 2.3: Schematic draft of the trunk sections with the lines a, b, c and d used to calculate lean, sweep and uprightness. $D B H$ diameter at breast height. 
A second set of measures was calculated on the basis of quantitative structural models (QSM) that were derived from the point clouds using the methodology presented in Raumonen et al. (2013) and Calders et al. (2015). QSMs describe the branching structure of trees with hierarchical collections of cylinders fitted to local details of the point cloud describing the tree (Raumonen 2015). Calders et al. (2015) validated this QSM approach by comparing TLS derived volume estimates with destructively harvested reference measurements. Figure 2.4 provides an exemplary image of a point cloud and the corresponding QSM of one of the sample trees.

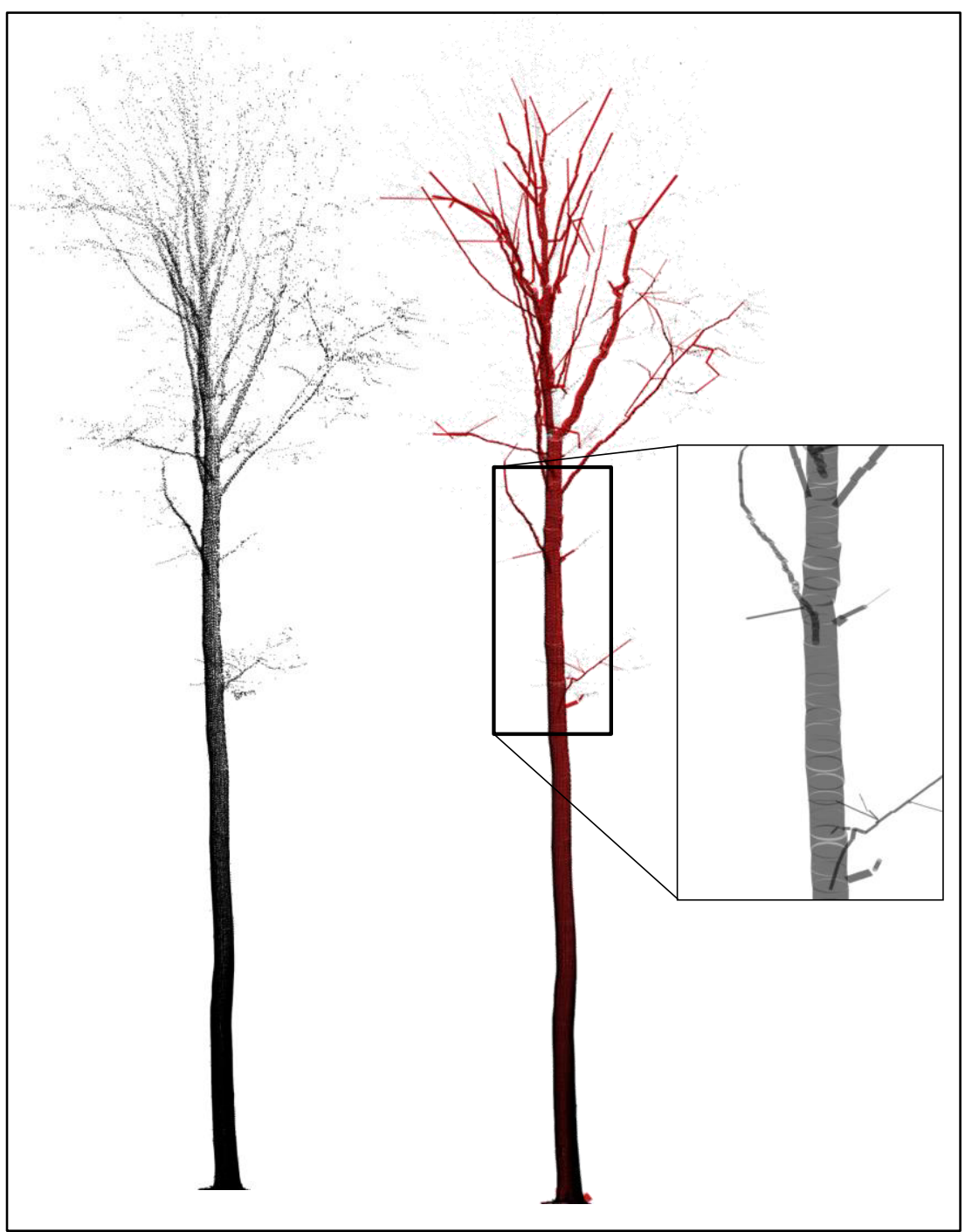

Figure 2.4: Point cloud from terrestrial laser scanning (left) and the corresponding quantitative structural model QSM (right). The close up (far right) visualizes the cylinder-based composition of the tree used for calculating volumes, branch angles, and branch lengths. All measures and information on their mathematical derivation are listed in Table 2.3. 
Table 2.3.: Structural measures determined for each sample tree $(\mathrm{n}=55) .1$ st and 2 nd refer to the branch order; branch order was defined as '1st' for branches branching from the main trunk and '2nd' for branches branching from the first-order branches. The adaxial branch angle between a branch and its parent branch is defined as the angle between the two cylinders (the first cylinder is the branch and the second is the parent branch).

\begin{tabular}{|c|c|c|c|}
\hline Measure & Abbreviation & Type & Calculation/ Reference \\
\hline Total tree height (m) & TTH & cloud-based & highest - lowest point (z-coord.) \\
\hline Diameter breast height $(\mathrm{cm})$ & $\mathrm{DBH}$ & cloud-based & Seidel et al. (2011b) \\
\hline Crown base height (m) & $\mathrm{CBH}$ & cloud-based & Metz et al. (2013) \\
\hline Maximum area $\left(\mathrm{m}^{2}\right)$ & Max $_{\text {area }}$ & cloud-based & Max $_{\text {AreaTLS }}$ in Seidel et al. (2015a) \\
\hline Height of $\operatorname{Max}_{\text {area }}(\mathrm{m})$ & $\mathrm{H}_{\text {maxarea }}$ & cloud-based & $\mathrm{H}_{\text {maxareaTLS }}$ in Seidel et al. (2015a) \\
\hline Crown volume $\left(\mathrm{m}^{3}\right)$ & $\mathrm{CV}$ & cloud-based & Metz et al. (2013) \\
\hline Crown surface area $\left(\mathrm{m}^{2}\right)$ & CSA & cloud-based & Metz et al. (2013) \\
\hline Crown length (m) & $\mathrm{CL}$ & cloud-based & TTH-CBH \\
\hline Crown asymmetry $(\mathrm{m})$ & $\mathrm{CA}$ & cloud-based & Seidel et al. (2011b) \\
\hline Mean crown radius (m) & CRmean & cloud-based & $\mathrm{CR}_{\text {meanTLS }}$ in Seidel et al. (2015a) \\
\hline Sweep & Sweep & cloud-based & see 2.4 , this publication \\
\hline Lean & Lean & cloud-based & see 2.4 , this publication \\
\hline Height-diameter ratio & $\mathrm{H} / \mathrm{D}$-ratio & cloud-based & TTH/DBH*100 \\
\hline Uprightness & $\mathrm{U}$ & cloud-based & see 2.4 , this publication \\
\hline Competition index & $\mathrm{CI}$ & cloud-based & Seidel et al. (2015b) \\
\hline Tree stem volume $\left(\mathrm{m}^{3}\right)$ & TSV & QSM-based & \\
\hline Wooden tree volume $\left(\mathrm{m}^{3}\right)$ & WTV & QSM-based & \\
\hline Branch volume $1^{\text {st }}\left(\mathrm{m}^{3}\right)$ & $\mathrm{BV} 1^{\text {st }}$ & QSM-based & \\
\hline Branch volume $2^{\text {nd }}\left(\mathrm{m}^{3}\right)$ & $\mathrm{BV} 2^{\text {nd }}$ & QSM-based & \\
\hline Mean branch angle $\left(^{\circ}\right)$ & MBA & QSM-based & $\tau$ Raumonen et al. (2013) \\
\hline Mean branch angle $1^{\text {st }}\left({ }^{\circ}\right)$ & MBA1st & QSM-based & \\
\hline Mean branch angle $2^{\text {nd }}\left({ }^{\circ}\right)$ & $\mathrm{MBA}^{\text {nd }}$ & QSM-based & \\
\hline Mean branch length (m) & MBL & QSM-based & \\
\hline Mean branch length $1^{\text {st }}(\mathrm{m})$ & MBL1st & QSM-based & \\
\hline Mean branch length $2^{\text {nd }}(\mathrm{m})$ & MBL2 ${ }^{\text {nd }}$ & QSM-based & \\
\hline
\end{tabular}




\subsubsection{Statistical analysis}

To assure the comparability of the individual trees considered in this study, the dimensions (DBH, TTH) of the sampled trees were controlled among the composition group ("pure" vs. "mix"). All trees considered were independent from one another. Significant differences were found for TTH (pure $=29.39 \pm 1.76$ vs. mixed $=32.04 \pm 2.71, \mathrm{p}<0.01$ ). This is why TTH was not excluded from the subsequent models for both composition groups. No significant differences among the tree groups were found for DBH. The composition group was evaluated with the analysis of covariance (ANCOVA) to compare the categorical independent variables 'composition' with the outcome of the dependent variables, while statistically controlling for the effect of the continuous variable 'TTH' as covariate, as the data suggested a relationship to the dependent variables. A linear relationship of the dependent (response) variables was assumed.

Homoscedasticity was controlled using the Fligner-Killeen test. Residuals were considered to be independent and normality of residuals was controlled visually (density plot, QQ plot) and with the Shapiro-Wilk test of normality. Linear regression analyses were conducted for quantifying the influence of SMI on the 25 structural measures of the beech trees. A significance level of $\mathrm{p}<0.05$ used. All statistical analyses, model fitting, and graphs were processed using the free software environment R, version 3.1.0 (R Core Team, 2014). 


\subsection{Results}

\subsubsection{Effect of management intensity on tree structure}

Four of the twenty-five tested measures were significantly related to the intensity of the silvicultural management, quantified as SMI. While lean $(\mathrm{p}<0.05)$, sweep $(\mathrm{p}<0.001)$ and the height of the maximal horizontal crown extension (Hmaxarea) $(\mathrm{p}<0.01)$ decreased with increasing SMI, the crown surface area $(\mathrm{CSA})(\mathrm{p}<0.01)$ significantly increased along the tested gradient of management intensity (see Figure 2.5).
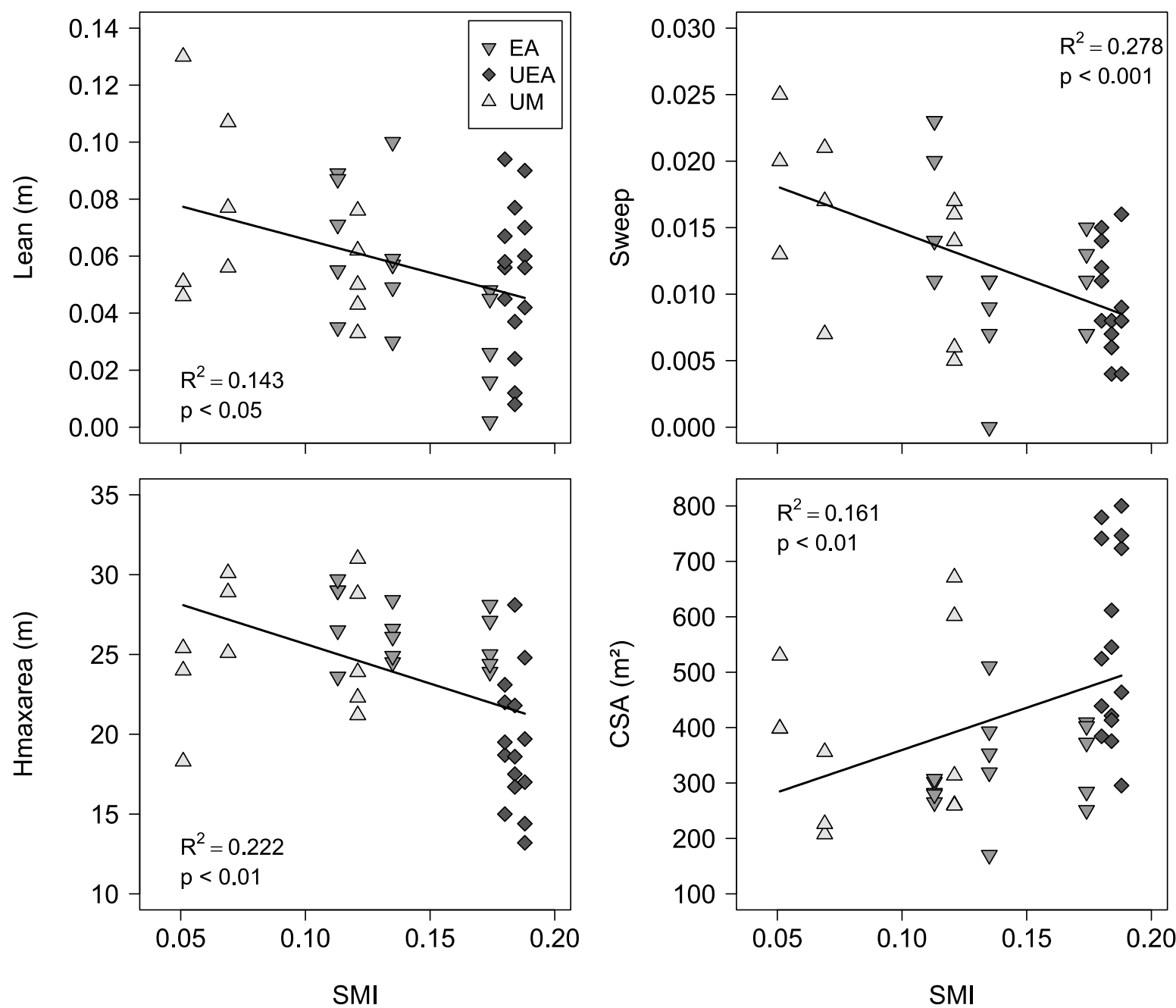

Figure 2.5: Relationship between SMI and tree structure attributes. EA even-aged stands, UEA uneven-aged stands, UM unmanaged stands $(\mathrm{n}=41)$. All attributes that were significantly affected by SMI are shown (level of significance $\mathrm{p}<0.05)$. 


\subsubsection{Effect of stand composition on tree structure}

Among the two different types of composition (pure vs. mixed), we found six attributes to differ significantly. Beech trees surrounded by valuable hardwoods showed a lower height of the maximal horizontal crown extension $(\mathrm{p}<0.01)$ and a lower H/D ratio $(\mathrm{p}<0.01)$ than beech trees surrounded by intraspecific neighbors. The mean branch length $(\mathrm{MBL})$ was shorter $(\mathrm{p}<0.01)$ and the mean branch angle $(\mathrm{MBA})(\mathrm{p}<0.01)$, as well as the branch angles of the first $\left(\mathrm{MBA}^{\mathrm{st}}\right)(\mathrm{p}<$ $0.05)$ and second branch order $\left(\mathrm{MBA}^{\text {nd }}\right)(\mathrm{p}<0.05)$ were larger in mixed composition compared to pure composition (see Table 2.4; Figure 2.6).

Table 2.4: Results of the analysis of covariance (ANCOVA) with the independent variable 'composition' and the covariate 'TTH' (total tree height).

\begin{tabular}{llll}
\hline Dept. Variable & Expl. Variable & $\boldsymbol{F}$-Value & $\boldsymbol{p}$-Value \\
\hline \hline Height of Max area & composition & 13.11 & $<0.01$ \\
& TTH & 2.46 & 0.13 \\
H/D-ratio & composition & 10.14 & $<0.01$ \\
& TTH & 9.51 & $<0.01$ \\
Mean branch length & composition & 5.50 & $<0.01$ \\
& TTH & 6.72 & $<0.01$ \\
Mean branch angle & composition & 8.13 & $<0.01$ \\
& TTH & 9.61 & $<0.01$ \\
Mean branch angle ${ }^{\text {st }}$ & composition & 4.67 & $<0.05$ \\
& TTH & 0.81 & 0.38 \\
Mean branch angle 2 & composition & 5.98 & $<0.05$ \\
\hline
\end{tabular}



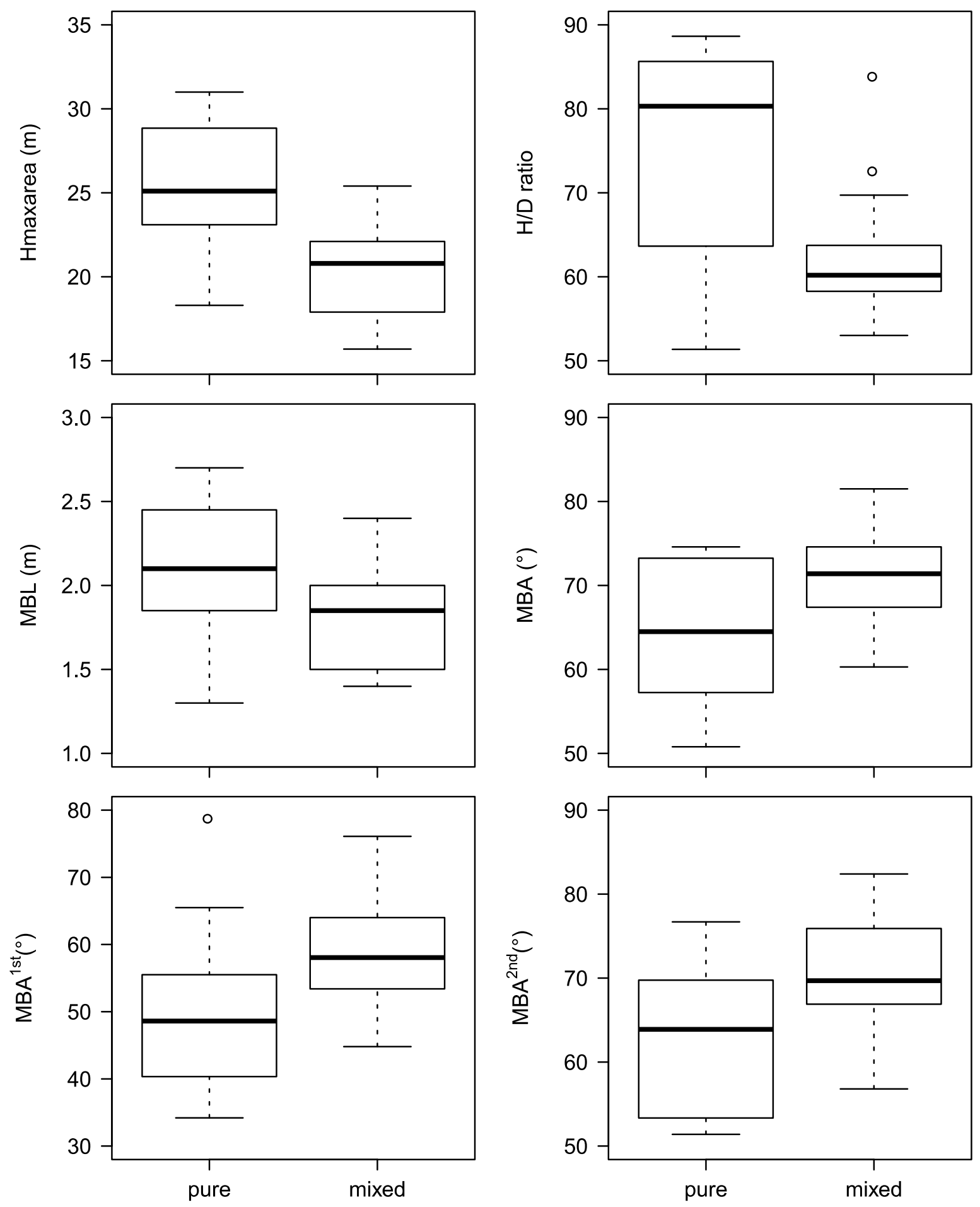

Stand composition

Stand composition

Figure 2.6: Boxplots of tree structure attributes that differed significantly between pure $(\mathrm{n}=11)$ and mixed stand composition. 


\subsection{Discussion}

\subsubsection{Effect of management intensity on tree structure}

The intensity of silvicultural interventions is one of the most important forest management decisions to control the ecological and economical value of a forest stand (Schall and Ammer, 2013). In the present study, we found that different levels of silvicultural management intensity significantly affected structural measures of beech trees. The height of the maximal horizontal crown extension decreased with increasing SMI, while the crown surface area increased. These findings are in line with earlier studies in coniferous (Larson et al., 2001; Macdonald and Hubert 2002) and deciduous forest stands (e.g. Medhurst and Beadle, 2001) and also with empirical knowledge, indicating that an intensification of thinning activities results in the development of larger tree crowns.

Lower stand densities, as present in the studied mature even-aged beech stands and particularly in the uneven-aged beech stands, resulted in less competition and an increased resource acquisition capacity per tree and therefore facilitated crown expansion. Wider tree spacing also delayed canopy closure and slowed the process of the loss of branches (Montagu et al., 2003).

Higher stand densities and closed canopies, as present in the unmanaged beech stands, however, reduced the light availability in lower canopy layers, which resulted in the upward shift of the maximal horizontal crown extension and in a decrease of the crown surface area (Fichtner et al., 2013). The loss of branches in the lower part of the tree crown presumably led to a redistribution of foliage toward the top of the canopy to improve the light interception. Changes in the distribution of biomass within the crown with alterations in stand density have been reported for other tree species (Medhurst and Beadle, 2001; Shrestha and Wynne, 2012).

Gary (1978) found that needles and branch wood of unthinned Pinus contorta Dougl. ex Loud. were displaced toward the top half of the canopy, while the foliage of thinned trees was evenly distributed. In addition to crown size, the vertical distribution of leaves and branches is a key factor of productivity (Jucker et al., 2015; Maguire and Bennett, 1996). Smith and Long (1989) found that variations in the canopy structure of even-aged $P$. contorta stands, such as canopy depth and foliar density, were related to stem wood production and stem wood growth efficiency. We also found (Juchheim et al., 2017) that beech trees in repeatedly thinned stands developed a vertically more even distribution of leaves and branches.

Growing space extensions due to tree removals are commonly used in forestry to promote crown growth and thereby accelerate radial increment (Fichtner et al., 2013). As a consequence, trees reach a certain target diameter faster. In the case of beech, shorter production cycles also 
reduce the risk of red-coloured heartwood and thus the probability of having poor-quality wood (Knoke and Schulz-Wenderoth, 2001).

Aside of branch free bole length, lean and sweep are key criteria for the quality assessment of round timber (CEN, 1995; CEN, 1997). Deviations from trunk straightness initiate the development of reaction wood, which causes substantial losses in volume and value of a tree trunk (Ehrenberg, 1970; Thies et al., 2004). We found that lean and sweep decreased with increasing silvicultural management intensity. This result was expected, since - aside of increasing total volume production - a primary goal of thinning is to produce high-quality trunks, which restrict wood processing as little as possible. However, high-quality trunks presumably contain a lower number of microhabitats, like snaped knots, etc., compared to trunks of lower quality. Winter and Möller (2008) found that the number of microhabitats in managed forests was not correlated to DBH, whereas it was in unmanaged forests.

\subsubsection{Effect of stand composition on tree structure}

Tree structure affects interactions between trees, because it influences the competitive effect and competitive response of trees (Lintunen, 2013). Our analysis revealed that the structure of the studied European beech trees varied significantly between intra and interspecific competition.

From literature, it is known that tree crowns and trunks can respond species-specifically to different neighborhood diversities (e.g. Yoshida and Kamitani, 2000; Pretzsch and Schütze, 2009; Lang et al., 2010; Olivier et al., 2016). This was shown by Thorpe et al. (2010) for crown length and radius of subalpine fir (Abies lasiocarpa (Hook.) Nutt.) and interior spruce (Picea glauca $x$ engelmanii) or by Lintunen (2013) for growth vigor and height growth of scots pine (Pinus sylvestris L.) and silver birch (Betula pendula Roth.).

Beech is known for its high crown plasticity and competitive strength in occupying canopy space (Pretzsch, 2014). Metz et al. (2013) found the highest crown competition and the lowest relative basal area increment for beech growing in intraspecific competition. For valuable hardwoods, only a marginally weaker strength in competition was measured, whereas conifer species had substantially lower competitive effects on beech. A study on crown plasticity of European beech in pure stands versus mixed stands with Norway spruce (Picea abies) detected shallower branches and a higher crown volume for beech trees growing in mixture (Bayer et al., 2013). Our analysis revealed similar results for the phenotypic plasticity of beech surrounded by valuable hardwoods as competitors. Flatter branch angles result in larger crowns and an increased space occupation of beech in mixed composition when compared to pure composition. This in turn may lead to a more effective absorption of incoming light and simultaneously to a suppression of neighboring alien 
species through shading. Canham et al. (1994) found that the shade tolerance of trees was closely correlated to the light-extinction characteristics. Shade-tolerant trees, like beech, have denser foliage and thus cast deeper shade than shade-intolerant species that allow greater light penetration. Highest self-thinning rates for beech were observed in pure stands, whereas mixtures with other tree species led to reduced competition and to lower restriction in crown size (Dieler and Pretzsch, 2013). The main reasons for higher crown volumes of trees growing in mixture are presumed to be improved light availability and nutrient supply due to complementary resource use and niche partitioning (Metz et al., 2013; Jucker et al., 2015). Trees that are exposed to intense light competition and restricted growth by mechanical abrasion extend their branches vertically and tend to develop thin and shallow crowns (Jucker et al., 2015). We observed this process when comparing beech trees growing in intra- versus interspecific competition. Beech trees surrounded by conspecific neighbors developed Y-shaped crowns with longer branches and steeper branch angles than beech trees surrounded by valuable hardwoods. The increased competitive pressure in pure beech stands also results in greater height of the maximal horizontal crown extension to improve light capture due to an increased concentration of leaves toward the top of the crown.

Another indicator for increased light competition is the tree H/D ratio. High competitive pressure results in largely maintaining height growth at the expense of diameter increment $(H / D$ ratio increases) to secure a canopy position and to maintain the connection to light as long as possible (Röhrig et al., 2006; Vospernik et al., 2010). Trees with higher H/D ratios are more susceptible to wind damage than trees with lower ratios (Cremer et al., 1982; Röhrig et al., 2006). In our study, tree $\mathrm{H} / \mathrm{D}$ ratio varied significantly between intra and interspecific competition. Our results suggest that beech trees growing in mixture were under lower competitive pressure and competed less for light during ontogeny than individuals growing in monoculture. Beech trees surrounded by valuable hardwoods were, therefore, able to allocate more resources to diameter increment than beech trees surrounded by conspecific neighbors.

\subsection{Conclusions}

We investigated the effect of management intensity and neighboring tree species diversity on the structure of beech trees in mature forests. Based on the high spatial resolution of the comprehensive data provided by terrestrial laser scanning, we were able to detect that structural measures of beech trees were significantly affected by silvicultural management intensity, as well as by intra and interspecific competition. Our study provides quantitative evidence for some widely accepted processes of phenological adaptation to competition and neighborhood diversity in beech trees that have only rarely been measured in situ. Forest management that aims at certain 
economical and/or ecological management goals may use the presented effects of management intensity and neighborhood identity to better manage individual tree structure.

\section{Author contribution statement}

DS and CA conceived and designed the research project. JJ conducted fieldwork and wrote the manuscript. DS, KC, and PR calculated structural measures of the sample trees. PA and JJ performed statistical analysis. DS and CA contributed to drafting the manuscript. PA, KC, and PR made important suggestions for its revision.

\section{Acknowledgements}

We thank the managers of the three Exploratories, Kirsten Reichel-Jung, Swen Renner, Katrin Hartwich, Sonja Gockel, Kerstin Wiesner, and Martin Gorke for their work in maintaining the plot and project infrastructure; Christiane Fischer and Simone Pfeiffer for giving support through the central office, Michael Owonibi for managing the central data base, and Markus Fischer, Eduard Linsenmair, Dominik Hessenmo“ller, Jens Nieschulze, Daniel Prati, Ingo Scho“ning, Franc ois Buscot, Ernst-Detlef Schulze, Wolfgang W. Weisser, and the late Elisabeth Kalko for their role in setting up the Biodiversity Exploratories project. The work has been funded by the DFG (German Science Foundation) Priority Program 1374 "Infrastructure-Biodiversity-Exploratories". Field work permits were issued by the responsible state environmental offices of Baden-Württemberg, Thu "ringen, and Brandenburg (according to $₫ 72 \mathrm{BbgNatSchG).} \mathrm{This} \mathrm{work} \mathrm{was} \mathrm{funded} \mathrm{by} \mathrm{research}$ grants granted to Dominik Seidel (reference number: Se 2383/2-1) and Christian Ammer (reference number: Am 149/15-1) by the German Research Foundation and by a research scholarship granted to Dominik Seidel by the German Research Foundation (reference number: Se 2383/1-1).

\section{Conflict of interest}

The authors declare that they have no conflict of interest. 


\subsection{References}

Ammer, C., \& Puettmann, K. (2009). Waldbau, quo vadis?-Waldbewirtschaftung zwischen Funktionenorientierung und Multifunktionalität (The road ahead of forest managementsingle or multiple management objectives). Forstarchiv, 80, 90-96.

Bayer, D., Seifert, S., \& Pretzsch, H. (2013). Structural crown properties of Norway spruce (Picea abies [L.] Karst.) and European beech (Fagus sylvatica [L.]) in mixed versus pure stands revealed by terrestrial laser scanning. Trees, 27(4), 1035-1047.

Bravo-Oviedo, A., Pretzsch, H., Ammer, C., Andenmatten, E., Barbati, A., Barreiro, S., ... \& Ouden, J. (2014). European mixed forests: definition and research perspectives. Forest Systems, 23, 518-533.

Brown, P. L., Doley, D., \& Keenan, R. J. (2004). Stem and crown dimensions as predictors of thinning responses in a crowded tropical rainforest plantation of Flindersia brayleyana F. Muell. Forest Ecology and Management, 196(2-3), 379-392.

Calders, K., Newnham, G., Burt, A., Murphy, S., Raumonen, P., Herold, M., ... \& Kaasalainen, M. (2015). Nondestructive estimates of above-ground biomass using terrestrial laser scanning. Methods in Ecology and Evolution, 6(2), 198-208.

Canham, C. D., Finzi, A. C., Pacala, S. W., \& Burbank, D. H. (1994). Causes and consequences of resource heterogeneity in forests: interspecific variation in light transmission by canopy trees. Canadian Journal of Forest Research, 24(2), 337-349.

CEN (1995). Softwood timber. Qualitative classification. prEN 1927:ff. Brussels: Comite' Europe'en de Normalisation

CEN (1997). Hardwood round timber. Qualitative classification. prEN 1316:ff. Brussels: Comite' Europe'en de Normalisation

Cremer, K. W., Borough, C. J., McKinnell, F. H., \& Carter, P. R. (1982). Effects of stocking and thinning on wind damage in plantations. NZJ For. Sci, 12(2), 244-268.

Danson, F. M., Hetherington, D., Morsdorf, F., Koetz, B., \& Allgower, B. (2007). Forest canopy gap fraction from terrestrial laser scanning. IEEE Geoscience and remote sensing letters, 4(1), 157-160. 
Dieler, J., \& Pretzsch, H. (2013). Morphological plasticity of European beech (Fagus sylvatica L.) in pure and mixed-species stands. Forest Ecology and Management, 295, 97-108.

Ehrenberg, C. (1970). Breeding for stem quality. Unasylva, 24(97/98). 23-31

Fichtner, A., Sturm, K., Rickert, C., Von Oheimb, G., \& Härdtle, W. (2013). Crown size-growth relationships of European beech (Fagus sylvatica L.) are driven by the interplay of disturbance intensity and inter-specific competition. Forest Ecology and Management, 302, 178-184.

Fischer, M., Bossdorf, O., Gockel, S., Hänsel, F., Hemp, A., Hessenmöller, D., ... \& Renner, S. (2010). Implementing large-scale and long-term functional biodiversity research: The Biodiversity Exploratories. Basic and Applied Ecology, 11(6), 473-485.

Gary, H. L. (1978). The vertical distribution of needles and branchwood in thinned and unthinned 80-year-old lodgepole pine [Pinus contorta, Wyoming]. Northwest Science.

Gentle, J.E. (1998). QR factorization. Numerical linear algebra for applications in statistics. Springer, Berlin, pp 95-97

Guericke, M. (2001). Untersuchungen zur Wuchsdynamik von Mischbeständen aus Buche und Europ. Lärche (Larix decidua, Mill.) als Grundlage für ein abstandsabhängiges Einzelbaumwachstumsmodell. Dissertation, University of Goettingen.

Hamilton, G. J. (1981). The effects of high intensity thinning on yield. Forestry: An International Journal of Forest Research, 54(1), 1-15.

Hawley, R.C. (1946). Practice of silviculture, 5th edn. John Wiley \&Sons, New York.

Hopkinson, C., Chasmer, L., Young-Pow, C., \& Treitz, P. (2004). Assessing forest metrics with a ground-based scanning lidar. Canadian Journal of Forest Research, 34(3), 573-583.

Ishii, H., \& Asano, S. (2010). The role of crown architecture, leaf phenology and photosynthetic activity in promoting complementary use of light among coexisting species in temperate forests. Ecological Research, 25(4), 715-722.

Juchheim, J., Ammer, C., Schall, P., \& Seidel, D. (2017). Canopy space filling rather than conventional measures of structural diversity explains productivity of beech stands. Forest Ecology and Management, 395, 19-26. 
Jucker, T., Bouriaud, O., \& Coomes, D. A. (2015). Crown plasticity enables trees to optimize canopy packing in mixed-species forests. Functional Ecology, 29(8), 1078-1086.

Kimmins, J.P. (2004). Forest Ecology: a foundation for sustainable forest management and environmental ethics in forestry, 3rd edn. Prentice Hall, Upper Saddle River.

Knoke, T., \& Wenderoth, S. S. (2001). Ein Ansatz zur Beschreibung von Wahrscheinlichkeit und Ausmaß der Farbkernbildung bei Buche (Fagus sylvatica L.). Forstwissenschaftliches Centralblatt vereinigt mit Tharandter forstliches Jahrbuch, 120(1-6), 154-172.

Lang, A. C., Härdtle, W., Bruelheide, H., Geißler, C., Nadrowski, K., Schuldt, A., ... \& von Oheimb, G. (2010). Tree morphology responds to neighbourhood competition and slope in speciesrich forests of subtropical China. Forest Ecology and Management, 260(10), 1708-1715.

Lang, A. C., Härdtle, W., Bruelheide, H., Kröber, W., Schröter, M., von Wehrden, H., \& von Oheimb, G. (2012). Horizontal, but not vertical canopy structure is related to stand functional diversity in a subtropical slope forest. Ecological research, 27(1), 181-189.

Lintunen, A. (2013). Crown architecture and its role in species interactions in mixed boreal forests. Dissertation, University of Helsinki

Macdonald, E., \& Hubert, J. (2002). A review of the effects of silviculture on timber quality of Sitka spruce. Forestry, 75(2), 107-138.

Maguire, D. A., \& Bennett, W. S. (1996). Patterns in vertical distribution of foliage in young coastal Douglas-fir. Canadian Journal of Forest Research, 26(11), 1991-2005.

Matsuzaki, J., Masumori, M., \& Tange, T. (2006). Stem phototropism of trees: a possible significant factor in determining stem inclination on forest slopes. Annals of Botany, 98(3), 573-581.

Medhurst, J. L., \& Beadle, C. L. (2001). Crown structure and leaf area index development in thinned and unthinned Eucalyptus nitens plantations. Tree Physiology, 21(12-13), 989-999.

Metz, J., Seidel, D., Schall, P., Scheffer, D., Schulze, E. D., \& Ammer, C. (2013). Crown modeling by terrestrial laser scanning as an approach to assess the effect of aboveground intra-and interspecific competition on tree growth. Forest Ecology and Management, 310, 275-288.

Montagu, K. D., Kearney, D. E., \& Smith, R. G. B. (2003). The biology and silviculture of pruning planted eucalypts for clear wood production—a review. Forest Ecology and Management, 179(1-3), 1-13. 
Newnham, G. J., Armston, J. D., Calders, K., Disney, M. I., Lovell, J. L., Schaaf, C. B., ... \& Danson, F. M. (2015). Terrestrial laser scanning for plot-scale forest measurement. Current Forestry Reports, 1(4), 239-251.

Olivier, M. D., Robert, S., \& Fournier, R. A. (2016). Response of sugar maple (Acer saccharum, Marsh.) tree crown structure to competition in pure versus mixed stands. Forest Ecology and Management, 374, 20-32.

Pape, R. (1999). Effects of thinning regime on the wood properties and stem quality of Picea abies. Scandinavian Journal of Forest Research, 14(1), 38-50.

Porté, A., \& Bartelink, H. H. (2002). Modelling mixed forest growth: a review of models for forest management. Ecological modelling, 150(1-2), 141-188.

Pretzsch, H. (2014). Canopy space filling and tree crown morphology in mixed-species stands compared with monocultures. Forest Ecology and Management, 327, 251-264.

Pretzsch, H., \& Schütze, G. (2009). Transgressive overyielding in mixed compared with pure stands of Norway spruce and European beech in Central Europe: evidence on stand level and explanation on individual tree level. European Journal of Forest Research, 128(2), 183-204.

Pretzsch, H., Del Río, M., Schütze, G., Ammer, C., Annighöfer, P., Avdagic, A., ... \& Drössler, L. (2016). Mixing of Scots pine (Pinus sylvestris L.) and European beech (Fagus sylvatica L.) enhances structural heterogeneity, and the effect increases with water availability. Forest Ecology and Management, 373, 149-166.

Puettmann, K. J., Coates, K. D., \& Messier, C. C. (2012). A critique of silviculture: managing for complexity. Island Press, Washington, DC

R Core Team (2014). R: a language and environment for statistical computing. Vienna, Austria: R Foundation for Statistical Computing.

Raumonen, P. (2015). Quantitative structure tree models from terrestrial laser scanner data. In: Proceedings of Silvilaser 2015, 28-30 Sept, La Grande Motte, France

Raumonen, P., Kaasalainen, M., Åkerblom, M., Kaasalainen, S., Kaartinen, H., Vastaranta, M., ... \& Lewis, P. (2013). Fast automatic precision tree models from terrestrial laser scanner data. Remote Sensing, 5(2), 491-520. 
Röhrig, E., Bartsch, N. and von Lüpke, B. (2006). Waldbau auf ökologischer Grundlage. 7th edn. Ulmer Verlag.

Schall, P., \& Ammer, C. (2013). How to quantify forest management intensity in Central European forests. European Journal of Forest Research, 132(2), 379-396.

Seidel, D., \& Ammer, C. (2014). Efficient measurements of basal area in short rotation forests based on terrestrial laser scanning under special consideration of shadowing. iForestBiogeosciences and Forestry, 7(4), 227.

Seidel D, Fleck S, Leuschner C, Hammett T (2011a) Review of ground-based methods to measure the distribution of biomass in forest canopies. Ann For Sci 68:225-244

Seidel, D., Leuschner, C., Müller, A., \& Krause, B. (2011). Crown plasticity in mixed forestsquantifying asymmetry as a measure of competition using terrestrial laser scanning. Forest Ecology and Management, 261(11), 2123-2132.

Seidel, D., Fleck, S., \& Leuschner, C. (2012). Analyzing forest canopies with ground-based laser scanning: a comparison with hemispherical photography. Agricultural and Forest Meteorology, 154, 1-8.

Seidel, D., Schall, P., Gille, M., \& Ammer, C. (2015). Relationship between tree growth and physical dimensions of Fagus sylvatica crowns assessed from terrestrial laser scanning. iForestBiogeosciences and Forestry, 8.

Seidel, D., Hoffmann, N., Ehbrecht, M., Juchheim, J., \& Ammer, C. (2015). How neighborhood affects tree diameter increment-New insights from terrestrial laser scanning and some methodical considerations. Forest Ecology and Management, 336, 119-128.

Shrestha, R., \& Wynne, R. H. (2012). Estimating biophysical parameters of individual trees in an urban environment using small footprint discrete-return imaging lidar. Remote Sensing, 4(2), 484-508.

Smith, F. W., \& Long, J. N. (1989). The influence of canopy architecture on stemwood production and growth efficiency of Pinus contorta var. latifolia. Journal of Applied Ecology, 681-691.

Takeda, T., Oguma, H., Sano, T., Yone, Y., \& Fujinuma, Y. (2008). Estimating the plant area density of a Japanese larch (Larix kaempferi Sarg.) plantation using a ground-based laser scanner. Agricultural and Forest Meteorology, 148(3), 428-438. 
Thies, M., Pfeifer, N., Winterhalder, D., \& Gorte, B. G. (2004). Three-dimensional reconstruction of stems for assessment of taper, sweep and lean based on laser scanning of standing trees. Scandinavian Journal of Forest Research, 19(6), 571-581.

Thorpe, H. C., Astrup, R., Trowbridge, A., \& Coates, K. D. (2010). Competition and tree crowns: a neighborhood analysis of three boreal tree species. Forest Ecology and Management 259(8), 1586-1596.

Umeki, K. (1995). A comparison of crown asymmetry between Picea abies and Betula maximowicriana. Canadian Journal of Forest Research, 25(11), 1876-1880.

Valladares, F. (2003). Light heterogeneity and plants: from ecophysiology to species coexistence and biodiversity. In Progress in botany (pp. 439-471). Springer, Berlin, Heidelberg.

Vospernik, S., Monserud, R. A., \& Sterba, H. (2010). Do individual-tree growth models correctly represent height: diameter ratios of Norway spruce and Scots pine?. Forest Ecology and Management, 260(10), 1735-1753.

Watt, P. J., \& Donoghue, D. N. M. (2005). Measuring forest structure with terrestrial laser scanning. International Journal of Remote Sensing, 26(7), 1437-1446.

Winter, S., \& Möller, G. C. (2008). Microhabitats in lowland beech forests as monitoring tool for nature conservation. Forest Ecology and Management, 255(3-4), 1251-1261.

Wohlfarth, E. (1935). Auswirkungen langjähriger Kronenpflege in mitteldeutschen Fichtenbeständen. Zeitschrift für Forst- und Jagdwesen, 67, 289-310.

Yoshida, T., \& Kamitani, T. (2000). Interspecific competition among three canopy-tree species in a mixed-species even-aged forest of central Japan. Forest Ecology and Management, 137(13), 221-230. 



\section{Chapter 3}

Canopy space filling rather than conventional measures of structural diversity explains productivity of beech stands

Julia Juchheim $\cdot$ Christian Ammer $\cdot$ Peter Schall $\cdot$ Dominik Seidel

Forest Ecology and Management 395 (2017), 19-26

DOI:10.1016/j.foreco.2017.03.036 


\begin{abstract}
Silvicultural success in achieving, among other management goals, maximum productivity strongly depends on knowledge of the relationship between stand density and the resulting growth response of a stand. However, there are still controversial discussions whether wood production can be enhanced by silvicultural thinning or reaches its maximum in unmanaged forest stands if time plays no role. Moreover, there is no universal answer whether structural diversity promotes or reduces productivity. In the present study we applied terrestrial laser scanning (TLS) to investigate the relationship between three-dimensional space filling, forest management intensity, productivity and conventional measures of structural diversity. We examined 35 beech-dominated forest plots along a gradient of management intensity in three regions of Germany. We found that space filling in leaf-on condition increased with management intensity, particularly in the shaded crown. Increased space filling in the shaded crown due to tree removals also resulted in higher stand productivity. We conclude that an increased space filling in the shaded canopy of managed European beech stands is responsible for the compensation of production losses in the upper canopy due to thinning activities. Conventional measures of structural diversity were not sensitive to the applied silvicultural activities. We also found no relationship between structural diversity described by conventional measures and stand productivity.
\end{abstract}

Keywords: biomass distribution, crown structure, Fagus sylvatica L., forest management, periodic annual increment, stand density, terrestrial laser scanning

\title{
3.1 Introduction
}

For decades forest management aimed at optimizing growth and yield in a stand under given environmental conditions and tree species compositions (Pretzsch, 2005; Puettmann et al., 2015). Silvicultural success in achieving, among other management goals, maximum productivity strongly depends on knowledge of the relationship between management type and intensity, leading to a certain forest structure and the resulting growth response of a stand (e.g. Röhrig et al., 2006).

An important management tool to control stand development and stability is the thinning intensity. It affects the density of a stand and temporarily reduces the competition enforced on the remaining trees. As a result, it has a strong impact on stand structure and tree growth, but also on the response to stressors such as drought (Ammer, 2017). Finally, thinnings may increase the revenue of forest management (Knoke, 1998; Mäkinen and Isomäki, 2004). Therefore, relating tree 
growth to stand density plays a pivotal role in forest management. Of particular importance was the identification of the optimal density for a given management goal.

That is why Zeide (2004) called "forestry the science of density optimization". If one aims at maximized stand level productivity optimal density is usually addressed as the basal area at which the annual basal area increment reaches the maximum on a given site (cf. Assmann, 1970). Langsæter (1943) was among the first researchers who postulated a relationship between volume increment and stand density. Based on long-term thinning experiments in European beech (Fagus sylvatica L.) stands Assmann (1970) found evidence for this hypothesis. More specifically, he identified a hump-shaped relationship between stand density and productivity. As long as the increased growth responses of favored trees outweigh the negative effects which may be associated with the removal of trees, the productivity curve is ascending; when the positive and the negative effects are in balance it reaches a peak and when the negative effects predominate the curve declines. Assmann (1970) explained this finding with the positive effects of thinning on the growth of the remaining trees due to increased resource availability. However, the existence of an 'optimal density' was questioned in the past (Curtis et al., 1997) and was shown to be depending on species identity, age and site fertility (Pretzsch, 2005). Moreover, there are still controversial discussions whether wood production can be enhanced by silvicultural thinning or reaches its maximum in unmanaged forest stands if time plays no role (Pretzsch, 2005; Seidel et al., 2015). Another feature determining tree and stand growth is the thinning type. Contrasting thinning types such as thinning from above (removing codominant trees) or thinning from below (removing mainly suppressed trees) strongly impact stand structure. It is well known that repeated removals of overstorey trees lead to a higher resource availability for mid- and understorey trees and result in more heterogeneous stand structures than thinnings from below which cause a structural homogenization (Röhrig et al., 2006). However, as for thinning intensity it is controversially discussed whether or not structural diversity results in higher (Lei et al., 2009; Dănescu et al., 2016) or lower stand growth (Liang et al., 2007; Long and Shaw, 2010; Ryan et al., 2010; Luu et al., 2013; Soares et al., 2016).

For practical convenience, in forestry the intensity of thinning activities is commonly quantified by the amount or proportion of basal area removed. Basal area can easily be measured and controlled in the field and is widely used as a measure to identify the optimal density, e.g. for maximum timber production. It does however not provide insight into the physiological explanation for productivity differences, e.g. the actual presence or absence of photosynthetically active plant material or the amount of available light in a stand. Other stand characteristics, for example leaf area, which are related to tree vitality, control light interception, carbon assimilation and transpiration (Lendzion and Leuschner, 2008) and affect productivity more directly. However, 
difficulties in determining characteristics like leaf area in the field hampered their wide application. To gain a deeper understanding of the relationship between stand density and productivity Harry et al. (1964) introduced the idea of 'crowding'. Crowding however changes with tree size and average distance among trees (Assmann, 1970; Zeide, 2005). A meaningful alternative to crowding is Reineke's stand density index (SDI; Reineke, 1933). This index relates the actual stand density to a theoretical maximum stocking density and is independent from age, diameter, site quality, and other variables (Zeide, 2005). As an alternative to density measures indices of structural complexity, such as the Gini coefficient of diameters or the Shannon index of diameters (e.g. Dănescu et al., 2016), were used to investigate the structure-productivity relationship. So far, there is no universal answer and it is controversially discussed whether structural diversity promotes or reduces productivity (Ishii et al., 2004, Dănescu et al., 2016; Soares et al., 2016).

A more meaningful quantitative measure to explain how management intensity affects stand density and how this feeds back to productivity may be the amount of space occupied by tree components, i.e. space filling. Unfortunately, the inaccessibility, sheer size and structural complexity of a forest stand hindered most approaches to address the actual space filling, meaning the three-dimensional density that takes into account all aboveground tree compartments including the leaves, at different stand densities.

Today, terrestrial laser scanning (TLS) is available as a powerful tool to measure comprehensive spatial structures in complex environments such as forests with reasonable effort (e.g. Watt and Donoghue, 2005; Dassot et al., 2011; Liang et al., 2016; Seidel et al., 2016a). The ground-based perspective of TLS allows for a detailed representation of the forest from the ground up to the canopy, especially if data from a large number of scan positions is combined (e.g. Danson et al., 2007). The technology also proved useful to determine the actual three-dimensional space filling of forests (Seidel et al., 2013).

The present study applied TLS in beech-dominated forests to investigate the relationship between three-dimensional space filling, forest management intensity, productivity and conventional measures of structural diversity. Our hypotheses are that (i) space filling, productivity and structural diversity are affected by management intensity, (ii) stand productivity increases with space filling but not with structural diversity described by conventional measures. 


\subsection{Materials and methods}

\subsubsection{Study sites}

The investigation was conducted within the framework of the Biodiversity Exploratories (www.biodiversity-exploratories.de), a long-dated and large-scaled project for biodiversity research (Fischer et al., 2010). The study plots of the Biodiversity Exploratories are located in three regions across Germany: the Biosphere Reserve Swabian Alb in the South-western part of Germany, the National Park Hainich and its surrounding areas in Central Germany and the UNESCO Biosphere Reserve Schorfheide-Chorin in the North-eastern part of Germany (Table 3.1).

Table 3.1: Summary of climatic and edaphic properties of the study plots. MAP = mean annual precipitation; $\mathrm{MAT}=$ mean annual temperature; $\mathrm{N}=$ number of investigated plots. For more detailed information about the research plots see Fischer et al. (2010).

\begin{tabular}{|c|c|c|c|}
\hline & Swabian Alb & Hainich-Dün & $\begin{array}{l}\text { Schorfheide- } \\
\text { Chorin }\end{array}$ \\
\hline Location & SW Germany & Central Germany & NE Germany \\
\hline Elevation (m a.s.l.) & $460-860$ & $285-550$ & $3-140$ \\
\hline $\operatorname{MAP}(\mathrm{mm}) / \operatorname{MAT}\left(\mathrm{C}^{\circ}\right)$ & $700-1000 / 6-7$ & $500-800 / 6.5-8$ & $500-600 / 8-8.5$ \\
\hline Dominant soil type forest & Eutric Cambisol & Luvisol & Dystric Cambisol \\
\hline Investigated forest types & $\begin{array}{l}\text { Mature age-class } \\
\text { forest }(\mathrm{N}=5) \text {; } \\
\text { Unmanaged forest } \\
(\mathrm{N}=3)\end{array}$ & $\begin{array}{l}\text { Mature age-class } \\
\text { forest }(\mathrm{N}=5) ; \\
\text { Unmanaged forest } \\
(\mathrm{N}=7) ; \\
\text { Selection forest } \\
(\mathrm{N}=5)\end{array}$ & $\begin{array}{l}\text { Mature age-class } \\
\text { forest }(\mathrm{N}=5) \text {; } \\
\text { Unmanaged forest } \\
(\mathrm{N}=5)\end{array}$ \\
\hline
\end{tabular}

For our study we selected 35 beech-dominated forest plots along a gradient of management intensity. We classified forest management intensity by using the silvicultural management intensity indicator (SMI; Schall and Ammer, 2013). The indicator consists of two components, the risk of stand loss which is mainly driven by the tree species, and the relative stand density. It scales from 0 to 1 . The first component quantifies the age dependent survival probabilities due to natural hazards at or before a reference age (180 years), while the second refers actual stand biomass to biomass carrying capacity of the site, calculated from yield tables. Both components are tree-species 
specific and reflect the central forest management decisions: choice of tree species and control of stand density (Schall and Ammer, 2013). The selected plots represent the main beech forest management types in Central Europe and comprise unmanaged stands and managed uneven-aged and even-aged stands. In order to reduce the effect of age and species diversity on space filling and stand productivity we selected stands with the developmental stage of mature timber (90-180 years old) and absent or low admixture of other tree species than beech (proportion of beech on total basal area: $70-100 \%)$.

\subsubsection{Terrestrial laser scanning and sampling design}

Around the center of each plot an area of $45 \mathrm{~m} \times 45 \mathrm{~m}$ was scanned with a Faro Focus 3D (Faro Technologies Inc., Lake Marry, USA) terrestrial laser scanner. The scanner was mounted at breast height $(1.3 \mathrm{~m})$ on a tripod and covered a field of view of $360^{\circ}$ and $305^{\circ}$ in horizontal and vertical direction respectively. The angular step width was set to $0.035^{\circ}$, resulting in about 44.4 million measurements per scan. Scans were conducted in summer 2014 and winter 2014/15 in order to obtain leaf-on and leaf-off data of the forest stands. In both seasons we used the exact same plots and scan settings. We started with a first scan (master scan) in the center of each plot, followed by 20-25 additional scans from different surrounding positions, depending on the density of the understory vegetation. In order to cope with the structural heterogeneity of the plots, we did not apply a fixed scan design. For the registration of the scans into the local coordinate system of the master scan (xyz $=\{0,0,0\}$ in the center of the plot), we evenly distributed 50-60 artificial checkerboard targets over the area.

\subsubsection{Basic evaluation methods}

As a measure of productivity, we determined periodic annual increment (PAI; $\mathrm{m}^{2} * \mathrm{ha}^{-1} * \mathrm{a}^{-1}$ ) of the plots as the average annual increment over the last 5-6 years (incl. the basal area removed through thinning and natural mortality). For calculating PAI we used the forest inventory data collected in 2010/11 and 2015/16 for the same subplots where we had collected our TLS data. PAI data was unavailable for four of our 35 plots. For 31 plots however, trees with $\mathrm{DBH} \geq 7 \mathrm{~cm}$ were repeatedly measured for diameter at breast height $(\mathrm{DBH})$ using a caliper. Plot basal area $(\mathrm{Ba})$ was then determined as the sum of the cross-sectional areas (at breast height) of all tree stems above $7 \mathrm{~cm}$ in diameter. 


\subsubsection{Structural diversity indices}

To test whether conventional measures of structural diversity would be useful to detect a possible structure-productivity relationship we calculated the Gini coefficient (Lexerød and Eid, 2006), the Shannon index and the Shannon evenness (e.g. Dănescu et al., 2016) as well as the Simpson index (Lexerød and Eid, 2006). Most of these indices were initially developed to characterize species diversity (Dănescu et al., 2016). In order to quantify the diameter diversity within the stands we replaced the number of species by the number of diameter classes, while the proportion of individuals belonging to each of the species was replaced by the proportion of basal area for each of the diameter classes. To calculate the number of diameter classes we used following the class widths: $\geq 7 \mathrm{~cm}$ and $<10 \mathrm{~cm}, \geq 10 \mathrm{~cm}$ and $<14 \mathrm{~cm}, \geq 14 \mathrm{~cm}$ and $<18 \mathrm{~cm}$ and so on.

\subsubsection{Point cloud processing}

After transferring the data from the scanner to a computer we used Faro Scene Software (Faro Technologies Inc., Lake Mary, FL, USA) to filter for erroneous points according to the standard settings of the software. Semi-automatic registration of all scans taken at a plot was then conducted based on the artificial checkerboard targets in Faro Scene. All registered and filtered scans were exported as pts.-files. We then imported all scans of each plot to Leica Cyclone 8 (Leica Geosystems AG, Heerbrugg, Switzerland) and unified the point clouds into a single point cloud representing the entire plot area of approximately 45 by $45 \mathrm{~m}$. A visualization of the stand point cloud was done for optical quality control even though all point clouds could be registered with an average registration error of less than $20 \mathrm{~mm}$. For further processing the point cloud of each stand was then exported as xyz-file for data reduction. At this point the intensity value, essential for optical assessment of the point cloud, was no longer stored resulting in reduction of data size. This was important to increase the processing speed in the following procedure. We used an algorithm written in Mathematica (Version 9, Wolfram Research, Champaign, USA) to calculate relative space filling (RSF). Therefore, the algorithm automatically selected a predefined horizontal extent of 40 by $40 \mathrm{~m}$ from the xyz file (Cartesian coordinates of center (XYZ): $\{0 / 0 / 0\}$, see Figure 3.1 for visualization). 


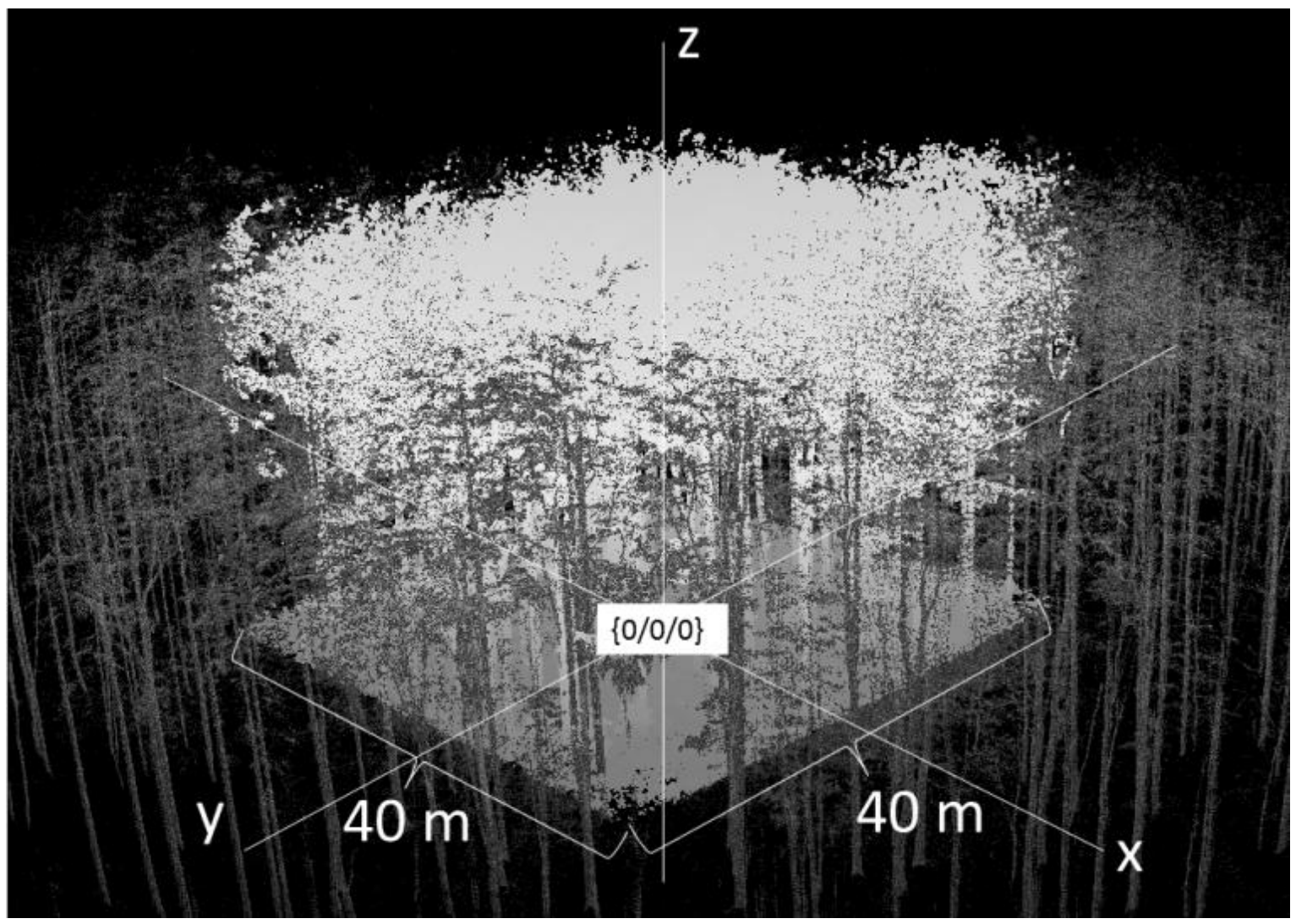

Figure 3.1: Exemplary point cloud of a plot with the coordinate center indicated by the $\{0 / 0 / 0\}$ coordinate and the horizontal dimensions of the final plot area $(40 \mathrm{~m} \times 40 \mathrm{~m}$, bright grey). The original point cloud was always scanned to cover a minimum of $45 \mathrm{~m}$ by $45 \mathrm{~m}$ in great detail. Grey areas in Figure 3.1 show the remaining part of the poin $\mathrm{t}$ cloud not used for further processing, often more than $100 \times 100 \mathrm{~m}$ in extent.

The entire point cloud was then converted into a voxel grid with $20 \mathrm{~cm}$ voxel edge length (Figure 3.2 lower right). To define a voxel grid we checked for points in each voxel cell and kept only voxels that contained at least one point. We chose $20 \mathrm{~cm}$ voxels since this was the smallest computable voxel size on the available hardware (16 GB RAM). In order to account for uneven terrain we normalized the topography within a $45 \mathrm{~m}$ by $45 \mathrm{~m}$ extent based on a digital elevation model derived from the voxel model data. Therefore, we selected the lowermost voxel in each grid cells of $20 \mathrm{~cm}$ by $20 \mathrm{~cm}$. Since this digital elevation model showed effects of tree stems being present or insufficient ground-return near the edges (Figure 3.2 upper left) it was further smoothed by taking the deepest value of the $20 \mathrm{~cm}$ by $20 \mathrm{~cm}$ model within grid cells of $5 \mathrm{~m}$ by $5 \mathrm{~m}$ (Figure 3.2 middle left) in a reduced horizontal extent of $40 \mathrm{~m}$ by $40 \mathrm{~m}$. This created a smooth, groundparallel surface that was free of edge effects. This surface was then interpolated in order to provide reference height levels at each $20 \mathrm{~cm}$ by $20 \mathrm{~cm}$ cell (Figure 3.2 lower left). Based on this $40 \mathrm{~m}$ by $40 \mathrm{~m}$ digital elevation model we corrected the voxel model of the same horizontal extent for the different terrain heights. This was done by uplifting or downshifting each $20 \mathrm{~cm}$ by $20 \mathrm{~cm}$ cell by 
the difference between the zero level given by the master scan $(z=0)$ and the actual height of each cell provided by the elevation model (Figure 3.2 upper right).

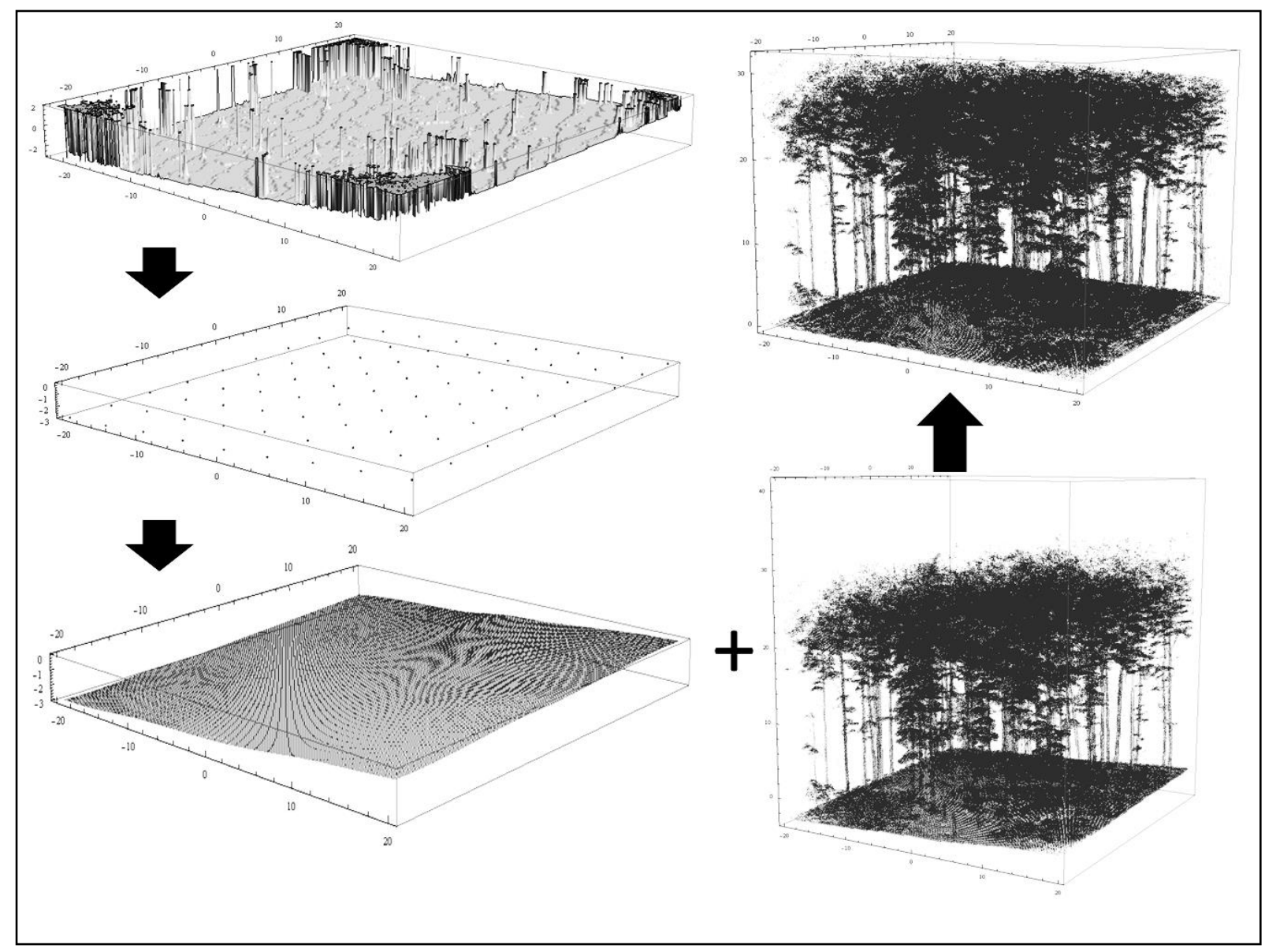

Figure 3.2: Visualization of the derivation of the digital elevation model (left) and its application to correct the voxel model for varying terrain heights. For better perceptibility only the center points of the voxels in the uncorrected voxel model (lower right) and its elevation-corrected pendant (upper right) are shown.

We used the elevation-corrected voxel model with $20 \mathrm{~cm}$ edge length to determine relative space filling, defined as the percentage of the total plot volume occupied by voxels. Therefore, we determined the total plot volume by its base area $\left(40 \times 40 \mathrm{~m}=1600 \mathrm{~m}^{2}\right.$ for all plots $)$ times stand height. Stand height (in $\mathrm{m}$ ) was determined as the uppermost height (voxel layer) in which at least one voxel was present. The volume occupied by voxels was simply calculated as the sum of all voxel volumes. The percentage of filled volume (relative space filling in leaf-on condition) was also calculated for vertical layers, each $10 \%$ of total stand height in thickness, starting from $0-10 \%, 10$ $20 \%, 20-30 \%$ and so forth. 


\subsubsection{Statistical analyses}

All statistical analyses were performed using the R software (Version 3.3.0; R Development Core Team 2016). Data were tested for normal distribution applying the Shapiro-Wilk Normality Test and for variance homogeneity using Levene's test. We calculated linear mixed effect models (package 'nlme') with site (Biodiversity Exploratory) as random effect. Polynomial models with linear, quadratic or cubic terms for SMI were conducted for quantifying the effect of SMI on PAI, on relative space filling and on structural diversity described by the Gini coefficient, the Simpson index, the Shannon index and the Shannon evenness. Furthermore, we applied linear regressions (linear, quadratic and cubic) to analyze the relationship between PAI and relative space filling and between PAI and structural diversity indices. We calculated Akaike's information criterion (AICc; corrected for small sample sizes) to identify the best-fitting model. A significance level of $\mathrm{p}<0.05$ was used for all statistical procedures. 


\subsection{Results}

\subsubsection{Effect of SMI on productivity, space filling and structural diversity}

The productivity on stand level was positively affected by silvicultural management intensity (pseudo- $\left.\mathrm{R}^{2}=0.50, \mathrm{p}<0.001\right)$, when the entire volume of the cuboid $(40 \mathrm{~m} \times 40 \mathrm{~m} \times$ stand height) was considered (Figure 3.3).

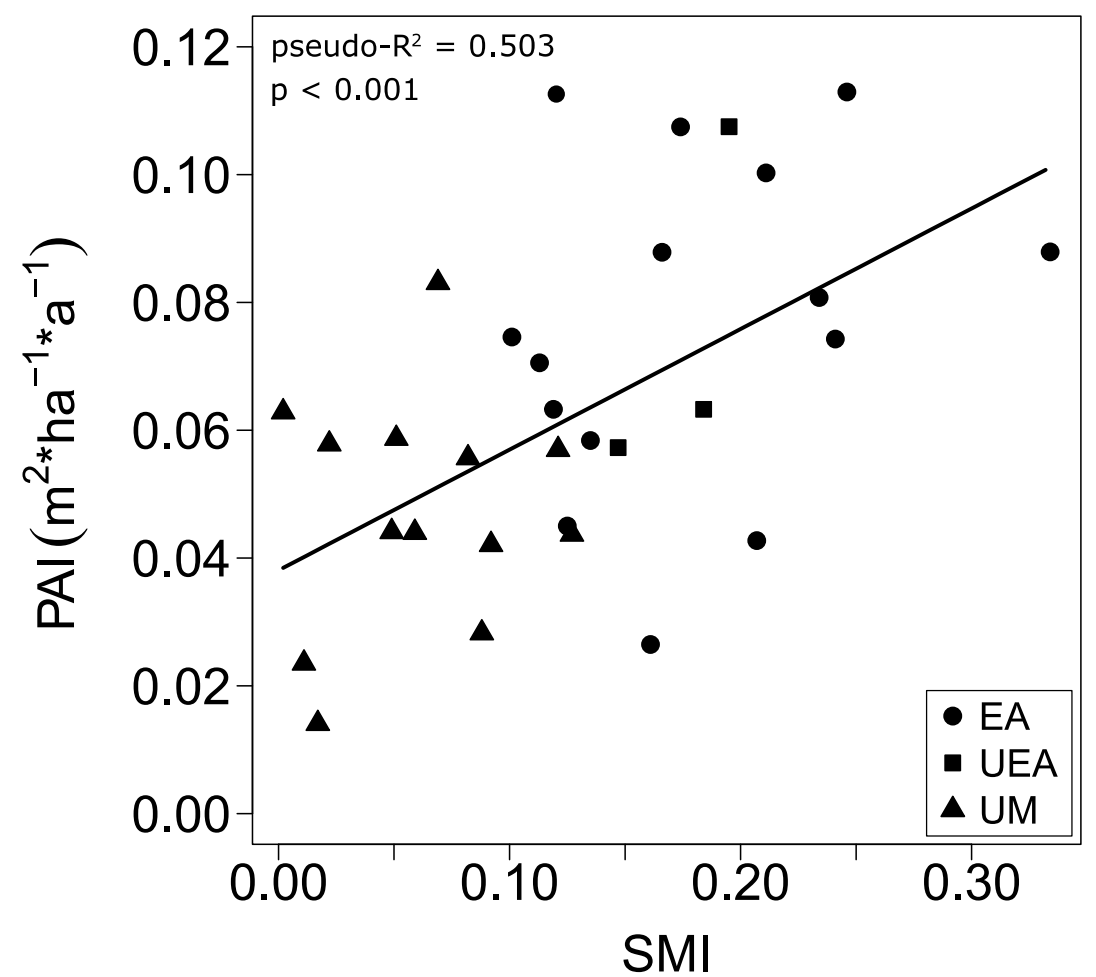

Figure 3.3: Relationship between SMI and periodic annual increment $(\mathrm{PAI}=0.038086+0.188747$ $*$ SMI, pseudo- $\left.\mathrm{R}^{2}=0.50, \mathrm{p}<0.001, \mathrm{n}=31\right) . \mathrm{EA}=$ mature even-aged stands, UEA = uneven-aged stands, $\mathrm{UM}=$ unmanaged stands.

We also detected a statistically significant relationship (pseudo- $\mathrm{R}^{2}=0.62, \mathrm{p}<0.001$ ) between the intensity of silvicultural management and the total occupied space (leaf-on). Space filling increased with increasing management intensity (Figure 3.4). In leaf-off condition, no significant relationship was found $(p=0.051)$. Note that our stand data does not cover the whole range $(0-$ 1) of management intensities. Therefore, it is unclear whether or not the curve would decline with further increasing intensity. 


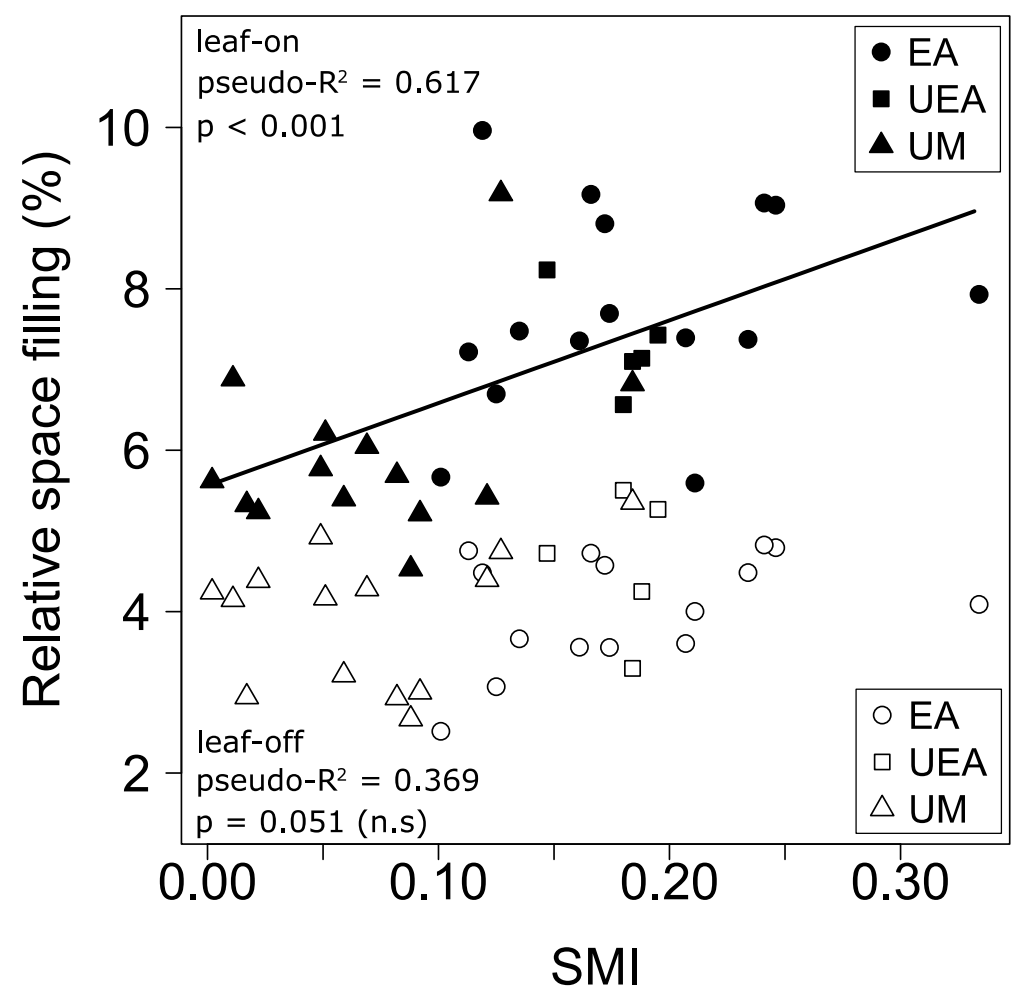

Figure 3.4: Relationship between SMI and relative space filling in leaf-on condition (RSF $=5.5605$ $+10.2398 * \mathrm{SMI}$, pseudo- $\left.\mathrm{R}^{2}=0.62, \mathrm{p}<0.001, \mathrm{n}=35\right)$ and relationship between SMI and relative space filling in leaf-off condition (pseudo- $\mathrm{R}^{2}=0.37, \mathrm{p}=0.051, \mathrm{n}=35$ ). $\mathrm{EA}=$ mature even-aged stands, $\mathrm{UEA}=$ uneven-aged stands, $\mathrm{UM}=$ unmanaged stands.

The analysis of the vertical layers in leaf-on condition showed that space occupation in the herb and shrub layer (layer $0-10 \%$ ) and in the shaded canopy (layer 40-50\%, 50-60\% and 60-70\%) were positively affected by an increasing intensity of silvicultural management. The sun-exposed canopy (layer $70-80 \%, 80-90 \%$ and $90-100 \%$ ) tended to be negatively affected by increasing silvicultural interventions however, the correlation was not significant (Table 3.2).

In contrast, structural diversity indices were not affected by silvicultural management intensity (Gini coefficient $p=0.286$, Simpson index $p=0.751$, Shannon index $p=0.134$ and Shannon evenness $\mathrm{p}=0.215$ ). 
Table 3.2: Results of the linear mixed effect model with relative space filling of a given layer as dependent variable and SMI as independent variable. Values given are the parameter estimate, the probability of error $\mathrm{p}$ for the model and the squared Pearson correlation coefficient between observed and model fitted values (pseudo- $\mathrm{R}^{2}$ ). Significant correlations $(\mathrm{p}<0.05)$ are highlighted in bold.

\begin{tabular}{llll}
\hline Variable & Estimate & $\boldsymbol{p}$-Value & pseudo- $\boldsymbol{R}^{2}$ \\
\hline Layer $0-10 \%$ & 31.50 & $<\mathbf{0 . 0 0 1}$ & 0.58 \\
Layer 10-20\% & 5.33 & 0.36 & 0.15 \\
Layer 20-30\% & 7.41 & 0.26 & 0.18 \\
Layer 30-40\% & 9.44 & 0.10 & 0.24 \\
Layer 40-50\% & 13.55 & $<\mathbf{0 . 0 1}$ & 0.39 \\
Layer 50-60\% & 24.43 & $<\mathbf{0 . 0 0 1}$ & 0.54 \\
Layer 60-70\% & 18.21 & $<\mathbf{0 . 0 5}$ & 0.26 \\
Layer 70-80\% & -2.91 & 0.81 & 0.23 \\
Layer $80-90 \%$ & -10.74 & 0.13 & 0.32 \\
Layer 90-100\% & -1.13 & 0.20 & 0.17 \\
\hline
\end{tabular}




\subsubsection{Effect of space filling on productivity}

An increased relative space filling of the total stand (full cuboid of $40 \mathrm{~m} \times 40 \mathrm{~m} \times$ stand height) in leaf-on condition led to a significant increase in productivity (pseudo- $\mathrm{R}^{2}=0.26, \mathrm{p}<0.05$ ) (Figure 3.5).

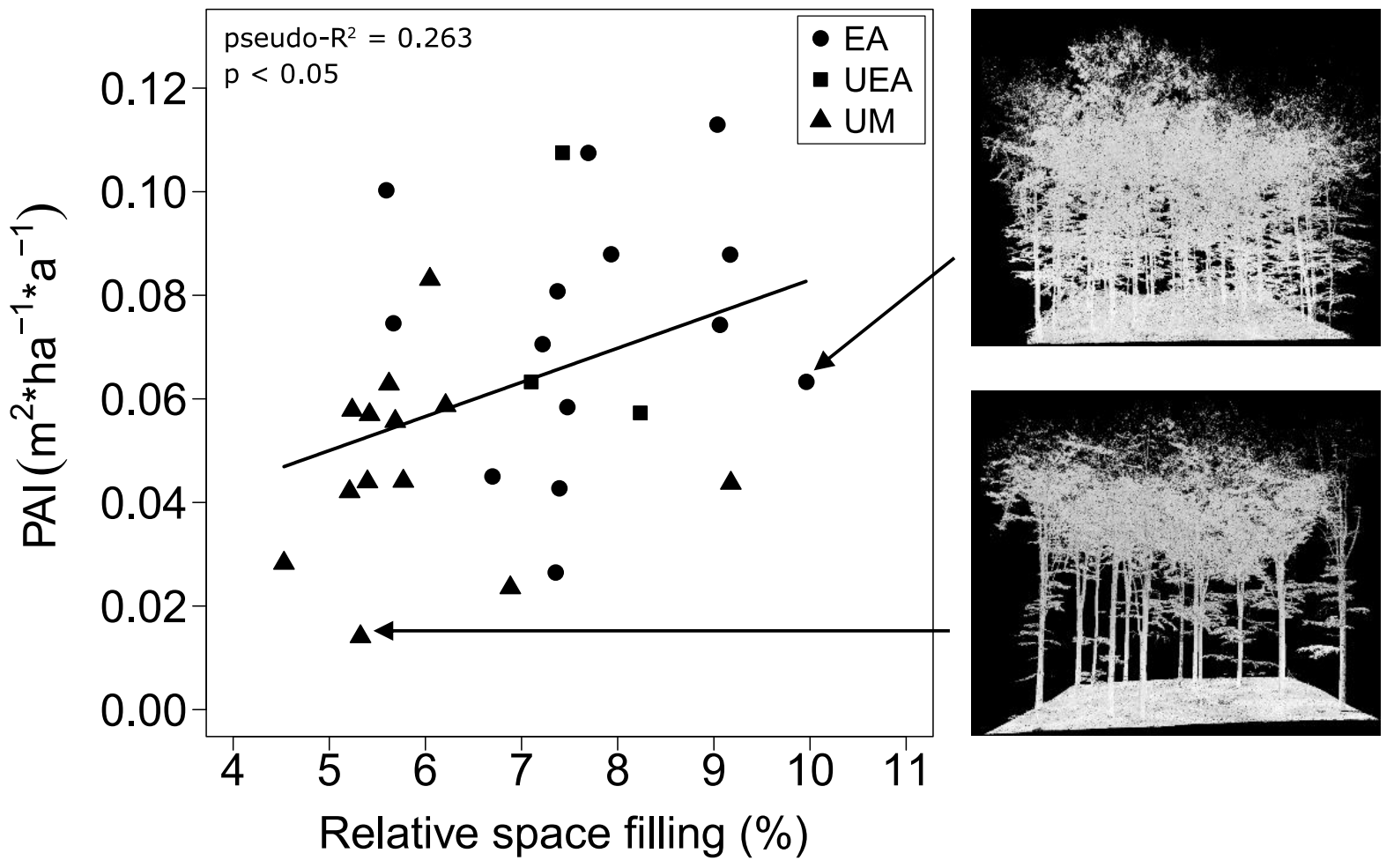

Figure 3.5: Relationship between relative space filling in leaf-on condition and periodic annual increment $\left(\mathrm{PAI}=0.017073+0.006589 * \mathrm{RSF}\right.$, pseudo- $\left.\mathrm{R}^{2}=0.26, \mathrm{p}<0.05, \mathrm{n}=31\right) . \mathrm{EA}=$ mature even-aged stands, $\mathrm{UEA}=$ uneven-aged stands, $\mathrm{UM}=$ unmanaged stands. Exemplary point cloud of a mature even-aged beech stand (upper right) and an unmanaged beech stand (lower right).

We also found that relative space filling in certain height layers of the stand was significantly related to stand productivity. Filling of the shaded canopy (layer 50-60\%) in leaf-on condition positively affected productivity. A high space filling in the sun-exposed canopy (layer $70-80 \%$ and $90-100 \%$ ) on the other hand was found in stands with lower productivity (Table 3.3). 
Table 3.3: Results of the linear mixed effect model with PAI as dependent variable and relative space filling of a given layer as independent variable. Values given are the parameter estimate, the probability of error $\mathrm{p}$ for the model and the squared Pearson correlation coefficient between observed and model fitted values (pseudo- $\mathrm{R}^{2}$ ). Significant correlations $(\mathrm{p}<0.05)$ are highlighted in bold.

\begin{tabular}{llll}
\hline Variable & Estimate & $\boldsymbol{p}$-Value & pseudo- $\boldsymbol{R}^{2}$ \\
\hline \hline Layer $0-10 \%$ & 1.05 & 0.12 & 0.09 \\
Layer $10-20 \%$ & 1.00 & 0.22 & 0.05 \\
Layer 20-30\% & 1.00 & 0.11 & 0.08 \\
Layer 30-40\% & 0.00 & 0.12 & 0.08 \\
Layer 40-50\% & 0.00 & 0.06 & 0.13 \\
Layer 50-60\% & 0.00 & $<\mathbf{0 . 0 1}$ & 0.35 \\
Layer 60-70\% & 1.27 & 0.08 & 0.17 \\
Layer 70-80\% & -0.00 & 0.49 & 0.01 \\
Layer 80-90\% & -0.00 & $<\mathbf{0 . 0 5}$ & 0.15 \\
Layer 90-100\% & -0.02 & $<\mathbf{0 . 0 5}$ & 0.20 \\
\hline
\end{tabular}

A high space occupation in the sun-exposed canopy (layer 70-80\%, 80-90\% and $90-100 \%$ ) resulted in a decrease of the space filling in the shaded part of the canopy (layer 40-50\%, 50-60\% and 60-70\%), whereas a low space occupation in the upper canopy led to an increase of the space filling in lower strata (Figure 3.6 exemplifies this trade-off). 

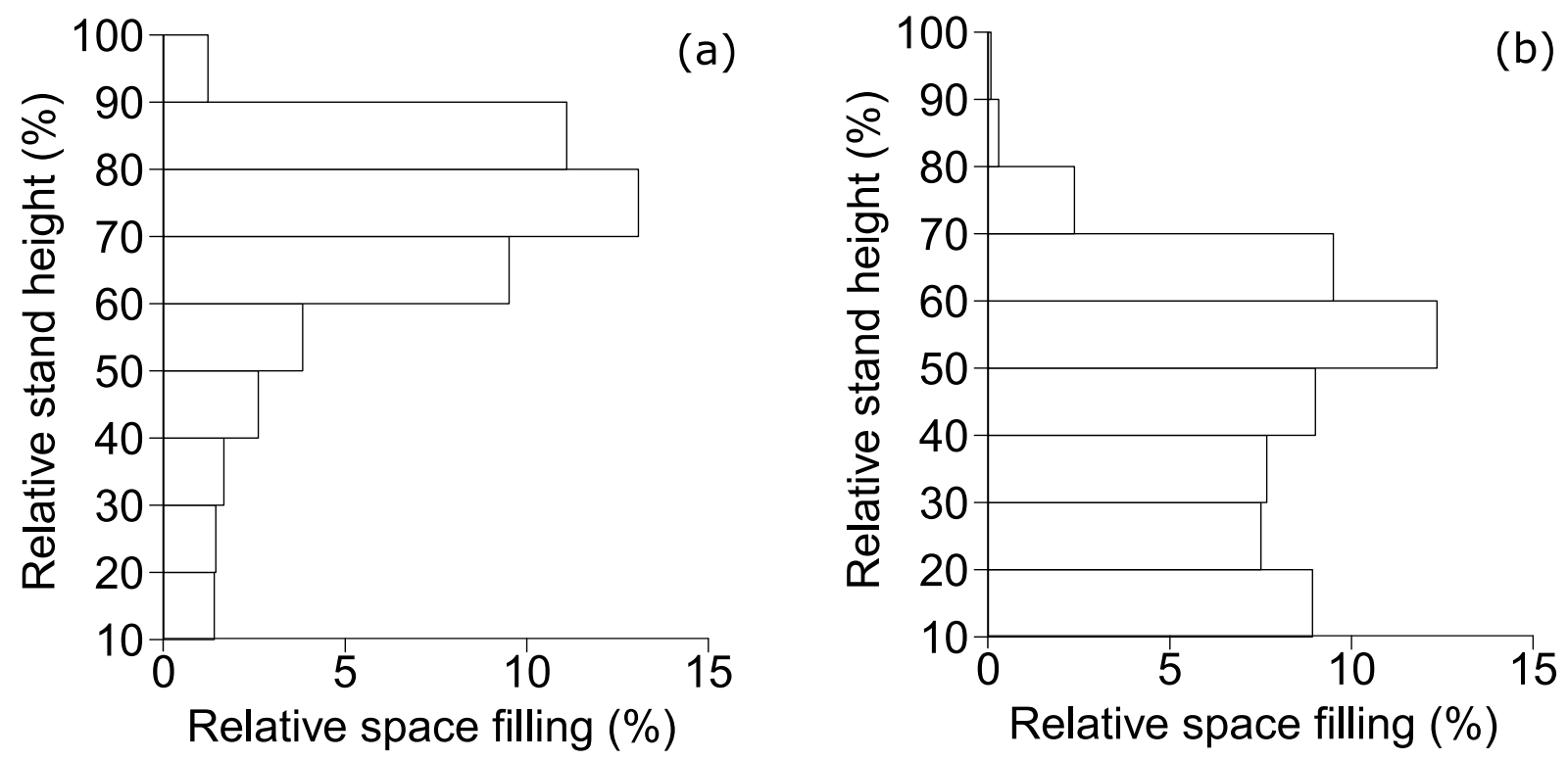

Figure 3.6: Relative space filling in different height layers. Example of an unmanaged beech stand (a) and an uneven-aged beech stand (b) in leaf-on condition. Since the lowermost layer (0-10\%) is largely dominated by herbs and shrubs that do not contribute to the measured stand productivity we avoided showing this layer here. Usually, the presence of ground returns, dead wood and herbs and shrubs results in a large space filling for this layer.

\subsubsection{Effect of structural diversity on productivity}

The productivity on stand level was not affected by structural diversity indices (Gini coefficient $\mathrm{p}$ $=0.196$, Simpson index $p=0.959$, Shannon index $p=0.882$ and Shannon evenness $p=0.306$ ).

\subsection{Discussion}

We initially hypothesized that space filling and structural diversity of forest stands respond to silvicultural management intensity (hypothesis (i)). In fact, we observed a significant linear relationship between space filling and management intensity. However, our data does not allow conclusions on the shape of the curve for management intensities beyond 0.35 (SMI). Here it should be mentioned that the rather low SMI values of the investigated stands were related to the high growing stock of the studied stands and the low risk of stand loss of mature beech forests, both of which reflect low management intensity sensu Schall and Ammer (2013). Anyway, our plots still cover a range of management intensities that can be considered representative for most beech stands in Germany. Though highly speculative, for SMI values larger than those observed in our data we assume a declining curve at very high intensities because intensive thinning would lead 
to very low stand densities and decreasing space filling, eventually to stand loss (in case of a clearcut). Heavily reduced stand density however, would not allow high space filling since open space between trees cannot be filled by the remaining trees to an infinite degree. Our data suggests that in the observed range of SMI the remaining trees were still able to overcompensate the losses through thinning. Supporting this, the conventional measures of structural diversity were not sensitive to the applied silvicultural activities and showed no response.

The SMI had a strong positive effect on the space filling of the herb and shrub layer and, more importantly, on the shaded canopy. The sun-exposed canopy on the other hand tended to be negatively affected by increasing silvicultural interventions as can be expected since trees of the overstory were removed; however, the correlation was not significant. These findings indicate that a certain increase in management intensity and the resulting loss in canopy closure not only positively affect the development of understory vegetation (e.g. Thomas et al., 1999; Vockenhuber et al., 2011) but, more importantly for stand productivity, also positively affect space filling in the shaded canopy (50-60\% of stand height). It seems as if this increase in space filling overcompensates the loss of occupied space in the upper crown. As a result, relative space filling of the total stand increased despite the removal of trees. As one would expect, our data also showed a positive relationship between the management intensity and the productivity of the stands. This relationship is, apart from the intention to create higher wood qualities, the basic motivation for a silvicultural treatment in the first place. The physiological explanation however has rarely been provided based on empirical data. Our study may explain observations of earlier studies in evenaged stands: trees growing in lower stand density developed larger crowns (in terms of crown length) when compared to trees growing in higher stand density, both in coniferous stands (Maguire and Bennett, 1996; Seidel et al., 2016b) as well as in deciduous forests (e.g. Medhurst and Beadle, 2001). Larger crowns result in higher crown surface areas (Burger, 1939) and, as indicated by our data, in higher relative space filling (i.e. an increased amount of leaves). This resulted in an increased productivity. Note that space filling but not structural diversity, described by the tested conventional measures, was related to stand productivity. This finding suggests two different aspects: First, the positive effect of thinnings on the productivity of species such as beech, which can effectively occupy the vertical space (Pretzsch and Schütze, 2009), can be traced back to a high three-dimensional space occupation with photosynthetic active material (see Figure 3.4, leaf-on vs. leaf-off condition). Second, the results suggest that studies which failed in finding positive effects of structural diversity on productivity may have simply focused on the wrong structural components. It seems as if measures of structural diversity which only take inhomogeneity of tree sizes into account, such as the Gini coefficient of diameters (Dănescu et al., 2016), Simpson index or Shannon index of diameters, do not well enough describe those structures which drive growth. 
This assumption points towards the need to redefine structural diversity and to develop structural indices which are closer related to tree and stand growth than the existing ones. It may therefore be that studies which denied a positive relationship between structural heterogeneity and productivity would have come to a different conclusion if they had used the structural attribute "space filling".

Our results may also help to explain Assmann's (1970) finding, who suggested identifying an optimum basal area when investigating the density-growth relationship. However, he could only speculate about the possible reasons for a positive effect of reducing stand density on productivity. More specifically he suggested that the removal of slow and "inefficiently" growing nondominant trees accelerate stand growth (Assmann, 1970; Pretzsch, 2005). Pretzsch and Schütze (2016) assumed that "the replacement of less efficient by better performing trees in the lower canopy layers may have a similar positive effect on stand productivity". Space filling may provide a missing ecophysiologically sound explanation for this finding. We hypothesize that moderate reductions in stand density result in a more even distribution of the photosynthetically active plant material due to longer crowns with a higher crown surface which caused the productivity peak detected in earlier studies (Assmann, 1970; Pretzsch, 2005). Previous studies determined the vertical distribution of foliage as a decisive factor of productivity (Maguire and Bennett, 1996). Smith and Long (1989) found that variations in the canopy structure of even-aged lodge pole pine stands, such as canopy depth and foliar density, were related to stemwood production and stemwood growth efficiency.

Increased relative space filling in the shaded canopy (50-60\% of stand height) as a result of thinning (reduced self-pruning, increased light availability) positively affected the stand productivity. We argue that at stand level productivity is also determined by the position of foliage in the canopy and not only by the amount of foliage. Structurally heterogeneous canopies with multi-layered foliage structures can enhance stand productivity due to a more efficient light interception and resource utilization (Ishii et al., 2004, but see Long and Shaw, 2010). A dense upper canopy layer (80-100\% of stand height), as present in beech stands of high basal area ("Hallenwald"), on the other hand seems to result in less efficient light use in single layered forests (cf. Figure 3.5). One explanation might be that in single-layered stands canopy temperatures at the very top of the trees might increase above levels that are optimal for stomatal conductance, especially during droughts (e.g. Legner, 2012). As European beech stands develop to single layered stands only if they are kept rather dense, the lower productivity of the latter may also result from water shortage (Piutti and Cescatti, 1997). In a recent study Gebhardt et al. (2014) showed for Norway spruce that thinnings substantially improved soil water availability and water consumption of the remaining trees resulting in improved tree growth. In contrast, trees in dense stands were strongly restricted in growth during dry periods. Other factors to consider are losses in growth 
efficiency in dense single layered stands due to mechanical abrasion in dense canopies (Hajek et al., 2015) as well as due to the die-back of limbs in lower strata that receive not enough light without thinning (self-pruning). Finally, our results suggest that the dense single-layered canopies simply have less foliage surface than multi-layered canopies and hence lower production potentials.

\subsection{Conclusions}

For the investigated beech stands increasing management intensity led to a more even vertical distribution of aboveground biomass, presumably through improved light availability in deeper stand layers. The longer crowns with higher crown surface areas overcompensated the loss of occupied space in the upper canopy. As a result, the relative space filling of the total stand increased despite the removal of trees. We conclude that increased space filling in certain canopy layers (50$60 \%$ of stand height) of European beech stands - as a result of tree removal and related higher light levels in the lower canopy - is the missing link explaining the compensation of production losses due to thinning activities. Future research should focus on the question whether this holds for other species that are less plastic in the response to altered light conditions.

\section{Acknowledgements}

We thank the managers of the three Exploratories, Kirsten Reichel-Jung, Swen Renner, Katrin Hartwich, Sonja Gockel, Kerstin Wiesner, and Martin Gorke for their work in maintaining the plot and project infrastructure; Christiane Fischer and Simone Pfeiffer for giving support through the central office, Michael Owonibi for managing the central data base, and Markus Fischer, Eduard Linsenmair, Dominik Hessenmöller, Jens Nieschulze, Daniel Prati, Ingo Schöning, François Buscot, Ernst-Detlef Schulze, Wolfgang W. Weisser and the late Elisabeth Kalko for their role in setting up the Biodiversity Exploratories project. The work has been funded by the DFG (German Science Foundation) Priority Program 1374 "Infrastructure-Biodiversity-Exploratories". Field work permits were issued by the responsible state environmental offices of Baden-Württemberg, Thüringen, and Brandenburg (according to $\int 72 \mathrm{BbgNatSchG).} \mathrm{This} \mathrm{work} \mathrm{was} \mathrm{funded} \mathrm{by} \mathrm{research}$ grants granted to Dominik Seidel (reference number: Se 2383/2-1) and Christian Ammer (reference number: Am 149/15-1) by the German Research Foundation and by a research scholarship granted to Dominik Seidel by the German Research Foundation (reference number: Se 2383/1-1). 


\subsection{References}

Ammer, C. (2016). Unraveling the importance of inter-and intraspecific competition for the adaptation of forests to climate change. In Progress in Botany Vol. 78 (pp. 345-367). Springer, Cham.

Assmann, E. (1970). The Principles of Forest Yield Study. Pergamon Press Ltd, Oxford, New York, Toronto, Sydney, Braunschweig.

Burger, H. (1939). Baumkrone und Zuwachs in zwei hiebsreifen Fichtenbeständen. Curtis, R.O., Marshall, D.D., Bell, J.F., 1997. LOGS: a pioneering example of silvicultural research in coast Douglas-fir. J. Forest (USA).

Dănescu, A., Albrecht, A. T., \& Bauhus, J. (2016). Structural diversity promotes productivity of mixed, uneven-aged forests in southwestern Germany. Oecologia, 182(2), 319-333.

Danson, F. M., Hetherington, D., Morsdorf, F., Koetz, B., \& Allgower, B. (2007). Forest canopy gap fraction from terrestrial laser scanning. IEEE Geoscience and remote sensing letters, 4(1), 157-160.

Dassot, M., Constant, T., \& Fournier, M. (2011). The use of terrestrial LiDAR technology in forest science: application fields, benefits and challenges. Annals of forest science, 68(5), 959-974.

Fischer, M., Bossdorf, O., Gockel, S., Hänsel, F., Hemp, A., Hessenmöller, D., ... \& Renner, S. (2010). Implementing large-scale and long-term functional biodiversity research: The Biodiversity Exploratories. Basic and Applied Ecology, 11(6), 473-485.

Gebhardt, T., Häberle, K. H., Matyssek, R., Schulz, C., \& Ammer, C. (2014). The more, the better? Water relations of Norway spruce stands after progressive thinning. Agricultural and Forest Meteorology, 197, 235-243.

Harry, J., Smith, G., \& Bailey, G. R. (1964). Influence of stocking and stand density on crown widths of Douglas fir and lodgepole pine. The Commonwealth Forestry Review, 43(3 (117), 243-246.

Hajek, P., Seidel, D., \& Leuschner, C. (2015). Mechanical abrasion, and not competition for light, is the dominant canopy interaction in a temperate mixed forest. Forest Ecology and Management, 348, 108-116. 
Ishii, H. T., Tanabe, S. I., \& Hiura, T. (2004). Exploring the relationships among canopy structure, stand productivity, and biodiversity of temperate forest ecosystems. Forest Science, 50(3), 342-355.

Knoke, T. (1998). Die Stabilisierung junger Fichtenbestände durch starke DurchforstungseingriffeVersuch einer ökonomischen Bewertung. Forstarchiv, 69, 219-226.

Langsæter, A. (1943). Om Tynning i Enaldret Gran-og Furuskog (Thinning of Evenaged Spruce and Pine Forests).

Legner, N. (2012). Spatial variation of photosynthetic capacity of early-, mid-, or late successional broad-leaved tree species in a temperate mixed forest. Dissertation. University of Goettingen

Lei, X., Wang, W., \& Peng, C. (2009). Relationships between stand growth and structural diversity in spruce-dominated forests in New Brunswick, Canada. Canadian Journal of Forest Research, 39(10), 1835-1847.

Lendzion, J., \& Leuschner, C. (2008). Growth of European beech (Fagus sylvatica L.) saplings is limited by elevated atmospheric vapour pressure deficits. Forest Ecology and Management, 256(4), 648-655.

Lexerød, N. L., \& Eid, T. (2006). An evaluation of different diameter diversity indices based on criteria related to forest management planning. Forest Ecology and Management, 222(1-3), $17-28$.

Liang, J., Buongiorno, J., Monserud, R. A., Kruger, E. L., \& Zhou, M. (2007). Effects of diversity of tree species and size on forest basal area growth, recruitment, and mortality. Forest Ecology and Management, 243(1), 116-127.

Liang, X., Kankare, V., Hyyppä, J., Wang, Y., Kukko, A., Haggrén, H., ... \& Holopainen, M. (2016). Terrestrial laser scanning in forest inventories. ISPRS Journal of Photogrammetry and Remote Sensing, 115, 63-77.

Long, J. N., \& Shaw, J. D. (2009). The influence of compositional and structural diversity on forest productivity. Forestry, 83(2), 121-128.

Luu, T. C., Binkley, D., \& Stape, J. L. (2013). Neighborhood uniformity increases growth of individual Eucalyptus trees. Forest Ecology and Management, 289, 90-97. 
Maguire, D. A., \& Bennett, W. S. (1996). Patterns in vertical distribution of foliage in young coastal Douglas-fir. Canadian Journal of Forest Research, 26(11), 1991-2005.

Mäkinen, H., \& Isomäki, A. (2004). Thinning intensity and growth of Scots pine stands in Finland. Forest Ecology and Management, 201(2-3), 311-325.

Medhurst, J. L., \& Beadle, C. L. (2001). Crown structure and leaf area index development in thinned and unthinned Eucalyptus nitens plantations. Tree Physiology, 21(12-13), 989-999.

Piutti, E., \& Cescatti, A. (1997). A quantitative analysis of the interactions between climatic response and intraspecific competition in European beech. Canadian Journal of Forest Research, 27(3), 277-284.

Pretzsch, H. (2005). Stand density and growth of Norway spruce (Picea abies (L.) Karst.) and European beech (Fagus sylvatica L.): evidence from long-term experimental plots. European Journal of Forest Research, 124(3), 193-205.

Pretzsch, H., \& Schütze, G. (2009). Transgressive overyielding in mixed compared with pure stands of Norway spruce and European beech in Central Europe: evidence on stand level and explanation on individual tree level. European Journal of Forest Research, 128(2), 183-204.

Pretzsch, H., \& Schütze, G. (2016). Effect of tree species mixing on the size structure, density, and yield of forest stands. European journal of forest research, 135(1), 1-22.

Puettmann, K. J., Wilson, S. M., Baker, S. C., Donoso, P. J., Drössler, L., Amente, G., ... \& Putz, F. E. (2015). Silvicultural alternatives to conventional even-aged forest management-what limits global adoption?. Forest Ecosystems, 2(1), 8.

Reineke, L.H. (1933). Perfecting a stand-density index for even-aged forests. Journal of Agricultural Research, 46, 627-638.

Röhrig, E., Bartsch, N. and von Lüpke, B. (2006). Waldbau auf ökologischer Grundlage. 7th edn. Ulmer Verlag.

Ryan, M. G., Stape, J. L., Binkley, D., Fonseca, S., Loos, R. A., Takahashi, E. N., ... \& Lima, A. M. (2010). Factors controlling Eucalyptus productivity: how water availability and stand structure alter production and carbon allocation. Forest Ecology and Management, 259(9), 1695-1703. 
Schall, P., \& Ammer, C. (2013). How to quantify forest management intensity in Central European forests. European Journal of Forest Research, 132(2), 379-396.

Seidel, D., Leuschner, C., Scherber, C., Beyer, F., Wommelsdorf, T., Cashman, M. J., \& Fehrmann, L. (2013). The relationship between tree species richness, canopy space exploration and productivity in a temperate broad-leaf mixed forest. Forest Ecology and Management, 310 366-374.

Seidel, D., Schall, P., Gille, M., \& Ammer, C. (2015). Relationship between tree growth and physical dimensions of Fagus sylvatica crowns assessed from terrestrial laser scanning. iForestBiogeosciences and Forestry, 8.

Seidel, D., Ehbrecht, M., \& Puettmann, K. (2016a). Assessing different components of threedimensional forest structure with single-scan terrestrial laser scanning: A case study. Forest ecology and management, 381, 196-208.

Seidel, D., Ruzicka, K. J., \& Puettmann, K. (2016b). Canopy gaps affect the shape of Douglas-fir crowns in the western Cascades, Oregon. Forest Ecology and Management, 363, 31-38.

Smith, F. W., \& Long, J. N. (1989). The influence of canopy architecture on stemwood production and growth efficiency of Pinus contorta var. latifolia. Journal of Applied Ecology, 681-691.

Soares, A. A., Leite, H. G., Souza, A. L., Silva, S. R., Lourenço, H. M., \& Forrester, D. I. (2016). Increasing stand structural heterogeneity reduces productivity in Brazilian Eucalyptus monoclonal stands. Forest Ecology and Management, 373, 26-32.

Thomas, S. C., Halpern, C. B., Falk, D. A., Liguori, D. A., \& Austin, K. A. (1999). Plant diversity in managed forests: understory responses to thinning and fertilization. Ecological applications, 9(3), 864-879.

Vockenhuber, E. A., Scherber, C., Langenbruch, C., Meißner, M., Seidel, D., \& Tscharntke, T. (2011). Tree diversity and environmental context predict herb species richness and cover in Germany's largest connected deciduous forest. Perspectives in Plant Ecology, Evolution and Systematics, 13(2), 111-119.

Watt, P. J., \& Donoghue, D. N. M. (2005). Measuring forest structure with terrestrial laser scanning. International Journal of Remote Sensing, 26(7), 1437-1446. 


\section{Chapter 3}

Zeide, B. (2004). Optimal stand density: a solution. Canadian Journal of Forest Research, 34(4), 846-854.

Zeide, B. (2005). How to measure stand density. Trees, 19(1), 1-14. 


\section{Chapter 4}

\section{Effect of tree species mixing on stand structural complexity}

Julia Juchheim - Martin Ehbrecht - Peter Schall - Christian Ammer •

Dominik Seidel

Forestry: An International Journal of Forest Research 93(1) (2019), 75-83

DOI: $10.1093 /$ forestry/cpz046 


\section{Abstract}

The proportion of mixed-species forests is presently increasing since they are commonly seen as providing a higher level of many ecosystem goods and services than monospecific stands. This may be due to a more complex three-dimensional distribution pattern of plant elements, which has often been noted, but to date rarely been quantified. In the present study, we used terrestrial laser scanning data to analyze the relationship between tree species mixing and stand structural complexity in three regions of Germany. We examined 60 forest plots representing commercially important and typical species combinations for Central Europe. The results showed an increasing but saturating relationship between stand structural complexity and tree species diversity. Moreover, we found that as the proportion of broadleaved trees increased, the stand structural complexity of coniferous stands also increased. Our study provides evidence that the conversion of monospecific conifer stands into mixed forests with broadleaved tree species as well as mixing tree species with interspecific differences in physiological and morphological traits can promote the development of structurally more complex stand structures.

Keywords: pure and mixed stands comparison, species interaction, terrestrial laser scanning, European beech (Fagus sylvatica L.), Norway spruce (Picea abies L. H. KARST), Scots pine (Pinus sylvestris L.)

\subsection{Introduction}

European forests have been affected by human activities for more than 2000 years (Spiecker, 2003; Verstraeten, 2013; Schulze et al., 2016). During the $19^{\text {th }}$ and $20^{\text {th }}$ centuries, in response to prior overexploitation and devastation of Central European forests, coupled with rising wood demand, large areas that had been naturally dominated by deciduous tree species were reforested with coniferous monocultures (Verstraeten, 2013; Pretzsch et al., 2015). These forest types, consisting mainly of Scots pine (Pinus sylvestris L.) or Norway spruce (Picea abies L. H. KARST) plantations were preferred because of their high productivity, simple stand management and suitability for the provision of construction lumber (Zerbe, 2002; Spiecker, 2003; Budde et al., 2011).

Nowadays, concerns about the negative effects of pure coniferous stands on soils (Knoke et al., 2008) as well as their greater susceptibility to storm, insect pests and fungal pathogens (Spiecker, 2003; Solberg, 2004) have led to a large-scale reconversion of conifer monocultures into mixed forests with broadleaved tree species (von Lüpke et al., 2004; Verstraeten, 2013). This has largely been achieved by reintroduction of broadleaves, particularly European beech (Fagus sylvatica L.), in 
single-species coniferous forests by advanced planting or by direct seeding (Ammer et al., 2008; Knoke et al., 2008).

Mixed stands are presumed to provide many ecosystem goods and services to a greater degree than pure stands. For example, diverse forests have been shown to provide higher productivity (Kelty, 2006; Liang et al., 2016; Ammer, 2019), greater carbon storage capacity (Hulvey et al., 2013) and a more efficient use of nutrients (Schwarz et al., 2014). In addition, they are considered more resilient to calamities (Griess and Knoke, 2011) and to have greater resistance to climate change (Knoke et al., 2008) when compared to conifer monocultures.

One possible reason for the improved resource efficiency in mixed stands is maybe reduced competition and/or facilitation due to niche complementarity (Del Río et al., 2014; Forrester and Bauhus, 2016). The mixing of tree species with interspecific differences in physiological and morphological traits can lead to vertical stratification and more efficient occupation of available space (Forrester and Pretzsch, 2015; Jucker et al., 2015; Forrester et al., 2018). This may enhance the structural complexity of mixed stands and can result in increased light absorption and higher productivity compared to pure stands (Williams et al., 2017).

Due to the complex interactions within mixtures, mixed species forests are generally regarded as being more challenging to manage than monospecific stands (Felton et al., 2010). A key to an understanding of the mechanisms behind species mixing effects, and thus for managing, sustaining and predicting the functioning of mixed stands, is quantification of forest structure (Pretzsch, 2014), which needs to be described by multiple structural attributes (del Río et al., 2016; Schall et al., 2018). These often comprise horizontal tree distribution (e.g. aggregation index by Clark and Evans, 1954; Pielou's distribution index (Pielou, 1959), dispersion index by Morisita, 1959), stand density and its spatial variation (e.g. stand density index by Reineke, 1933), tree size differentiation (e.g. coefficient of variation of tree sizes; diameter differentiation by Füldner, 1995), species diversity (e.g. diversity index by Shannon, 1948) or tree species intermingling (e.g. species intermingling index by Füldner, 1996). Besides these indices consisting of single stand structural attributes, there are also some indices that combine several attributes (e.g. structural complexity index by Zenner and Hibbs, 2000, enhanced structural complexity index by Beckschäfer et al., 2013).

Studies in which the above-mentioned indices were used, have found positive (Hakkenberg et al., 2016), non-significant (Neumann and Starlinger, 2001), as well as development stage-dependent relationships (Zeller and Pretzsch, 2019) between stand structure and species diversity. However, conventional measures of stand structure are based on one- or two-dimensional attributes, such as tree height and diameter or tree spacing, and do not comprehensively cover the three-dimensional nature of important forest components, e.g. irregularities in individual tree crowns, which have a 
strong influence on stand productivity and biodiversity (Ishii et al., 2004; Dănescu et al., 2016; Juchheim et al., 2017a). Little is known of the relationship between tree species diversity and measures of three-dimensional stand structure. One reason for the lack of such information may be the complexity and inaccessibility of the object of interest; that is, the structure of a forest and all plant elements therein (e.g. Seidel et al., 2011).

LiDAR (Light Detection and Ranging) has recently shown great potential in this regard, measuring the complex structure of forest ecosystems more holistically than one- or twodimensional measures (Newnham et al., 2015; Seidel et al., 2016a; Ehbrecht et al., 2017; Juchheim et al., 2017a). Approaches to quantify canopy structure include among others, measures such as rugosity, which describes vertical and horizontal variability in canopy vegetation as well as leaf area density (Hosoi et al., 2010; Li et al., 2017) or porosity, characterizing internal canopy architecture (Hardiman et al., 2011; Atkins et al., 2018).

We defined stand structural complexity as the summary measure of all visible dimensional, architectural, and distributional patterns of tree individuals and their aboveground organs in a given forest volume at a given point in time. We assessed stand structural complexity based on a stand structural complexity index (SSCI) using TLS-data. The SSCI was introduced by Ehbrecht et al. (2017) and takes into account structural complexity in all three dimensions and in great detail (mmresolution). The index correlates significantly positively with conventional indices of stand structure, such as the structural complexity index of Zenner and Hibbs (2000), the tree size differentiation index of Füldner (1995) and the Gini-coefficient of diameters. It is, however, considered a more holistic measure than previous indices, as it quantifies structural complexity based on the three-dimensional spatial arrangement of all visible plant elements.

In the present study, we used terrestrial LiDAR data to analyze the relationship between tree species mixing and stand structural complexity in temperate forests in Germany. We hypothesized that: (1) stand structural complexity increases with increasing tree species diversity, and that (2) an increasing proportion of broadleaved trees positively affects stand structural complexity of coniferous stands.

\subsection{Materials and methods}

\subsubsection{Study sites}

Our study was conducted in three regions of Germany which are part of the biodiversity exploratories (see Fischer et al., 2010 and Schall et al., 2018 for details on forests). The study sites 
were located in the Swabian Alb in southwest (SW) Germany, Hainich-Dün in central Germany, and Schorfheide-Chorin in northeast (NE) Germany (Table 4.1).

Table 4.1: General information of the study regions (modified from Fischer et al., 2010).

\begin{tabular}{|c|c|c|c|}
\hline & Swabian Alb & Hainich-Dün & Schorfheide-Chorin \\
\hline Location & SW Germany & Central Germany & NE Germany \\
\hline $\begin{array}{l}\text { Altitude above } \\
\text { sea level }\end{array}$ & $460-860 \mathrm{~m}$ & $285-550 \mathrm{~m}$ & $3-140 \mathrm{~m}$ \\
\hline $\begin{array}{l}\text { Mean annual } \\
\text { temperature }\end{array}$ & $6.0-7.0^{\circ} \mathrm{C}$ & $6.5-8.0^{\circ} \mathrm{C}$ & $8.0-8.5^{\circ} \mathrm{C}$ \\
\hline $\begin{array}{l}\text { Mean annual } \\
\text { precipitation }\end{array}$ & $700-1000 \mathrm{~mm}$ & $500-800 \mathrm{~mm}$ & $500-600 \mathrm{~mm}$ \\
\hline Main soil type & Cambisols (eutric) & Luvisols & Cambisols (dystric) \\
\hline \multicolumn{4}{|l|}{$\begin{array}{l}\text { Main tree species } \\
\text { (No. of plots) }\end{array}$} \\
\hline European beech & 15 & 8 & 9 \\
\hline Scots pine & 0 & 0 & 12 \\
\hline Norway spruce & 12 & 4 & 0 \\
\hline
\end{tabular}

For our investigation, 60 forest plots were selected $(100 \times 100 \mathrm{~m}$ in size) representing commercially important mixture types that are frequently found across Central Europe. These were, firstly, managed even-aged forests of European beech (F. sylvatica L.) with varying proportions of other broadleaved tree species, such as sycamore maple (Acer psendoplatanus L.), European ash (Fraxinus excelsior L.), sessile oak (Quercus petraea (Matt.) Lieb.) and small-leaved lime (Tilia cordata Mill.). Secondly, we chose managed even-aged forests of Norway spruce (P. abies L.) and Scots pine (P. sylvestris L.) containing varying proportions of beech and other broadleaved tree species. 
Table 4.2: Stand characteristics of the study plots. Min minimum, SD standard deviation, Max maximum, yrs years, $D B H$ Diameter at breast height, $N$ number of stems per hectare, $B A$ basal area per hectare, $P B L$ basal area proportion of broadleaves, SSCI Structural Complexity Index, eH exponential Shannon-Index.

Main tree species

Beech Spruce Pine

\begin{tabular}{|c|c|c|c|c|}
\hline \multirow{4}{*}{ Age (yrs) } & Min & 71 & 44 & 43 \\
\hline & Mean ( \pm SD) & $121 \pm 28$ & $67 \pm 15$ & $91 \pm 28$ \\
\hline & Median & 121 & 68 & 104 \\
\hline & $\operatorname{Max}$ & 186 & 91 & 129 \\
\hline \multirow{4}{*}{ DBH (cm) } & Min & 22.4 & 23.8 & 21.8 \\
\hline & $\operatorname{Mean}( \pm \mathrm{SD})$ & $33.2 \pm 7.9$ & $31.4 \pm 6.3$ & $32 \pm 6.1$ \\
\hline & Median & 34.1 & 30.6 & 33.4 \\
\hline & $\operatorname{Max}$ & 55.8 & 44.3 & 42.3 \\
\hline \multirow{4}{*}{ N (no.ha-1) } & Min & 115 & 282 & 116 \\
\hline & Mean $( \pm \mathrm{SD})$ & $316 \pm 131$ & $540 \pm 169$ & $406 \pm 220$ \\
\hline & Median & 298 & 543 & 334 \\
\hline & Max & 596 & 914 & 915 \\
\hline \multirow{4}{*}{ BA $\left(\mathrm{m}^{2} h \mathrm{~h}^{-1}\right)$} & Min & 22.6 & 30.8 & 17.3 \\
\hline & Mean ( \pm SD) & $29.3 \pm 4.3$ & $42.7 \pm 5.9$ & $31.2 \pm 6.6$ \\
\hline & Median & 28.7 & 43.1 & 31.6 \\
\hline & $\operatorname{Max}$ & 38.8 & 52.8 & 38.6 \\
\hline \multirow{4}{*}{ PBL (\%) } & Min & 63.4 & 0 & 0 \\
\hline & Mean ( \pm SD) & $93.5 \pm 11.1$ & $11.2 \pm 14.6$ & $14.6 \pm 16.4$ \\
\hline & Median & 99.4 & 4.1 & 7.1 \\
\hline & $\operatorname{Max}$ & 100 & 38.8 & 46.2 \\
\hline \multirow{4}{*}{ SSCI } & Min & 2.9 & 2.9 & 1.8 \\
\hline & Mean $( \pm \mathrm{SD})$ & $4.8 \pm 1.1$ & $3.7 \pm 0.7$ & $3.1 \pm 0.9$ \\
\hline & Median & 4.7 & 3.6 & 3.0 \\
\hline & Max & 7.5 & 5.5 & 4.4 \\
\hline \multirow{4}{*}{$\mathrm{eH}$} & Min & 1 & 1 & 1 \\
\hline & Mean ( \pm SD) & $1.8 \pm 0.5$ & $1.7 \pm 0.8$ & $1.5 \pm 0.5$ \\
\hline & Median & 1.7 & 1.4 & 1.3 \\
\hline & Max & 3.1 & 3.6 & 2.1 \\
\hline
\end{tabular}

Plots with beech as the main tree species were located in each of the three study areas. Sprucedominated stands occurred in the Swabian Alb and Hainich, while plots with pine as the main tree species were located in Schorfheide-Chorin. Coniferous forests had been planted in the past, while 
broadleaved forests naturally regenerated after repeated shelterwood cuttings under the canopy of the remaining trees. Silvicultural interventions are conducted in all investigated stands every 5-10 years; the rotation period is around $80-120$ years. Plot characteristics can be found in Table 4.2.

\subsubsection{Data acquisition and computation of single-scan based structural measures}

At each forest plot, species identity and diameter at breast height $(\mathrm{DBH})$ of all trees (caliper limit $\mathrm{DBH} \geq 7 \mathrm{~cm})$ were recorded. Plot basal area $(\mathrm{BA})$ was calculated as the sum of the cross-sectional areas (at breast height) of all tree stems greater or equal $7 \mathrm{~cm}$ in diameter. We determined the proportion of the respective species as the ratio between the species BA and the total BA of the stand.

$p_{i}=\frac{B A_{i}}{B A_{\text {total }}}$

where $p_{i}$ is the proportion of species i, $B A_{i}$ its basal area, and $B A_{\text {total }}$ the total basal area of the stand (Equation (1)).

Species diversity was calculated by the exponential Shannon-Index $(e H)$,

$e H=\exp \left(-\sum_{i=1}^{N} p_{i} * \ln p_{i}\right)$

where $p_{i}$ is the basal area share of the constituent species relative to the total basal area of the stand (Equation (2)).

\subsubsection{Determination of stand structural complexity}

At each study plot we made nine systematically distributed single scans with a Faro Focus 3D (Faro Technologies Inc., Lake Marry, FL, US) terrestrial laser scanner at (for details see Ehbrecht et al., 2017). The scanner covered a $360 \times 300^{\circ}$ field of view and was mounted on a tripod at $1.3 \mathrm{~m}$ height. The angular resolution was $0.035^{\circ}$, which resulted in 44.4 million laser beams per scan. Scans were conducted under leaf-on conditions between June and August 2014. An algorithm written in Mathematica (Vers. 9, Wolfram Research, Champaign, IL, US) was used to compute the laser scanning-based SSCI. The index consists of two parts, the mean fractal dimension (MeanFrac, see 
Ehbrecht et al., 2017) and the effective number of layers (ENL, see Ehbrecht et al., 2016). ENL is a measure of vertical stand structure that takes the number of one-meter thick layers and their respective filling by foliage and woody components relative to the total space filling into account. ENL increases with increasing stand height and a more even filling of the layers. Fractal dimension was calculated for every polygon, that was created for each of the 1280 cross-sections per scan. The arithmetic mean (MeanFrac) was then scaled by the ENL according to the following formula (Equation (3)).

$S S C I=$ MeanFrac ${ }^{\ln (E N L)}$

\subsubsection{Statistical analysis}

All statistical analyses were performed using the software R, version 3.5.2 (Core Team, 2018). To analyze the effect of increasing tree species diversity $(\mathrm{eH})$ on stand structural complexity we fitted various models with plot BA as covariate. According to Allan et al. (2014) we calculated different asymptotic regression models (package nls2; Grothendieck, 2013) in which the intercept, intercept and rate constant, intercept and asymptote, or all three parameters depended on BA. To control for regional differences in SSCI, we modeled the intercept of each asymptotic model as a function of region, which equals fitting region as a categorical factor in linear models. The formula for the asymptotic exponential model was:

$S S C I=a+(b-a) e^{-e^{c} e H}$

Where $a$ is the horizontal asymptote (called Asym in R code), $b$ is the intercept (R0) and $c$ is the natural logarithm of the rate constant (lrc). The starting values for the parameters were computed with the self-starting function SSasymp (Pinheiro and Bates, 2000). We calculated Akaike's information criterion (AICc; corrected for small sample sizes) to determine the most appropriate model. To illustrate the effect of BA we used the best asymptotic regression model to predict curves for a low $\left(20 \mathrm{~m}^{2} \mathrm{ha}^{-1}\right)$, medium $\left(30 \mathrm{~m}^{2} \mathrm{ha}^{-1}\right)$ and high BA $\left(40 \mathrm{~m}^{2} \mathrm{ha}^{-1}\right)$. To assess the effect of an increasing proportion of broadleaves (PBL) on stand structural complexity of coniferous stands we conducted linear mixed effects models (package nlme; Pinheiro et al., 2016) and removed the plots with a broadleaves proportion of 100 per cent from the analysis. We used plot BA as a covariate to account for its direct influence on SSCI and treated region as a random effect to control for differences in SSCI among the three study regions (Table 4.3). 
The formula for the linear mixed effects model was:

SSCI $=\beta_{0}+\beta_{1} * P B L+\beta_{2} * B A+u *$ study region $+\varepsilon$

where $\beta_{0}$ is the intercept, $u$ is the random effect of the clustering/ region and $\varepsilon$ are the random errors. We selected the most appropriate model based on AICc values. A significance level of $\mathrm{p}$ $<0.05$ was used for all statistical procedures. 


\subsection{Results}

\subsubsection{Effect of increasing tree species diversity on stand structural complexity}

We found that stand structural complexity follows an asymptotic exponential relationship with tree species diversity. SSCI increased from low to high tree species diversity. Since we detected a weak negative linear relationship between SSCI and BA $\left(\mathrm{R}^{2}=0.075, \mathrm{p}=0.34\right)$, we included plot BA as a covariate in our models. The best performing model according to Akaike's information criterion (AICc) explained 59 per cent of the variance in SSCI and modeled the asymptote and rate constant as a function of $\mathrm{BA}$ and included study region as a random effect. The predicted curves for different stand densities showed that plots with lower basal areas exhibited greater complexity of stand structure than plots with higher basal areas (Figure 4.1a).We identified no significant relationship between BA and tree species diversity, as mixed-species stands didn't differ in their BA from monocultures. Moreover, we found that the structural complexity of the stands varied across the study regions. The lowest SSCI-values were identified at Schorfheide-Chorin, medium values at Hainich and the highest SSCI-values at the Swabian Alb (Figure 4.1b). The results of the asymptotic regression models are shown in Table 4.3.
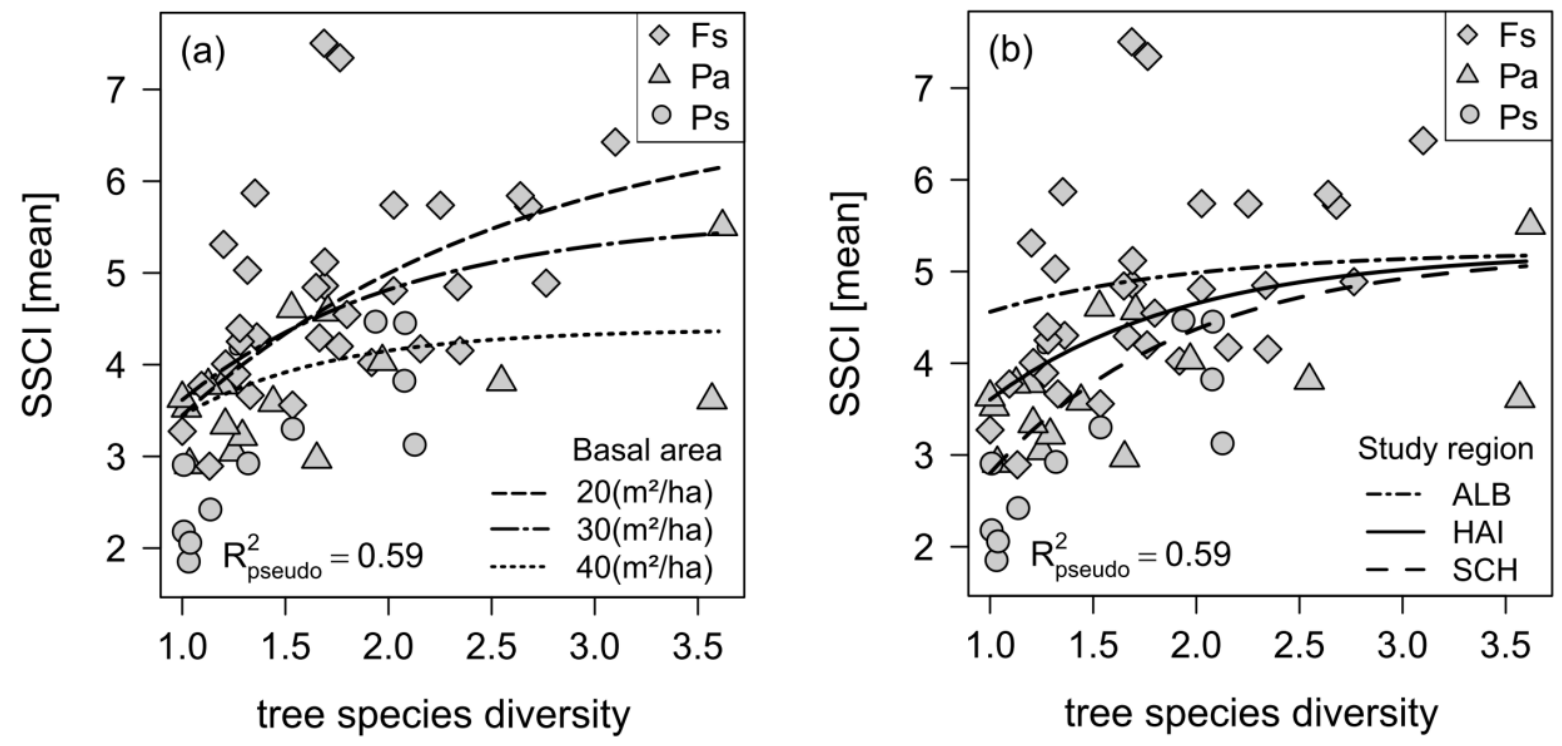

Figure 4.1: Relationship between mean SSCI and tree species diversity (exponential Shannon-Index) factoring out plot BA (a), and relationship between mean SSCI and tree species diversity factoring out study region (b). Lines correspond to fitted relationships of the asymptotic model. Symbols indicate main tree species: $\mathrm{Fs}=$ F. sylvatica, $\mathrm{Pa}=$ P. abies, $\mathrm{Ps}=$ P. sylvestris. 


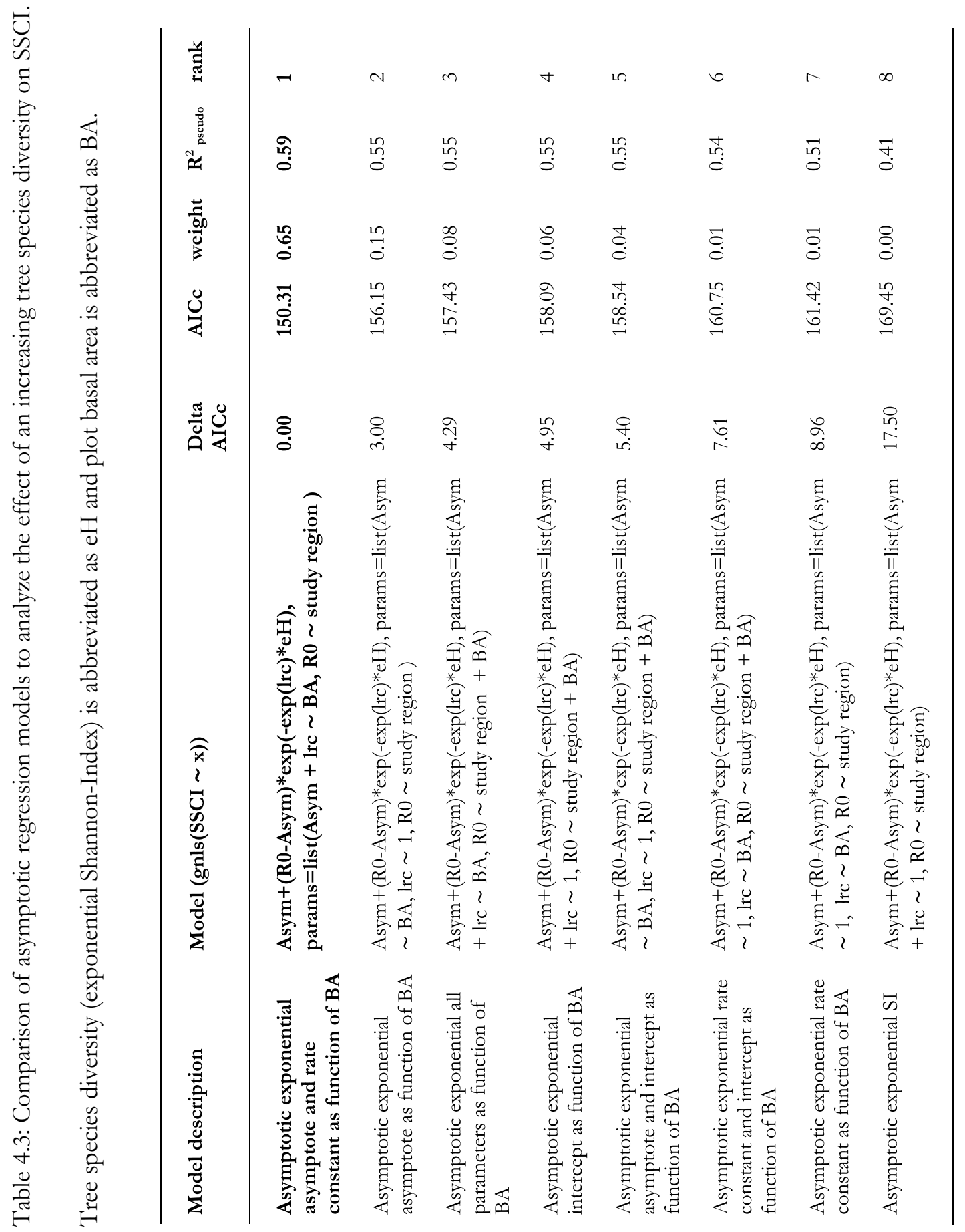




\subsubsection{Effect of an increasing PBL on stand structural complexity of coniferous stands}

Stand structural complexity of coniferous forest stands significantly increased with an increasing proportion of broadleaved trees $\left(\mathrm{R}_{\text {pseudo }}^{2}=0.62, \mathrm{p}<0.001\right)$. We found no significant relationship between SSCI and plot BA. Including plot BA as a covariate also didn't improve the fit of the model. The complexity of stand structure differed among the three regions. We found the highest SSCI-values at Swabian Alb, medium values at Hainich and the lowest SSCI-values at SchorfheideChorin (Figure 4.2). The results of the linear mixed effects models are shown in Table 4.4.

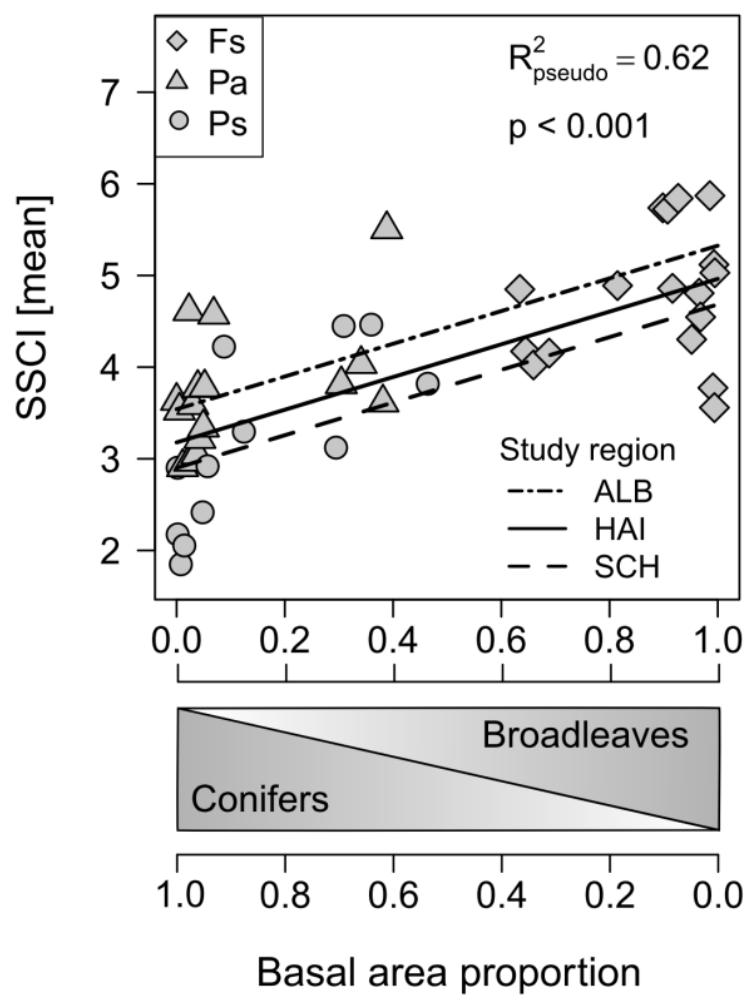

Figure 4.2: Relationship between mean SSCI per plot and species proportion determined by BA. Lines correspond to fitted relationships of the linear mixed-effect model. Symbols indicate main tree species: $\mathrm{Fs}=$ F. sylvatica, $\mathrm{Pa}=P$. abies, $\mathrm{Ps}=P$. sylvestris. 
Table 4.4: Comparison of linear mixed-effects models to analyze the effect of an increasing BA share of broadleaved tress on SSCI of coniferous stands. Basal area proportion of broadleaves and plot basal area are abbreviated as PBL and BA, respectively. Study region is included as a random effect. The best fitting model is shown in bold.

\begin{tabular}{lllllc}
\hline Model $(\operatorname{lme}(\mathrm{SSCI} \sim \mathrm{x})$ ) & $\begin{array}{l}\text { Delta } \\
\mathrm{AIC}_{\mathrm{c}}\end{array}$ & $\mathrm{AIC}_{\mathbf{c}}$ & weight & pseudo-R $^{2}$ & rank \\
\hline \hline PBL, random $=\sim 1 \mid$ study region & $\mathbf{0 . 0 0}$ & $\mathbf{1 0 2 . 6 5}$ & $\mathbf{0 . 9 8}$ & $\mathbf{0 . 6 2}$ & $\mathbf{1}$ \\
$\mathrm{PBL}+\mathrm{BA}$, random $=\sim 1 \mid$ study region & 8.12 & 110.76 & 0.21 & 0.62 & 2 \\
$\mathrm{BA}$, random $=\sim 1 \mid$ study region & 32.00 & 134.65 & 0.00 & 0.32 & 3 \\
\hline
\end{tabular}

\subsection{Discussion}

\subsubsection{Effect of increasing tree species diversity on stand structural complexity}

Our first hypothesis stated that stand structural complexity increases with increasing species diversity. Our findings confirmed this hypothesis since we found an increasing but saturating relationship between SSCI and the exponential Shannon diversity index (pseudo- $\mathrm{R}^{2}=0.59$ ). We assume that a higher species diversity promotes the development of denser and structurally more complex canopies if tree species with complementary physiological and morphological traits are mixed. Interestingly, the function that describes the relationship between diversity and productivity has a similar shape (Ammer, 2019) to that of species diversity and stand structural complexity. This might mean that to a certain degree, complex stand structures due to species diversity positively influence stand productivity (Morin et al., 2011; Pretzsch and Schütze, 2014; Dănescu et al., 2016).

Previous studies have demonstrated that interactions between species with different traits can result in greater plasticity of crown properties. This was shown for example, by Juchheim et al. (2017b) for the angle and length of branches, Olivier et al. (2016) for crown volume and crown density, and Forrester et al. (2017) for the crown-projection area. In addition, interspecific variations in crown architecture and height can lead to complementarity in canopy space occupation by the branches and foliage of each species (Ammer, 2019). For instance, stand structural heterogeneity increases (Pretzsch et al., 2016) by combining species with different shade tolerances or vertically oriented species with more laterally expanding tree species (Pretzsch and Schütze, 2005; Pretzsch and Schütze, 2009; Pretzsch et al., 2015). Jucker et al. (2015) found 
evidence that both mechanisms, greater crown plasticity and vertical stratification, are responsible for increased canopy space occupation in mixed-species stands. Their study revealed that canopy packing increased with tree species richness across different forest types in Europe, indicating that diverse forests utilize above-ground space more efficiently than monocultures. This is in line with our results, since SSCI is determined by the spatial arrangement of tree components and is therefore, to a certain extent, density-dependent.

We found that the complexity of forest structure increased only up to a point, beyond which further species addition seem to have no additional impact on structural complexity. We assume that the relationship saturates when multiple functional types are present, and the different spatial aboveground niches are starting to overlap. The number of tree species that are necessary to gain optimal functional diversity, however, depends on the complementarity of the species in the mixture (Ammer, 2019).

Moreover, our findings revealed that stands with a lower BA exhibited greater SSCI than forests with a higher BA (Figure 4.1b). This could be due to the fact that wider tree spacing reduced competition and increased resource acquisition capacity per tree, therefore facilitating crown expansion. Previous studies have shown that trees in coniferous as well as in deciduous forests growing at lower stand density develop larger crowns in comparison to trees that are growing in stands of higher density (Maguire and Bennett, 1996; Medhurst and Beadle, 2001; Seidel et al., 2016b). Lower stand density can also result in larger crown surface areas (Juchheim et al., 2017b) and in more heterogeneous stand structures with higher space fillings (Juchheim et al., 2017a).

In contrast to previous studies (Vilà et al., 2013; Pretzsch, 2016), we didn't find a higher BA in mixed-species forests. Stands with a low tree diversity didn't differ in their BA from stands with a high tree diversity. A possible reason for this could be the high stand density of the monocultures that were part of our study plots.

Furthermore, we observed that the shape of the curve representing the relationship between species diversity and stand structural complexity differed across the study regions, but consistently reached an asymptote at high species diversity. SSCI at low species diversity was lowest at Schorfheide-Chorin, intermediate at Hainich and highest at the Swabian Alb site (Figure 4.1a).

We assume that the observed higher stand structural complexity at low species diversity at both the Hainich and Swabian Alb sites was due to different thinning regimes of the beech dominated stands in the three regions. A more precise discussion of the contrasting thinning types and their possible impact on stand structure is given below. 


\subsubsection{Effect of an increasing PBL on stand structural complexity of coniferous stands}

Our second hypothesis, that increasing the proportion of broadleaved trees increases the stand structural complexity of coniferous stands, was confirmed by our results $\left(R^{2}=0.62\right.$, $p<0.001$, see Figure 4.2). This finding corresponds with earlier studies demonstrating that mixing of deciduous with coniferous tree species enhances structural heterogeneity (Pretzsch and Schutze, 2014; Pretzsch and Schutze, 2016). Possible reasons are, as already mentioned, greater plasticity and different space occupation patterns due to contrasting characteristics between the studied species.

Pretzsch et al. (2016) examined mature pure and mixed stands of Scots pine and European beech and found higher stand density and broader and more variable formation of trees along the vertical crown profile in the mixed forests. At the individual tree level, Dieler and Pretzsch (2013) showed that European beech crowns were larger when mixed with Scots pine compared to beech in pure stands. Beech crown plasticity was also observed when grown with Norway spruce, with greater crown volumes in comparison to those in monocultures (Bayer et al., 2013). Although they are considered rather unplastic species, crown plasticity has also been detected among pine and spruce trees in mixture with beech (Bayer et al., 2013; Pretzsch et al., 2016).

We found that the slope and intercept of the regression line for SSCI varied across sites, but it consistently increased depending on the share of broadleaved trees. SSCI was lowest at Schorfheide-Chorin, intermediate at Hainich and highest at the Swabian Alb site (Figure 4.2). This was presumably due both to differences in main tree species and to contrasting thinning regimes of the beech dominated stands at the three study sites (see Figure 4.3). Scots pine dominated stands, which had a generally lower SSCI than Norway spruce, were located in the Schorfheide, while the Swabian Alb and Hainich sites had stands with spruce as main tree species. Whereas the spruce trees developed longer crowns, pine trees were characterized by long branch-free stems, which probably resulted in the lower SSCI-values of the pine stands.

The examined deciduous forests were stands with beech as main tree species mixed with other broadleaved tree species, such as sycamore maple, European ash, sessile oak and small-leaved lime, which were sporadically found in each of the three study areas. However, broadleaved forests at the Swabian Alb and Hainich sites were managed by thinning from above whereas the forests at the Schorfheide-Chorin were managed by thinning from below. It is well documented that thinning from below increases the equality of tree size distribution by removing mainly smaller suppressed trees and therefore reducing the structural heterogeneity of the stand. In contrast, thinning from above leads to greater availability of resources for mid and understory trees by removing codominant trees in the overstory, resulting in more heterogeneous stand structures (Röhrig et al., 
2006; Soares et al., 2017). We therefore assume that thinning from above resulted in higher SSCIvalues and multi-layered canopies in the beech dominated stands at the Swabian Alb and Hainich sites, while thinning from below led to lower SSCI-values and single-layered canopies at the Schorfheide.
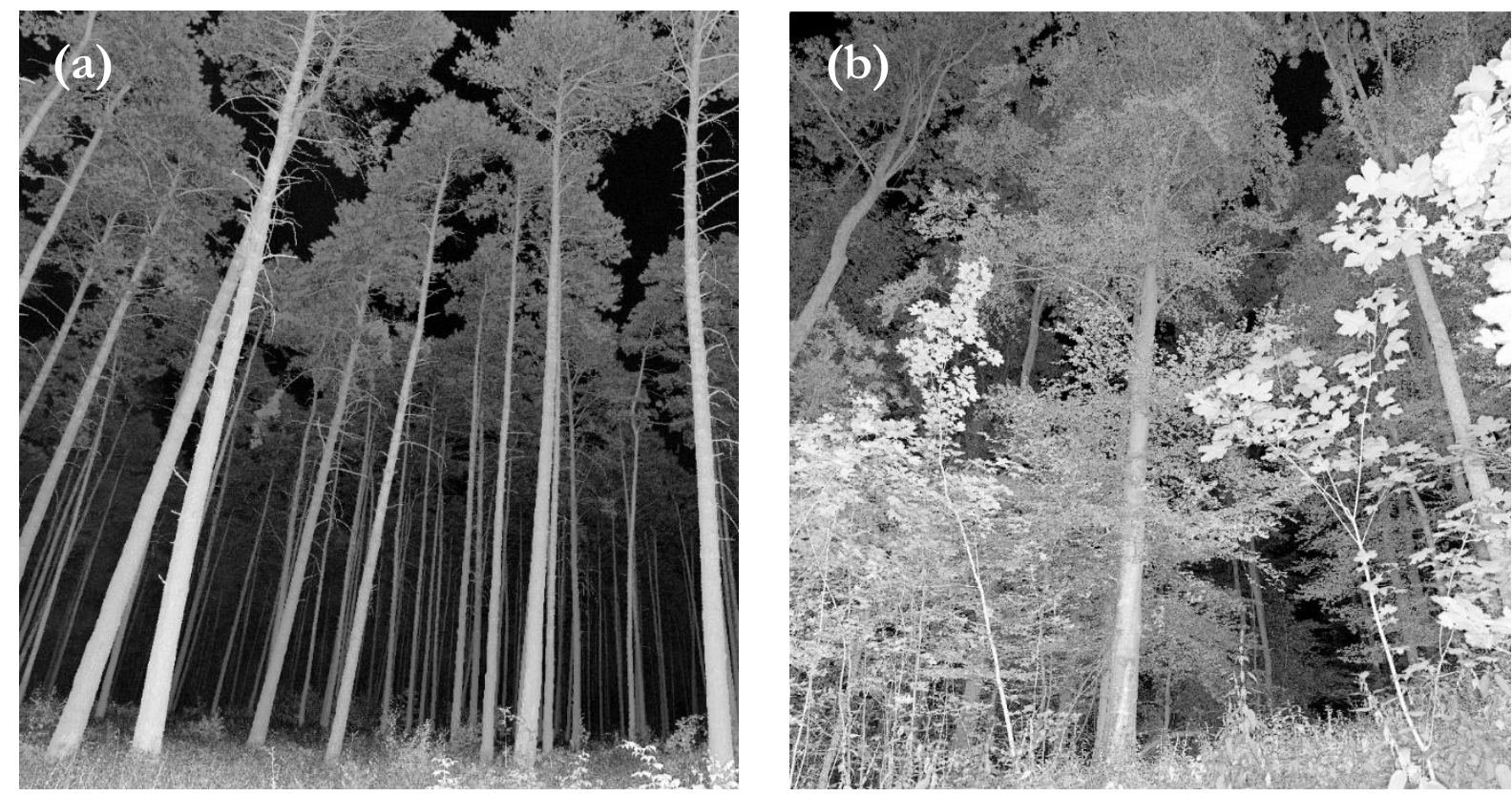

Fig. 4.3: Examples of stands with low (a) and high (b) stand structural complexity. (a) Laser scan of a pine forest in the Schorfheide and (b) laser scan of a mixed-species forest in the Swabian Alb.

\subsection{Conclusion}

In the present study, we used high resolution 3D data on forest structure provided by terrestrial laser scanning to quantify the relationship between tree species mixing and stand structural complexity. Based on a holistic and objective measure (SSCI) that takes the arrangement of plant elements in all three dimensions into account, we were able to provide evidence that increasing tree species diversity enhances the complexity of stand structure. Moreover, our results showed that enriching coniferous stands with broadleaved trees increased stand structural complexity. We conclude that species enrichment of coniferous forests and the creation of species-rich forests in general can increase stand structural complexity.

\section{Acknowledgements}

We thank the managers of the three Exploratories, Kirsten Reichel-Jung, Katrin Lorenzen and all former managers for their work in maintaining the plot and project infrastructure; Christiane 
Fischer and Jule Mangels for giving support through the central office, Michael Owonibi for managing the central data base, and Markus Fischer, Eduard Linsenmair, Dominik Hessenmöller, Daniel Prati, Ingo Schöning, François Buscot, Ernst-Detlef Schulze, Wolfgang W. Weisser and the late Elisabeth Kalko for their role in setting up the Biodiversity Exploratories project. Field work permits were issued by the responsible state environmental offices of Baden-Württemberg, Thüringen, and Brandenburg (according to $\int 72 \mathrm{BbgNatSchG)}$ ).

\section{Conflict of interest statement}

None declared.

\section{Funding}

The work has been funded by the DFG (German Science Foundation) Priority Program1374 "Infrastructure-Biodiversity-Exploratories" and through funds granted to Dominik Seidel (reference number: Se 2383/2-1); Christian Ammer (reference number: Am 149/15-1) by the DFG as well as by a research scholarship granted to Dominik Seidel by the DFG (reference number: Se 2383/4-1). 


\subsection{References}

Allan, E., Bossdorf, O., Dormann, C. F., Prati, D., Gossner, M. M., Tscharntke, T., ... \& Böhm, S. (2014). Interannual variation in land-use intensity enhances grassland multidiversity. Proceedings of the National Academy of Sciences, 111(1), 308-313.

Ammer, C. (2019). Diversity and forest productivity in a changing climate. New Phytologist, 221(1), $50-66$.

Ammer, C., Bickel, E., \& Kölling, C. (2008). Converting Norway spruce stands with beech-a review of arguments and techniques. Austrian Journal of Forest Science, 125(1), 3-26.

Atkins, J. W., Fahey, R. T., Hardiman, B. S., \& Gough, C. M. (2018). Forest canopy structural complexity and light absorption relationships at the subcontinental scale. Journal of Geophysical Research: Biogeosciences, 123(4), 1387-1405.

Bayer, D., Seifert, S., \& Pretzsch, H. (2013). Structural crown properties of Norway spruce (Picea abies [L.] Karst.) and European beech (Fagus sylvatica [L.]) in mixed versus pure stands revealed by terrestrial laser scanning. Trees, 27(4), 1035-1047.

Beckschäfer, P. (2013). Enhanced structural complexity index: an improved index for describing forest structural complexity. Open Journal of Forestry, 3(01), 23-29.

Budde, S., Schmidt, W., \& Weckesser, M. (2011). Impact of the admixture of European beech (Fagus sylvatica L.) on plant species diversity and naturalness of conifer stands in Lower Saxony. Waldökologie, Landschaftsforschung und Naturschutz, 11, 49-61.

Clark, P. J., \& Evans, F. C. (1954). Distance to nearest neighbor as a measure of spatial relationships in populations. Ecology, 35(4), 445-453.

Core Team, R. 2018 R: A Language and Environment for Statistical Computing. R Foundation for Statistical Computing, Vienna, Austria.

Dănescu, A., Albrecht, A. T., \& Bauhus, J. (2016). Structural diversity promotes productivity of mixed, uneven-aged forests in southwestern Germany. Oecologia, 182(2), 319-333.

Del Río, M., Condés, S., \& Pretzsch, H. (2014). Analyzing size-symmetric vs. size-asymmetric and intra-vs. inter-specific competition in beech (Fagus sylvatica L.) mixed stands. Forest Ecology and Management, 325, 90-98. 
Del Río, M., Pretzsch, H., Alberdi, I., Bielak, K., Bravo, F., Brunner, A., ... \& Pach, M. (2016). Characterization of the structure, dynamics, and productivity of mixed-species stands: review and perspectives. European journal of forest research, 135(1), 23-49.

Dieler, J., \& Pretzsch, H. (2013). Morphological plasticity of European beech (Fagus sylvatica L.) in pure and mixed-species stands. Forest Ecology and Management, 295, 97-108.

Ehbrecht, M., Schall, P., Juchheim, J., Ammer, C., \& Seidel, D. (2016). Effective number of layers: a new measure for quantifying three-dimensional stand structure based on sampling with terrestrial LiDAR. Forest Ecology and Management, 380, 212-223.

Ehbrecht, M., Schall, P., Ammer, C., \& Seidel, D. (2017). Quantifying stand structural complexity and its relationship with forest management, tree species diversity and microclimate. Agricultural and Forest Meteorology, 242, 1-9

Felton, A., Lindbladh, M., Brunet, J., \& Fritz, Ö. (2010). Replacing coniferous monocultures with mixed-species production stands: an assessment of the potential benefits for forest biodiversity in northern Europe. Forest Ecology and Management, 260(6), 939-947.

Fischer, M., Bossdorf, O., Gockel, S., Hänsel, F., Hemp, A., Hessenmöller, D., ... \& Renner, S. (2010). Implementing large-scale and long-term functional biodiversity research: The Biodiversity Exploratories. Basic and Applied Ecology, 11(6), 473-485.

Forrester, D. I., \& Pretzsch, H. (2015). Tamm Review: On the strength of evidence when comparing ecosystem functions of mixtures with monocultures. Forest Ecology and Management, 356, 41-53.

Forrester, D. I., \& Bauhus, J. (2016). A review of processes behind diversity-productivity relationships in forests. Current Forestry Reports, 2(1), 45-61.

Forrester, D. I., Ammer, C., Annighöfer, P. J., Barbeito, I., Bielak, K., Bravo-Oviedo, A., ... \& Hurt, V. (2018). Effects of crown architecture and stand structure on light absorption in mixed and monospecific Fagus sylvatica and Pinus sylvestris forests along a productivity and climate gradient through Europe. journal of ecology, 106(2), 746-760.

Füldner, K. (1995). Strukturbeschreibung von Buchen-Edellaubholz-Mischwäldern. Ph.D. thesis. Forstl Fak Göttingen. Cuvillier Verlag, Göttingen, p. 146. 
Füldner, K. (1996). Die Strukturelle Vierergruppe-ein Stichprobenverfahren zur Erfassung von Strukturparametern in Wäldern. Beiträge zur Waldinventur. Cuvillier Verlag, Göttingen: S, 13-30.

Griess, V. C., \& Knoke, T. (2011). Growth performance, windthrow, and insects: meta-analyses of parameters influencing performance of mixed-species stands in boreal and northern temperate biomes. Canadian Journal of Forest Research, 41(6), 1141-1159.

Grothendieck, G. 2013 nls2: Non-linear Regression with Brute Force. R Package Version 0.2. Available online at: http://CRAN.R-project.org/package=nls2

Hakkenberg, C. R., Song, C., Peet, R. K., \& White, P. S. (2016). Forest structure as a predictor of tree species diversity in the North Carolina Piedmont. Journal of vegetation science, 27(6), $1151-1163$.

Hardiman, B. S., Bohrer, G., Gough, C. M., Vogel, C. S., \& Curtis, P. S. (2011). The role of canopy structural complexity in wood net primary production of a maturing northern deciduous forest. Ecology, 92(9), 1818-1827.

Hosoi, F., Nakai, Y., \& Omasa, K. (2010). Estimation and error analysis of woody canopy leaf area density profiles using 3-D airborne and ground-based scanning lidar remote-sensing techniques. IEEE Transactions on Geoscience and Remote Sensing, 48(5), 2215-2223.

Hulvey, K. B., Hobbs, R. J., Standish, R. J., Lindenmayer, D. B., Lach, L., \& Perring, M. P. (2013). Benefits of tree mixes in carbon plantings. Nature Climate Change, 3(10), 869.

Ishii, H. T., Tanabe, S. I., \& Hiura, T. (2004). Exploring the relationships among canopy structure, stand productivity, and biodiversity of temperate forest ecosystems. Forest Science, 50(3), 342-355.

Juchheim, J., Ammer, C., Schall, P., \& Seidel, D. (2017). Canopy space filling rather than conventional measures of structural diversity explains productivity of beech stands. Forest ecology and management, 395, 19-26.

Juchheim, J., Annighöfer, P., Ammer, C., Calders, K., Raumonen, P., \& Seidel, D. (2017). How management intensity and neighborhood composition affect the structure of beech (Fagus sylvatica L.) trees. Trees, 31(5), 1723-1735. 
Jucker, T., Bouriaud, O., \& Coomes, D. A. (2015). Crown plasticity enables trees to optimize canopy packing in mixed-species forests. Functional Ecology, 29(8), 1078-1086.

Kelty, M. J. (2006). The role of species mixtures in plantation forestry. Forest Ecology and Management, 233(2-3), 195-204.

Knoke, T., Ammer, C., Stimm, B., \& Mosandl, R. (2008). Admixing broadleaved to coniferous tree species: a review on yield, ecological stability and economics. European Journal of Forest Research, 127(2), 89-101.

Li, S., Dai, L., Wang, H., Wang, Y., He, Z., \& Lin, S. (2017). Estimating leaf area density of individual trees using the point cloud segmentation of terrestrial LiDAR data and a voxelbased model. Remote Sensing, 9(11), 1202

Liang, J., Crowther, T. W., Picard, N., Wiser, S., Zhou, M., Alberti, G., ... \& De-Miguel, S. (2016). Positive biodiversity-productivity relationship predominant in global forests. Science, 354(6309), aaf8957.

Lüpke, B. v., Ammer, C., Bruciamaachie, M. et al. 2004 Silvicultural strategies for conversion. In H., Spiecker, J. Hansen, E., Klimo, J. P. Skovsgaard, H. Sterba, K. v. Teuffel (eds.), Norway spruce conversion - options and consequences. European Forest Institute Research Report 18, Brill NV, Leiden, Boston, 121-164.

Maguire, D. A., \& Bennett, W. S. (1996). Patterns in vertical distribution of foliage in young coastal Douglas-fir. Canadian Journal of Forest Research, 26(11), 1991-2005.

Medhurst, J. L., \& Beadle, C. L. (2001). Crown structure and leaf area index development in thinned and unthinned Eucalyptus nitens plantations. Tree Physiology, 21(12-13), 989-999.

Morin, X., Fahse, L., Scherer-Lorenzen, M., \& Bugmann, H. (2011). Tree species richness promotes productivity in temperate forests through strong complementarity between species. Ecology Letters, 14(12), 1211-1219.

Morisita, M. (1959). Measuring of the dispersion of individuals and analysis of the distributional patterns. Mem. Fac. Sci. Kyushu Univ. Ser. E, 2(21), 5-23.

Neumann, M., \& Starlinger, F. (2001). The significance of different indices for stand structure and diversity in forests. Forest Ecology and Management, 145(1-2), 91-106. 
Newnham, G. J., Armston, J. D., Calders, K., Disney, M. I., Lovell, J. L., Schaaf, C. B., ... \& Danson, F. M. (2015). Terrestrial laser scanning for plot-scale forest measurement. Current Forestry Reports, 1(4), 239-251.

Olivier, M. D., Robert, S., \& Fournier, R. A. (2016). Response of sugar maple (Acer saccharum, Marsh.) tree crown structure to competition in pure versus mixed stands. Forest Ecology and Management, 374, 20-32.

Pielou, E. C. (1959). The use of point-to-plant distances in the study of the pattern of plant populations. The Journal of Ecology, 607-613.

Pinheiro, J. C., \& Bates, D. M. (2000). Mixed-effects models in S and S-PLUS. New York: Springer. $538 \mathrm{p}$.

Pinheiro, J.C., Bates, D., DebRoy, S., Sarkar, D. and Core Team, R. (2016). Nlme: Linear and Nonlinear Mixed Effects Models [R Package Version 3.1-128].

Pretzsch, H., \& Schütze, G. (2005). Crown allometry and growing space efficiency of Norway spruce (Picea abies [L.] Karst.) and European beech (Fagus sylvatica L.) in pure and mixed stands. Plant Biology, 7(06), 628-639.

Pretzsch, H., \& Schütze, G. (2009). Transgressive overyielding in mixed compared with pure stands of Norway spruce and European beech in Central Europe: evidence on stand level and explanation on individual tree level. European Journal of Forest Research, 128(2), 183-204.

Pretzsch, H. (2014). Canopy space filling and tree crown morphology in mixed-species stands compared with monocultures. Forest Ecology and Management, 327, 251-264.

Pretzsch, H., \& Schütz, G. J. (2014). Size-structure dynamics of mixed versus pure forest stands. Forest systems, 23(3), 560-572.

Pretzsch, H., Del Río, M., Ammer, C., Avdagic, A., Barbeito, I., Bielak, K., ... \& Fabrika, M. (2015). Growth and yield of mixed versus pure stands of Scots pine (Pinus sylvestris L.) and European beech (Fagus sylvatica L.) analysed along a productivity gradient through Europe. European Journal of Forest Research, 134(5), 927-947.

Pretzsch, H. (2016). Ertragstafel-Korrekturfaktoren für Umwelt- und Mischungseffekte. AFZ Der Wald. 
Pretzsch, H., Del Río, M., Schütze, G., Ammer, C., Annighöfer, P., Avdagic, A., ... \& Drössler, L. (2016). Mixing of Scots pine (Pinus sylvestris L.) and European beech (Fagus sylvatica L.) enhances structural heterogeneity, and the effect increases with water availability. Forest Ecology and Management, 373, 149-166.

Pretzsch, H., \& Schütze, G. (2016). Effect of tree species mixing on the size structure, density, and yield of forest stands. European journal of forest research, 135(1), 1-22.

Reineke, L.H. (1933). Perfecting a stand-density index for even-aged forests. Journal of Agricultural Research, 46, 627-638.

Röhrig, E., Bartsch, N. and von Lüpke, B. (2006). Waldbau auf ökologischer Grundlage. 7th edn. Ulmer Verlag.

Schall, P., Schulze, E. D., Fischer, M., Ayasse, M., \& Ammer, C. (2018). Relations between forest management, stand structure and productivity across different types of Central European forests. Basic and Applied Ecology, 32, 39-52.

Schwarz, M. T., Bischoff, S., Blaser, S., Boch, S., Schmitt, B., Thieme, L., ... \& Wilcke, W. (2014). More efficient aboveground nitrogen use in more diverse Central European forest canopies. Forest Ecology and Management, 313, 274-282.

Seidel, D., Fleck, S., Leuschner, C., \& Hammett, T. (2011). Review of ground-based methods to measure the distribution of biomass in forest canopies. Annals of Forest Science, 68(2), 225-244.

Seidel, D., Ehbrecht, M., \& Puettmann, K. (2016). Assessing different components of threedimensional forest structure with single-scan terrestrial laser scanning: A case study. Forest ecology and management, 381, 196-208.

Seidel, D., Ruzicka, K. J., \& Puettmann, K. (2016). Canopy gaps affect the shape of Douglas-fir crowns in the western Cascades, Oregon. Forest Ecology and Management, 363, 31-38.

Schulze, E. D., Aas, G., Grimm, G. W., Gossner, M. M., Walentowski, H., Ammer, C., ... \& Von Gadow, K. (2016). A review on plant diversity and forest management of European beech forests. European journal of forest research, 135(1), 51-67.

Shannon, C. E. (1948). A mathematical theory of communication. Bell system technical journal, 27(3), 379-423. 
Soares, A. A., Leite, H. G., Cruz, J. P., \& Forrester, D. I. (2017). Development of stand structural heterogeneity and growth dominance in thinned Eucalyptus stands in Brazil. Forest Ecology and Management, 384, 339-346.

Spiecker, H. (2003). Silvicultural management in maintaining biodiversity and resistance of forests in Europe-temperate zone. Journal of Environmental Management, 67(1), 55-65.

Verstraeten, G. (2013). Conversion of deciduous forests to spruce plantations and back: evaluation of interacting effects on soil, forest floor, earthworm and understorey communities. Dissertation. Ghent University.

Vilà, M., Carrillo-Gavilán, A., Vayreda, J., Bugmann, H., Fridman, J., Grodzki, W., ... \& Trasobares, A. (2013). Disentangling biodiversity and climatic determinants of wood production. PloS one, 8(2), e53530.

Williams, L. J., Paquette, A., Cavender-Bares, J., Messier, C., \& Reich, P. B. (2017). Spatial complementarity in tree crowns explains overyielding in species mixtures. Nature Ecology \& Evolution, 1(4), 0063.

Zeller, L., \& Pretzsch, H. (2019). Effect of forest structure on stand productivity in Central European forests depends on developmental stage and tree species diversity. Forest ecology and management, 434, 193-204.

Zenner, E. K., \& Hibbs, D. E. (2000). A new method for modeling the heterogeneity of forest structure. Forest Ecology and Management, 129(1-3), 75-87.

Zerbe, S. (2002). Restoration of natural broad-leaved woodland in Central Europe on sites with coniferous forest plantations. Forest Ecology and Management, 167(1-3), 27-42. 


\section{Chapter 5}

Synopsis 
The structure of forests affects most processes, functions, and services in forest ecosystems (e.g. light interception, water balance, habitat suitability, wood quality, or recreational benefit) (Pretzsch et al., 2015). Changes in silvicultural management alter forest structure and, as a consequence, also the ecological and economical value of a forest stand. Silvicultural success in achieving a certain management goal is therefore strongly dependent on knowledge about the consequences of forest management on the resulting tree and stand structure. The results presented in this thesis contribute to a better understanding of how different management approaches modify tree and stand structure and may provide insights for the advancement of silvicultural practices to promote desired ecosystem functions and services of forests.

\subsection{Effect of silvicultural management intensity on tree and stand structure}

The obtained results in chapter 2 demonstrated that different levels of silvicultural management intensity significantly influenced architectural characteristics of beech trees, which supports our second hypothesis. Our findings showed an increasing crown surface area and a decreasing height of the maximal horizontal crown extension with increasing management intensity.

Growing space extensions through thinnings are commonly used in forestry to promote the crown expansion of the remaining trees (Fichtner et al., 2013). The lower competitive pressure in beech stands with a higher management intensity resulted in a downward shift of the vertical foliage distribution, which reduces self-shading and thus improves light availability in deeper stand layers (Martin-Ducup et al., 2018). Under high intraspecific competition, however, as present in stands with a lower management intensity, light is a limiting factor. The higher stand densities and closed canopies in the unmanaged stands decreased the light availability in lower canopy layers, which led to the loss of branches in lower tree parts and an upward shift of the photosynthetic material to improve light interception.

A similar result could also be observed at stand level in chapter 3 of this thesis. We found that a decreasing management intensity resulted in single-layered canopies and lower space filling values for most of the unmanaged stands in our study. A higher management intensity and thus lower stand densities on the other hand, enabled the development of structurally complex canopies with multi-layered foliage structures and therefore higher space filling values for the majority of the managed beech stands (see Figure 5.1). 

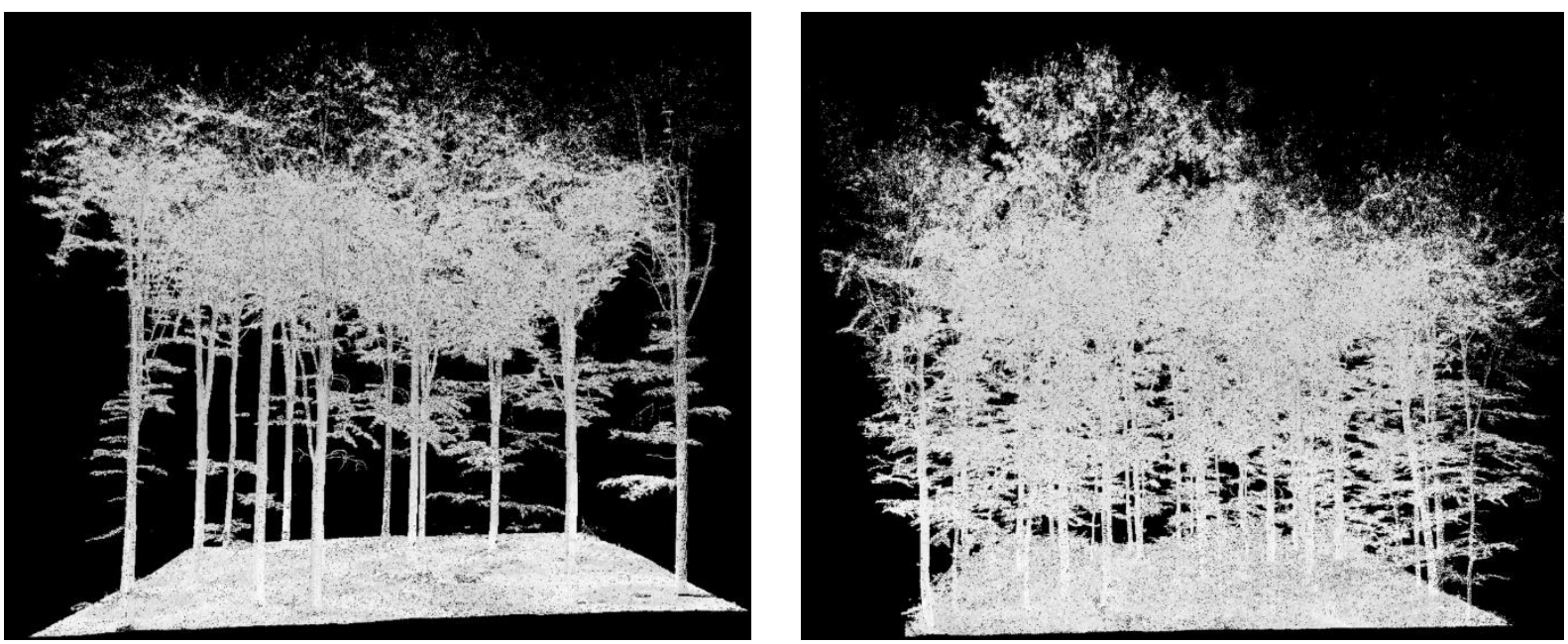

Figure 5.1: Exemplary point cloud of an unmanaged beech stand with low space filling (left) and a mature even-aged beech stand with high space filling (right).

These findings confirm our third hypothesis and demonstrate that silvicultural practices do not necessarily reduce the structural heterogeneity of forests. Our results show that in mature beech forests, stand density reductions through thinnings, which prevent the development of a closed canopy, even result in a more heterogeneous stand structure compared to unmanaged forests with no silvicultural interventions. However, an increase in management intensity can only lead to an increase in space filling and a more heterogeneous stand structure up to a certain point. Very high thinning intensities would result in very low stand densities and thus in decreasing space filling, since the resulting empty space cannot be filled to an infinite degree by lateral or vertical crown expansion of the remaining trees.

The presented results confirmed empiric knowledge that silvicultural management controls the structure of forests to a great extent. It is for example well known, that uneven-aged forest management (single-tree selection system) results in different diameters, heights and age of trees and thus in a high small-scale structural heterogeneity at stand level (Bagnaresi et al., 2002, Ehbrecht et al., 2017), which was also expressed by high space filling values in our study. However, in contrast to previous studies (e.g. Kuuluvainen et al., 1996; Glatthorn et al., 2017) we found a more heterogeneous stand structure in the managed even-aged forests in comparison to the unmanaged forests. This might be explained on the one hand by the fact that even-aged-forestry can vary widely in timing, intensity and frequency of thinning as well as by the final harvest age and therefore can affect stand structure in different ways.

In a study by Glatthorn et al. (2017), who found a greater canopy structural heterogeneity for Slovakian primeval forests compared to managed even-aged forests, stem densities were on average higher in the managed than in the primeval beech forests. The managed forests showed a closed canopy as beech stands in Slovakia are normally thinned only about 10 years before final harvest. 
The lower structural heterogeneity of the Slovakian managed even-aged forests might therefore be attributed to the less frequent silvicultural interventions as for example in even-aged forests in Germany. Another possible explanation for the contrasting results might be the fact that forest management of the unmanaged beech stands in our study has ceased only a few decades ago (2070 years).

In Central Europe beech-dominated primeval forests are extremely rare and are mainly restricted to the Carpathian Mountains (Parviainen, 2005). Nearly all unmanaged beech forests in reserves and national parks were formerly managed to some degree and many of these forests are still on the way to develop old-growth structures (Brunet et al., 2010). This also applies to the investigated unmanaged beech stands. As a consequence, most of the structural characteristics that are often associated with old-growth forests, such as multi-layered canopies, a high variation of tree sizes and age, many large and old trees, standing dead trees, and a large number of lying dead wood were absent in these forests. Management interventions in the studied beech stands have been ceased in the mature timber stage and the stands were still in the optimum stage as indicated by a closed canopy, low amounts of dead wood and a lack of decaying trees. They formed hall-like forests, characterized by mainly stems in the lower height levels and a uniform stand structure, with little or no shrub and herb layer. The existing stand structure demonstrates that forest management cessation in the early-optimum or mid-optimum stage does not result in a more heterogeneous stand structure within a few decades. If no larger natural (e.g. heavy windthrows) or anthropogenic disturbances occur during this time, the structurally less complex optimum stage will remain until e.g. natural causes result in the decay of over-aged trees and provide space and light for younger ones. To shorten this possibly long period of low structural heterogeneity in beech forests, it may thus be considered to create larger canopy openings before the abandonment of forest management.

This might however be different in forests with tree species which have a less vigorous lateral crown expansion and a lower crown plasticity, such as conifers. For example, Sitzia et al. (2012) found a higher tree species richness, a higher log and snag volume and a two-layered stand structure 50 years after the cessation of forest management in mature silver fir (Abies alba) stands.

Our findings show that terrestrial laser scanning is a suitable tool to accurately measure, and as a result, better understand tree and forest structures. The presented results highlight that forest management history and particularly the length of the period since management abandonment are playing a crucial role in studies using a silvicultural management gradient. To cover levels of zero or low management intensity, it is not only of relevance that the forests are no longer managed, but rather that it is differentiated between short-term and long-term unmanaged forests and that both are included in such an investigation. 
Future studies should examine the effect of silvicultural interventions on three-dimensional tree and stand structure across a greater management gradient, different environmental conditions and various tree species. This could further improve our understanding of how structural heterogeneity is created and how it could be promoted by silvicultural practices.

\subsection{Effect of forest structure on stand productivity}

In forest ecology, the number of studies addressing the effect of tree species diversity on forest functioning is rapidly increasing (Hooper et al., 2005; Kelty, 2006; Liang et al., 2016; Ammer, 2019), whereas the influence of structural diversity has only recently begun to gain importance. The few existing studies that have so far investigated the relationship between stand structural attributes and productivity are moreover contradictory and have reported positive (Lei et al., 2019), negative (Soares et al., 2016) or non-significant effects (Long and Shaw, 2010).

Our findings in chapter 2 revealed that an increased space filling of the total stand in leaf-on condition as a result of thinning positively influenced stand productivity, which is consistent with our fourth hypothesis. Vacant growing space in the canopy was occupied by a more even vertical distribution of foliage and the expansion of lateral branches particularly in the shade crown whereas in deeper stand layers, space was filled by crown expansion of small trees and advanced regeneration. The increased space filling in the shade canopy (40-70\% of stand height) and in the understory ( $0-10 \%$ of stand height) overcompensated the loss of occupied space through thinning. Consequently, space filling of the entire stand increased despite the removal of trees. This finding is remarkable as it demonstrates the highly efficient space occupation of European beech as a result of its great morphological plasticity. However, as mentioned earlier, an increase in management intensity can only lead to an increase in space filling up to a certain point. Our results indicate that in the observed range of management intensity the remaining trees were still able to overcompensate the losses caused by thinning.

Stand density reductions through thinning commonly intend to reduce competition and improve resource availability, uptake as well as use efficiency of residual trees (Pretzsch, 2009, Bouriaud et al., 2019). A positive impact of silvicultural interventions on the growth of beech trees has been reported by several studies (Le Goff and Ottorini, 1999; van der Maaten, 2013), the physiological explanation however, has seldom been provided on the basis of empirical data.

Our data revealed that in leaf-on condition, in particular an increased space filling in the shade canopy positively influenced the productivity of the stand. This indicates that at stand level, productivity is also affected by the distribution of foliage and not only by the foliage quantity. Space filling in leaf-off condition was not related to productivity. We also found no significant 
relationship between space filling in leaf-off condition and silvicultural management intensity. We argue that an increased space filling in the shade canopy of managed European beech stands is the missing link explaining the compensation of production losses due to stand density reductions.

Trees with shade leaves generally produce larger leaf areas and can maintain a positive carbon balance under very low light intensities (Falster and Westoby, 2003; Ellenberg and Leuschner, 2010; Legner et al., 2013). Thus, in forests where light is the main limiting factor, the presence of a pronounced shade canopy presumably leads to higher carbon gain and greater relative growth rates. A dense sun canopy layer (80-100\% of stand height) and the absence of a deep-reaching shade crown in beech forests with high stand densities, on the other hand seems to result in less efficient light use and negatively affected stand productivity. According to this reasoning, a positive effect of an increased space filling in the shade canopy on stand productivity may however only exist for tree species that are capable of developing a distinct shade crown with low light acclimated leaves. To find out whether a similar effect also applies to other tree species, further comparative studies on the influence of three-dimensional canopy structure on stand productivity with tree species which differ in their leaf morphological and photosynthetic traits are needed.

Conventional measures of structural diversity such as the Gini coefficient and the Shannon and Simpson index of diameters were not related to stand productivity. In addition, no significant relationship between management intensity and structural diversity described by conventional measures was identified. The findings support a previous study of Ishii et al. (2004) who pointed out that " $[\ldots]$ conventional, ground-based measurements such as species composition and treesize distribution, only indirectly reflect the three-dimensional structure of forest ecosystems and processes that define the relationship between ecosystem structure and function. [...] processes that determine productivity of forest ecosystems, such as photosynthesis and nutrient uptake, occur in the canopy and in the soil, not at breast height". It seems as if structural diversity measures which are only based on tree size inequality might not be suitable to fully capture those structural components which are related to stand productivity. It could thus be that studies which didn't find a positive effect of structural diversity on stand productivity might have received other results if they had used three-dimensional structural attributes such as "space filling".

Although upper-canopy trees normally contribute the largest part to biomass and production in forests, the occurrence of small trees and advanced regeneration can also play an important role in increasing stand-level increment (Ishii et al., 2004). A more heterogeneous canopy, as present in the studied managed beech stands, allows trees in the understory to receive more light and contribute more to stand productivity than a closed canopy, as present in the unmanaged stands. In addition, it has been shown that vertically structured forests increase the resource availability for 
different species assemblages (Müller et al., 2018). Thus, a higher canopy space filling might also enhance the biodiversity of some taxonomic groups as an added benefit.

It should however be noted that productivity was quantified by the periodic annual increment of the stands and our analysis is therefore limited to above-ground productivity. For clarification whether total biomass growth of a forest is positively affected by an increased vertical foliage distribution, further research should also focus on below-ground productivity. Moreover, although a more complete occupation of growing space may be beneficial regarding tree growth and biodiversity, larger crowns may have negative economic effects as well. A more heterogeneous vertical structure enables deeper light penetration and thus the growth of leaves and branches in lower parts of the stem, which decreases timber quality. A lower height of the crown base, branchiness and knottiness occur more frequently in more complex forests (Pretzsch and Rais, 2016).

Our observations highlight the relevance of three-dimensional structural attributes for answering forest ecological questions and make an important contribution to a better understanding of the relationship between forest management, canopy structure and stand productivity of mature beech stands.

\subsection{Effect of tree species mixing on tree and stand structure}

Our fifth hypothesis stated that the complexity of the three-dimensional stand structure increases with increasing trees species diversity. Our results supported this hypothesis since we found an increasing but saturating relationship between stand structural complexity (SSCI) and the exponential Shannon diversity index. The findings demonstrated that the SSCI increases only up to a point, beyond which further species seem to have no additional effect on the structural complexity of the stands. We assume that the relationship saturates at higher levels of diversity, because the overlap between the different tree species in functionality increases. Interestingly, the relationship between diversity and stand productivity shows a curve similar to that of species diversity and structural complexity (Ammer, 2019). This might mean that to a certain extent, complex stand structures due to species diversity positively influence the productivity at stand level. The shape of both curves, however, presumably depends on the species composition and therefore on the identity and number of tree species that are necessary to gain optimal functional diversity.

Figure 5.2a shows that forests with beech as main tree species (basal are share of beech $>50 \%$ ) had the highest structural complexity in our study, despite the fact that the tree species diversity in these forests did not significantly differ from forests with spruce or pine as main tree species (see Figure 5.2b). 


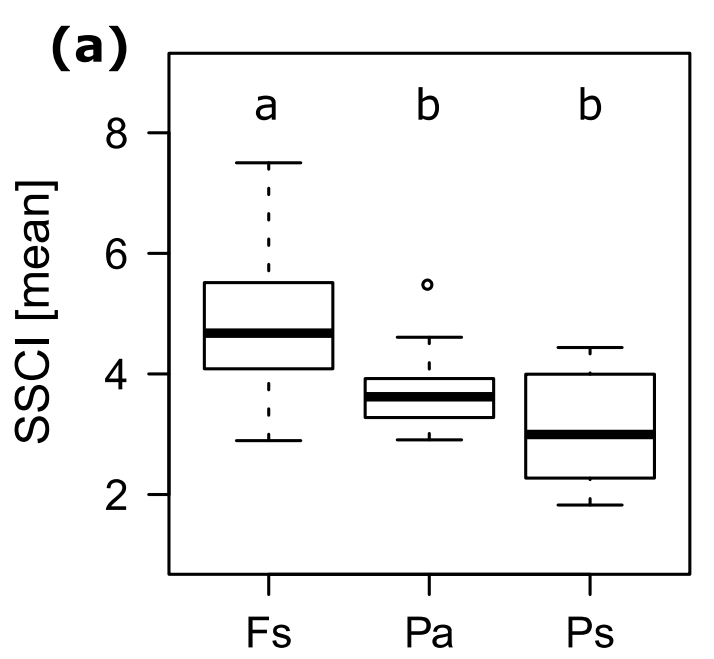

Main tree species

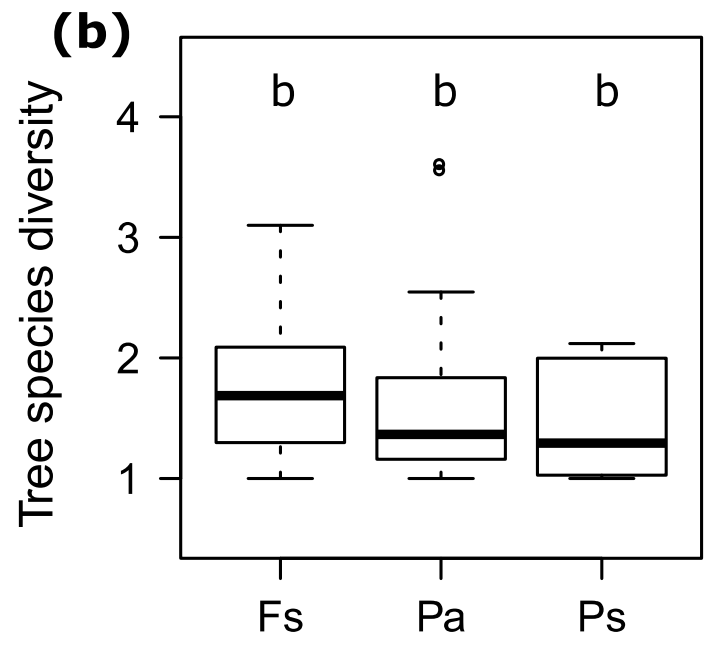

Main tree species

Figure 5.2: Mean SSCI of stands with F. sylvatica (Fs), P. abies $(\mathrm{Pa})$ and P. sylvestris $(\mathrm{Ps})$ as main tree species (a) and tree species diversity of stands with F. sylvatica $(\mathrm{Fs})$, P. abies $(\mathrm{Pa})$ and P. sylvestris $(\mathrm{Ps})$ as main tree species (b). Significant differences are indicated by different letters (ANOVA, $\mathrm{p}<0.01$ ).

However, as for the entire sample (cf. chapter 4), the stand structural complexity of the beech dominated stands also follows an asymptotic exponential relationship with increasing tree species diversity (Figure 5.3).

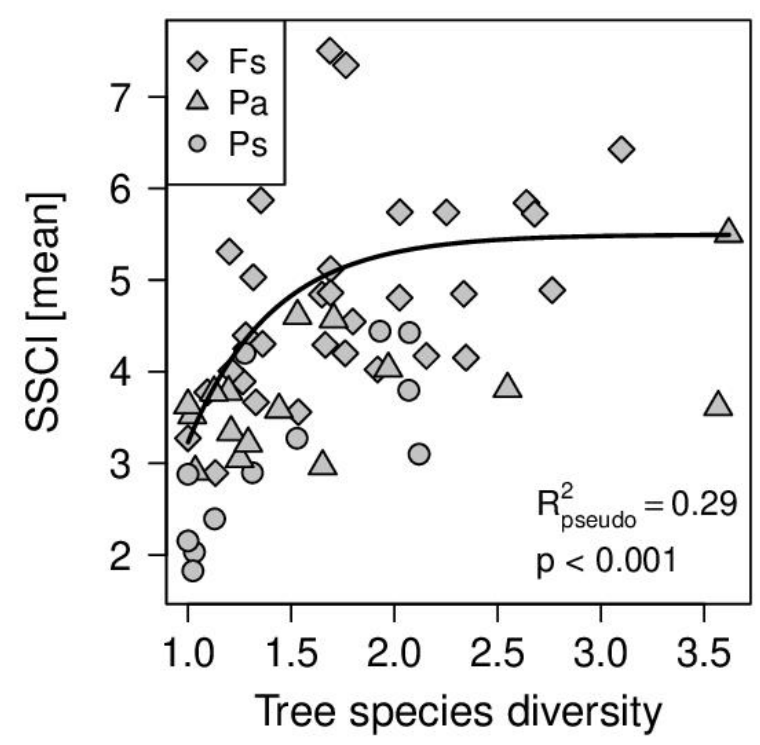

Figure 5.3: Relationship between mean SSCI and tree species diversity for beech dominated stands (see also Ehbrecht et al. 2017). Symbols indicate main tree species: $\mathrm{Fs}=$ F. sylvatica, $\mathrm{Pa}=$ P. abies, $\mathrm{Ps}=$ P. sylvestris.

The higher complexity of the beech dominated stands was particularly evident when the influence of an increasing basal area proportion of broadleaved trees on the stand structural complexity of coniferous stands was examined. The obtained finding confirmed our sixth 
hypothesis, stating that the stand structural complexity of coniferous stands increases with an increasing share of broadleaves. This result is of high relevance and provides evidence that the conversion of monospecific conifer stands into mixed forests, which became a major objective of forest management and policy in many countries in Central Europe, can promote the development of structurally more complex stand structures. However, given the contrasting crown morphologies of coniferous and broadleaved tree species, one might have expected rather a humped-shaped relationship than a linear relationship and thus higher SSCI-values for mixtures of coniferous and broadleaved tree species than for mixtures of different broadleaves.

This could be explained on the one hand by the fact that not only broadleaved and coniferous trees species differ largely in their growth patterns. Broadleaves of the genera Fagus, Acer, Tilia, Carpinus and Fraxinus, which were the most abundant broadleaved trees in our study, were also found to differ considerably regarding crown architecture, shade tolerance, growth rate and other morphological and functional traits (Frech et al., 2003, Ellenberg and Leuschner, 2010). Mixing trees with complementary architectural and physiological characteristics has been shown to result in an increased vertical structuring (Pretzsch et al., 2017). In the present study, complementary filling of canopy space could for instance occur, when shade-tolerant species with slow growth, such as beech or lime (Tilia spec.), coexist with more light-demanding species with fast growth such as ash (Fraxinus excelsior L.). Moreover, gymnosperm species are supposed to have a lower crown plasticity than angiosperms (Getzin and Wiegand, 2007) leading to a more uniform intertree spacing and crown extent. The linear relationship might also be explained by the fact that the examined stands dominated by broadleaved species consisted to a large extent of beech tress and the beech proportion thus increased with an increasing share of broadleaves.

Tree species with a high crown plasticity and a vigorous lateral crown expansion such as European beech can better occupy additional space emerging in mixed stands than less plastic species such as Scots pine and Norway spruce (Pretzsch, 2019). Higher plasticity together with an increased vertical stratification due to crown complementarity in mixtures ultimately results in a denser canopy space filling which is often accompanied by a higher structural complexity (Jucker et al., 2015; Pretzsch et al., 2017). Figure 5.4 shows the effect of an increasing basal area share of beech on the stand structural complexity of the studied forest stands in chapter 4 (in contrast to Figure 4.2 in chapter 4, Figure 5.4 also includes plots with a basal area share of $100 \%$ broadleaved tree species and $100 \%$ beech respectively, whereas stands with a basal area share of $0 \%$ beech were excluded). 


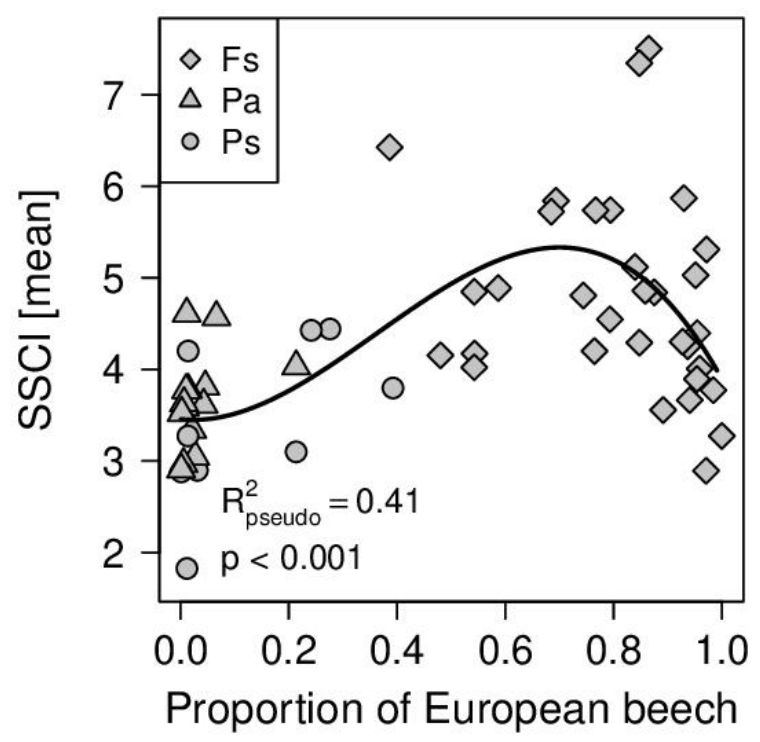

Figure 5.4: Relationship between mean SSCI per plot and basal area proportion of beech. Symbols indicate main tree species: $\mathrm{Fs}=F$. sylvatica, $\mathrm{Pa}=P$. abies, $\mathrm{Ps}=$ P. sylwestris.

The curve demonstrates that the highest structural complexity seems to be achieved at a beech proportion of around $70 \%$ and therefore at a basal area share of around $30 \%$ of the admixed tree species. A further increase in the proportion of beech trees as well as in the share of other tree species, however, seems to reduce the structural complexity.

This result shows that a single morphologically highly plastic tree species, which can extremely efficiently occupy free canopy space, is able to increase the structural complexity of different forest types. The finding moreover supports the idea that certain tree species benefit from mixing with other species. (Pretzsch, 2014). As beech has a low self-tolerance in comparison to other tree species (Zeide, 1985), competition for growing space and the resulting self-thinning is often stronger in pure beech stands. The enrichment of beech monocultures with other species can reduce the competitive pressure, so that the thinning in mixture proceeds less intense than the selfthinning (Pretzsch et al., 2012). Consequently, it has repeatedly been reported that the admixture of other tree species can increase the stand productivity of beech (Pretzsch and Schütze, 2009; Pretzsch et al., 2013; Tö̈go et al., 2015).

The potential of beech to plastically respond to changes in local canopy conditions by exploring more space in mixed stands could also be demonstrated by our results in chapter 2 of this thesis. The obtained findings confirmed our first hypothesis, stating that structural attributes of beech trees vary significantly between trees exposed to intra- or interspecific competition. We found that beech trees growing in unmanaged stands in mixture with other broadleaved tree species developed flatter branch angles and a lower height of the maximal horizontal crown extension than beech tress growing in unmanaged pure stands. This resulted in wider and deeper crowns for beech 
surrounded by allospecific neighbors, whereas the higher competitive pressure and the lower light availability for beech trees surrounded by conspecific neighbors led to thinner crowns and an upward shift of the foliage. These results also indicate that mixing with other broadleaved tree species is beneficial to beech and may lead to a more efficient light interception. However, we investigated in this study only the effect of "neighborhood diversity" on the structure of beech trees and thus solely differentiated whether a local neighborhood included other species than the focal tree. Since crown size and shape (Pretzsch, 2014), and thus the resource-use efficiency of beech (Fichtner et al., 2013) are highly dependent on the species composition of the competitors, further studies should also consider the identity of the surrounding broadleaves species.

Our work shows that TLS-derived structural measures can enhance the quantification of crown plasticity and enable an improved knowledge of the mixing effects on stand structural complexity. Overall, our findings highlight that not only the number of mixed species but also the composition of the mixture and thus the species identities and their respective share determines stand structural complexity. It could thus be useful, to form groups of tree species according to their functional characteristics rather than their taxonomy. Future investigations should examine the relevance of species identity and determine those functional traits which mostly affect the relationship between diversity and structural complexity. Such studies may further contribute to a better understanding of the frequently reported positive effects of structurally complex multi-species forests on ecosystem functioning. 


\subsection{Conclusion}

The results of this thesis provide novel insights on the effects of silvicultural management intensity and tree species diversity on the three-dimensional tree and stand structure. We found terrestrial laser scanning to be a highly suitable tool to measure non-destructively and accurately the structure of individual tree crowns as well as the space filling and structural complexity of different forest stands.

Our findings demonstrate the superior ability of European beech to occupy canopy space and to plastically respond to changes in stand density and neighborhood composition. Moderate reductions in stand density of beech forests and the resulting greater light transmission to lower canopy strata enabled the development of a multi-layered shade canopy and a dense understory, which overcompensated the loss of occupied space through thinning. Consequently, space filling of the entire stand increased despite the removal of trees. The increased space filling, particularly in the shade canopy, positively influenced stand productivity. A decreasing silvicultural management intensity and thus higher stand densities on the other hand, led to a closed and monolayered canopy and therefore to lower space filling and stand productivity values.

Our results show that managed beech forests, where regular thinning activities prevent a complete canopy closure, develop a higher structural heterogeneity than beech forests that have not been managed in the last 20 to 70 years. If no larger natural or anthropogenic disturbances occur, forest management cessation in the early-optimum or mid-optimum stage does not result in a more heterogeneous stand structure within a few decades. The presented findings highlight that forest management history and particularly the length of the period since management abandonment are playing a crucial role in studies using a silvicultural management gradient.

Moreover, this thesis provides evidence that structural attributes of beech trees vary significantly between trees exposed to intra- or interspecific competition and that beech trees growing in mixture with other broadleaved trees develop larger crowns compared to pure stands.

We found that the creation of species-rich forests as well as the conversion of monospecific conifer stands into mixed broadleaved forests promotes the development of structurally more complex stand structures. We could furthermore demonstrate that an enrichment of beech forests with other tree species (up to $\sim 30 \%$ ) leads to a more complex stand structure and that an increasing basal area share of beech (up to $\sim 70 \%$ ) increases the structural complexity of different forest types. The obtained results underline that not only the number of mixed species but also the composition of the mixture and thus the identities of the species and their respective share determines stand structural complexity. To what extent our findings can be transferred to other tree species and different environmental conditions is subject to further research. 
In addition to the results mentioned, this thesis has made a significant contribution to the further development of the laser scanning methodology in forest stands. On the one hand, new algorithms for the analysis of space filling were developed, which can also be used in uneven terrain. On the other hand, automated methods for determining branch angles, lengths and volumes could be applied in order to generate data on the inner crown structure. Many of the measured structural attributes are hardly, in some cases not at all, obtainable with conventional field measurements. Since LiDAR devices and the methods for data evaluation will be further improved in the future, this technology has enormous potential to contribute to a comprehensive understanding of the tree and stand structure. 


\subsection{References}

Ammer, C. (2019). Diversity and forest productivity in a changing climate. New Phytologist, 221(1), $50-66$.

Bagnaresi, U., Giannini, R., Grassi, G., Minotta, G., Paffetti, D., Prato, E. P., \& Placidi, A. P. (2002). Stand structure and biodiversity in mixed, uneven-aged coniferous forests in the eastern Alps. Forestry, 75(4), 357-364.

Bouriaud, O., Don, A., Janssens, I. A., Marin, G., \& Schulze, E. D. (2019). Effects of forest management on biomass stocks in Romanian beech forests. Forest Ecosystems, 6(1), 19.

Brunet, J., Fritz, Ö., \& Richnau, G. (2010). Biodiversity in European beech forests-a review with recommendations for sustainable forest management. Ecological Bulletins, 77-94.

Burger, H. (1939). Baumkrone und Zuwachs in zwei hiebsreifen Fichtenbeständen. Mitteilung der Schweizerischen Anstalt für das Forstliche Versuchswesen, 21, 147-176.

Ehbrecht, M., Schall, P., Ammer, C., \& Seidel, D. (2017). Quantifying stand structural complexity and its relationship with forest management, tree species diversity and microclimate. Agricultural and Forest Meteorology, 242, 1-9.

Ellenberg, H., \& Leuschner, C. (2010). Vegetation Mitteleuropas mit den Alpen: in ökologischer, dynamischer und historischer Sicht (Vol. 8104). Utb.

Falster, D. S., \& Westoby, M. (2003). Leaf size and angle vary widely across species: what consequences for light interception?. New Phytologist, 158(3), 509-525.

Fichtner, A., Sturm, K., Rickert, C., Von Oheimb, G., \& Härdtle, W. (2013). Crown size-growth relationships of European beech (Fagus sylvatica L.) are driven by the interplay of disturbance intensity and inter-specific competition. Forest Ecology and Management, 302, 178-184.

Frech, A., Leuschner, C., Hagemeier, M., \& Holscher, D. (2003). Neighbor-dependent canopy dimensions of ash, hornbeam, and lime in a species-rich mixed forest (Hainich National Park, Thuringia). Forstwissenschaftliches Centralblatt, 122(1), 22-35. 
Garber, S. M., \& Maguire, D. A. (2005). The response of vertical foliage distribution to spacing and species composition in mixed conifer stands in central Oregon. Forest Ecology and Management, 211(3), 341-355.

Getzin, S., \& Wiegand, K. (2007). Asymmetric tree growth at the stand level: random crown patterns and the response to slope. Forest Ecology and Management, 242(2-3), 165-174.

Glatthorn, J., Pichler, V., Hauck, M., \& Leuschner, C. (2017). Effects of forest management on stand leaf area: comparing beech production and primeval forests in Slovakia. Forest Ecology and Management, 389, 76-85.

Hooper, D. U., Chapin, F. S., Ewel, J. J., Hector, A., Inchausti, P., Lavorel, S., ... \& Schmid, B. (2005). Effects of biodiversity on ecosystem functioning: a consensus of current knowledge. Ecological monographs, 75(1), 3-35.

Ishii, H. T., Tanabe, S. I., \& Hiura, T. (2004). Exploring the relationships among canopy structure, stand productivity, and biodiversity of temperate forest ecosystems. Forest Science, 50(3), 342-355.

Jucker, T., Bouriaud, O., \& Coomes, D. A. (2015). Crown plasticity enables trees to optimize canopy packing in mixed-species forests. Functional Ecology, 29(8), 1078-1086.

Kelty, M. J. (2006). The role of species mixtures in plantation forestry. Forest Ecology and Management, 233(2-3), 195-204.

Kuuluvainen, T., Penttinen, A., Leinonen, K., \& Nygren, M. (1996). Statistical opportunities for comparing stand structural heterogeneity in managed and primeval forests: an example from boreal spruce forest in southern Finland. Silva Fennica, 30, 315-328.

Le Goff, N., \& Ottorini, J. M. (1999). Effects of thinning on beech growth. Interaction with climatic factors. Revue Forestiere Francaise (France).

Legner, N., Fleck, S., \& Leuschner, C. (2013). Low light acclimation in five temperate broad-leaved tree species of different successional status: the significance of a shade canopy. Annals of Forest Science, 70(6), 557-570.

Lei, X., Wang, W., \& Peng, C. (2009). Relationships between stand growth and structural diversity in spruce-dominated forests in New Brunswick, Canada. Canadian Journal of Forest Research, 39(10), 1835-1847. 
Liang, J., Crowther, T. W., Picard, N., Wiser, S., Zhou, M., Alberti, G., ... \& De-Miguel, S. (2016). Positive biodiversity-productivity relationship predominant in global forests. Science, 354(6309), aaf8957.

Long, J. N., \& Shaw, J. D. (2010). The influence of compositional and structural diversity on forest productivity. Forestry, 83(2), 121-128.

Maguire, D. A., \& Bennett, W. S. (1996). Patterns in vertical distribution of foliage in young coastal Douglas-fir. Canadian Journal of Forest Research, 26(11), 1991-2005.

Martin-Ducup, O., Schneider, R., \& Fournier, R. A. (2018). Analyzing the vertical distribution of crown material in mixed stand composed of two temperate tree species. Forests, 9(11), 673.

Müller, J., Brandl, R., Brändle, M., Förster, B., de Araujo, B. C., Gossner, M. M., ... \& Schmidt, S. (2018). LiDAR-derived canopy structure supports the more-individuals hypothesis for arthropod diversity in temperate forests. Oikos, 127(6), 814-824.

Parviainen, J. (2005). Virgin and natural forests in the temperate zone of Europe. Forest, Snow and Landscape Research, 79(1/2), 9-18.

Pretzsch, H. (2009). Forest dynamics, growth, and yield. In Forest dynamics, growth and yield (pp. 1-39). Springer, Berlin, Heidelberg.

Pretzsch, H., \& Schütze, G. (2009). Transgressive overyielding in mixed compared with pure stands of Norway spruce and European beech in Central Europe: evidence on stand level and explanation on individual tree level. European Journal of Forest Research, 128(2), 183-204.

Pretzsch, H., Matthew, C., \& Dieler, J. (2012). Allometry of tree crown structure. Relevance for space occupation at the individual plant level and for self-thinning at the stand level. In Growth and Defence in Plants (pp. 287-310). Springer, Berlin, Heidelberg.

Pretzsch, H., Bielak, K., Block, J., Bruchwald, A., Dieler, J., Ehrhart, H. P., ... \& Zingg, A. (2013). Productivity of mixed versus pure stands of oak (Quercus petraea (Matt.) Liebl. and Quercus robur L.) and European beech (Fagus sylvatica L.) along an ecological gradient. European Journal of Forest Research, 132(2), 263-280.

Pretzsch, H. (2014). Canopy space filling and tree crown morphology in mixed-species stands compared with monocultures. Forest Ecology and Management, 327, 251-264. 
Pretzsch, H., Forrester, D. I., \& Rötzer, T. (2015). Representation of species mixing in forest growth models. A review and perspective. Ecological Modelling, 313, 276-292.

Pretzsch, H., \& Rais, A. (2016). Wood quality in complex forests versus even-aged monocultures: review and perspectives. Wood science and technology, 50(4), 845-880.

Pretzsch, H., Forrester, D. I., \& Bauhus, J. (2017). Mixed-species forests. Ecology and management. Springer, Berlin, 653.

Pretzsch, H. (2019). The effect of tree crown allometry on community dynamics in mixed-species stands versus monocultures. A review and perspectives for modeling and silvicultural regulation. Forests, 10(9), 810.

Short, E. A., \& Burkhart, H. E. (1992). Predicting crown-height increment for thinned and unthinned loblolly pine plantations. Forest Science, 38(3), 594-610.

Sitzia, T., Trentanovi, G., Dainese, M., Gobbo, G., Lingua, E., \& Sommacal, M. (2012). Stand structure and plant species diversity in managed and abandoned silver fir mature woodlands. Forest Ecology and Management, 270, 232-238.

Soares, A. A., Leite, H. G., Souza, A. L., Silva, S. R., Lourenço, H. M., \& Forrester, D. I. (2016). Increasing stand structural heterogeneity reduces productivity in Brazilian Eucalyptus monoclonal stands. Forest Ecology and Management, 373, 26-32.

Toïgo, M., Vallet, P., Perot, T., Bontemps, J. D., Piedallu, C., \& Courbaud, B. (2015). Overyielding in mixed forests decreases with site productivity. Journal of Ecology, 103(2), 502-512.

van der Maaten, E. (2013). Thinning prolongs growth duration of European beech (Fagus sylvatica L.) across a valley in southwestern Germany. Forest Ecology and Management, 306, 135141.

Zeide, B. (1985). Tolerance and self-tolerance of trees. Forest Ecology and Management, 13(3-4), 149-166. 

Appendix 


\section{List of figures}

Figure 1.1: Geographic location of the three study areas in Germany

Figure 1.2: The principle of terrestrial laser scanning: the scanner is mounted on a tripod and turns 180 degrees in horizontal direction and 300 in vertical direction, providing a field of view of $360 \times$ 300 degrees.

Figure 1.3: Point clouds of forest plots from single- (left) and multi-scan data (right). The left point cloud shows a shadowing effect behind the tree trunks due to the lack of information from only one perspective in the single-scan approach. The more laborious multi-scan approach allows an almost complete capture of the forest plot.

Figure 1.4: Draft of the single-scan (left) and multi-scan design (right). Scanner positions are indicated with a star. The masterscan (filled black) is located in the center of the plot.

Figure 1.5: Point cloud of a manually selected beech tree.

Figure 2.1: Map of the twelve study plots near the City of Mühlhausen, Thuringia, Germany. Basemap: Bing Aerial Maps.

Figure 2.2: Graphical visualization of the experimental design based on 12 plots and a total of 55 tree individuals.

Figure 2.3: Schematic draft of the trunk sections with the lines a, b, c and d used to calculate lean, sweep and uprightness. DBH diameter at breast height.

Figure 2.4: Point cloud from terrestrial laser scanning (left) and the corresponding quantitative structural model QSM (right). The close up (far right) visualizes the cylinder-based composition of the tree used for calculating volumes, branch angles, and branch lengths. All measures and information on their mathematical derivation are listed in Table 2.3.

Figure 2.5: Relationship between SMI and tree structure attributes. EA even-aged stands, UEA uneven-aged stands, UM unmanaged stands $(n=41)$. All attributes that were significantly affected by SMI are shown (level of significance $\mathrm{p}<0.05$ )

Figure 2.6: Boxplots of tree structure attributes that differed significantly between pure $(\mathrm{n}=11)$ and mixed stand composition.

Figure 3.1: Exemplary point cloud of a plot with the coordinate center indicated by the $\{0 / 0 / 0\}$ coordinate and the horizontal dimensions of the final plot area $(40 \mathrm{~m} \times 40 \mathrm{~m}$, bright grey). The original point cloud was always scanned to cover a minimum of $45 \mathrm{~m}$ by $45 \mathrm{~m}$ in great detail. Grey areas in Figure 3.1 show the remaining part of the poin $\mathrm{t}$ cloud not used for further processing, often more than $100 \times 100 \mathrm{~m}$ in extent. .56 
Figure 3.2: Visualization of the derivation of the digital elevation model (left) and its application to correct the voxel model for varying terrain heights. For better perceptibility only the center points of the voxels in the uncorrected voxel model (lower right) and its elevation-corrected pendant (upper right) are shown.

Figure 3.3: Relationship between SMI and periodic annual increment $(\mathrm{PAI}=0.038086+0.188747$ $* \mathrm{SMI}$, pseudo- $\left.\mathrm{R}^{2}=0.50, \mathrm{p}<0.001, \mathrm{n}=31\right) . \mathrm{EA}=$ mature even-aged stands, $\mathrm{UEA}=$ uneven-aged stands, $\mathrm{UM}=$ unmanaged stands.

Figure 3.4: Relationship between SMI and relative space filling in leaf-on condition (RSF $=5.5605$ $+10.2398 * \mathrm{SMI}$, pseudo- $\left.\mathrm{R}^{2}=0.62, \mathrm{p}<0.001, \mathrm{n}=35\right)$ and relationship between SMI and relative space filling in leaf-off condition (pseudo- $\mathrm{R}^{2}=0.37, \mathrm{p}=0.051, \mathrm{n}=35$ ). $\mathrm{EA}=$ mature even-aged stands, UEA = uneven-aged stands, $\mathrm{UM}=$ unmanaged stands.

Figure 3.5: Relationship between relative space filling in leaf-on condition and periodic annual increment $\left(\mathrm{PAI}=0.017073+0.006589 * \mathrm{RSF}\right.$, pseudo- $\left.\mathrm{R}^{2}=0.26, \mathrm{p}<0.05, \mathrm{n}=31\right) . \mathrm{EA}=$ mature even-aged stands, UEA = uneven-aged stands, UM = unmanaged stands. Exemplary point cloud of a mature even-aged beech stand (upper right) and an unmanaged beech stand (lower right)...62 Figure 3.6: Relative space filling in different height layers. Example of an unmanaged beech stand (a) and an uneven-aged beech stand (b) in leaf-on condition. Since the lowermost layer $(0-10 \%)$ is largely dominated by herbs and shrubs that do not contribute to the measured stand productivity we avoided showing this layer here. Usually, the presence of ground returns, dead wood and herbs and shrubs results in a large space filling for this layer.

Figure 4.1: Relationship between mean SSCI and tree species diversity (exponential ShannonIndex) factoring out plot BA (a), and relationship between mean SSCI and tree species diversity factoring out study region (b). Lines correspond to fitted relationships of the asymptotic model. Symbols indicate main tree species: $\mathrm{Fs}=$ F. sylvatica, $\mathrm{Pa}=$ P. abies, $\mathrm{Ps}=$ P. sylvestris.

Figure 4.2: Relationship between mean SSCI per plot and species proportion determined by BA. Lines correspond to fitted relationships of the linear mixed-effect model. Symbols indicate main tree species: $\mathrm{Fs}=F$. sylvatica, $\mathrm{Pa}=P$. abies, $\mathrm{Ps}=P$. sylvestris.

Figure 5.1: Exemplary point cloud of an unmanaged beech stand with low space filling (left) and a mature even-aged beech stand with high space filling (right).

Figure 5.2: Mean SSCI of stands with F. sylvatica (Fs), P. abies $(\mathrm{Pa})$ and P. sylvestris $(\mathrm{Ps})$ as main tree species (a) and tree species diversity of stands with F. sylvatica (Fs), P. abies (Pa) and P. sylvestris (Ps) as main tree species (b). Significant differences are indicated by different letters (ANOVA, $\mathrm{p}<0.01$ ). 
Figure 5.3: Relationship between mean SSCI and tree species diversity for beech dominated stands

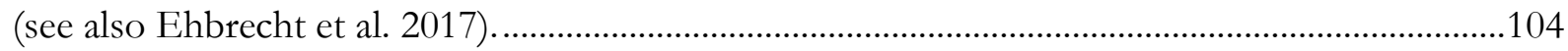

Figure 5.4: Relationship between mean SSCI per plot and basal area proportion of beech.........106 


\section{List of tables}

Table 2.1: Characterization of the study plots near the city of Mühlhausen, Germany.......

Table 2.2: Dimensions of sample trees $(n=55)$ presented as mean $( \pm$ standard deviation $)$ derived from the TLS data.

Table 2.3.: Structural measures determined for each sample tree $(\mathrm{n}=55) .1 \mathrm{st}$ and $2 \mathrm{nd}$ refer to the branch order; branch order was defined as ' 1 st' for branches branching from the main trunk and '2nd' for branches branching from the first-order branches. The adaxial branch angle between a branch and its parent branch is defined as the angle between the two cylinders (the first cylinder is the branch and the second is the parent branch).

Table 2.4: Results of the analysis of covariance (ANCOVA) with the independent variable 'composition' and the covariate 'T'TH' (total tree height). 36

Table 3.1: Summary of climatic and edaphic properties of the study plots. MAP = mean annual precipitation; $\mathrm{MAT}=$ mean annual temperature; $\mathrm{N}=$ number of investigated plots. For more detailed information about the research plots see Fischer et al. (2010).

Table 3.2: Results of the linear mixed effect model with relative space filling of a given layer as dependent variable and SMI as independent variable. Values given are the parameter estimate, the probability of error $\mathrm{p}$ for the model and the squared Pearson correlation coefficient between observed and model fitted values $\left(\right.$ pseudo- $\left.\mathrm{R}^{2}\right)$. Significant correlations $(\mathrm{p}<0.05)$ are highlighted in bold.

Table 3.3: Results of the linear mixed effect model with PAI as dependent variable and relative space filling of a given layer as independent variable. Values given are the parameter estimate, the probability of error $\mathrm{p}$ for the model and the squared Pearson correlation coefficient between observed and model fitted values $\left(p s e u d o-R^{2}\right)$. Significant correlations $(p<0.05)$ are highlighted in bold.

Table 4.1: General information of the study regions (modified from Fischer et al., 2010)...... .77

Table 4.2: Stand characteristics of the study plots. Min minimum, SD standard deviation, Max maximum, yrs years, $D B H$ Diameter at breast height, $N$ number of stems per hectare, $B A$ basal area per hectare, PBL basal area proportion of broadleaves, SSCI Structural Complexity Index, eH exponential Shannon-Index.

Table 4.3: Comparison of asymptotic regression models to analyze the effect of an increasing tree species diversity on SSCI.

Table 4.4: Comparison of linear mixed-effects models to analyze the effect of an increasing BA share of broadleaved tress on SSCI of coniferous stands. Basal area proportion of broadleaves and 
plot basal area are abbreviated as PBL and BA, respectively. Study region is included as a random effect. The best fitting model is shown in bold. 85 


\section{Danksagung}

An dieser Stelle möchte ich mich bei den zahlreichen Menschen bedanken, die mich auf vielfältigste Art und Weise bei der vorliegenden Arbeit begleitet und unterstützt haben.

Mein herzlicher Dank geht an Prof. Dr. Christian Ammer für seine Betreuung und Unterstützung während der letzten Jahre. Vielen Dank für die wertvollen Ratschläge, die konstruktiven Anmerkungen zu meinen Manuskripten, die motivierenden Worte, sowie das große Vertrauen und Verständnis insbesondere nach der Rückkehr aus meiner Elternzeit.

Dr. Dominik Seidel danke ich für die großartige Betreuung rund um das Thema Laserscanning, die stets rekordverdächtig schnelle Durchsicht meiner Manuskripte, seine positive Art und dafür, dass er sich immer Zeit genommen hat, wenn ich eine Frage hatte.

Bei Prof. Dr. Dirk Hölscher bedanke ich mich für das zweite Gutachten dieser Arbeit. Prof. Dr. Holger Kreft gebührt für die Teilnahme an der Prüfungskommission ebenso mein Dank.

Für die finanzielle Unterstützung im Rahmen des Schwerpunktprogrammes „BiodiversitätsExploratorien“ (SPP1374) danke ich der Deutschen Forschungsgemeinschaft (DFG). Ein Dank geht auch an die lokale Managementteams der Exploratorien für die Koordination der Feldarbeiten, das Management der Untersuchungsflächen und die gute Infrastruktur.

Des Weiteren danke ich meinen Kollegen der Abteilung Waldbau und Waldökologie der gemäßigten Zonen in Göttingen. Ich habe mich von Anfang an wohl gefühlt und bin sehr dankbar für das gute Arbeitsklima. Dr. Peter Schall danke ich für seinen hilfreichen Rat bei allen Fragen zu $\mathrm{R}$ sowie für seine Geduld, wenn ich nach einem Statistikgespräch auf sein „Verstoasch?“ mal wieder mit einem Kopfschütteln geantwortet habe. Bei Katharina Burkardt und Silke Marks möchte ich mich von ganzem Herzen für ihr offenes Ohr und die viele wunderbaren gemeinsamen Unternehmungen bedanken. Weiterhin danke ich Dr. Martin Ehbrecht für die tolle gemeinsame Feldarbeit und seinen bemerkenswerten Orientierungssinn, ohne den ich womöglich immer noch auf der Suche nach einzelnen Waldflächen wäre. Ein großes Dankeschön geht an meine ehemaligen Bürokollegin und Freundin Kirsten Höwler. Wir haben einige schwierige aber noch viel mehr schöne Zeiten gemeinsam erlebt. Vielen Dank für deine Hilfsbereitschaft in so vielen Situationen und dafür, dass du immer für mich da warst!

Bedanken möchte ich mich auch bei Nina Dannenhauer, Christina Henß, Hannah Bemm und Katharina Bagniewski für die großartige Freundschaft, ihre mentale Unterstützung und die zahlreichen Ablenkungen und schönen Momente abseits von der Arbeit.

Dr. Florian Knutzen bin ich sehr dankbar für die unzähligen Entscheidungshilfen, die vielen Fachgespräche, die hilfreichen Verbesserungsvorschläge sowie die aufbauenden Worte. 
Tiefster Dank gebührt meinen Eltern, die stets an mich geglaubt und dazu ermutigt haben meinen Weg zu gehen und mich immer unterstützt haben. Abschließend gilt mein besonderer Dank Florian Dirner für seine grenzenlose Geduld, seine Unterstützung und sein unendliches Verständnis sowie unserer Tochter Maila, die mein Leben unglaublich bereichert und meinen Blick immer wieder auf die wesentlichen Dinge des Lebens gelenkt hat. 


\section{Publication list}

Juchheim, J., Ehbrecht, M., Schall, P., Ammer, C., \& Seidel, D. (2020). Effect of tree species mixing on stand structural complexity. Forestry: An International Journal of Forest Research, 93(1): 75-83.

Seidel, D., Ehbrecht, M., Juchheim, J., Schall, P., \& Ammer, C. (2017). Terrestrisches Laserscanning erfasst komplexe Waldstrukturen. Allgemeine Forstzeitschrift/Der Wald 72 (17): 25-28.

Juchheim, J., Annighöfer, P., Ammer, C., Calders, K., Raumonen, P., \& Seidel, D. (2017). How management intensity and neighborhood composition affect the structure of beech (Fagus sylvatica L.) trees. Trees, 31(5), 1723-1735.

Juchheim, J., Ammer, C., Schall, P., \& Seidel, D. (2017). Canopy space filling rather than conventional measures of structural diversity explains productivity of beech stands. Forest Ecology and Management 395: $19-26$.

Ehbrecht, M., Schall, P., Juchheim, J., Ammer, C., \& Seidel, D. (2016). Effective number of layers: A new measure for quantifying three-dimensional stand structure based on sampling with terrestrial LiDAR. Forest Ecology and Management 380: 212-223.

Seidel, D., Hoffmann, N., Ehbrecht, M., Juchheim, J., \& Ammer, C. (2015). How neighborhood affects tree diameter increment-New insights from terrestrial laser scanning and some methodical considerations. Forest Ecology and Management, 336: 119-128 



\section{Declaration of originality and certificate of ownership}

I hereby declare that I am the sole author of this dissertation entitled "Quantifying the impact of forest management intensity and tree species diversity on individual tree shape and threedimensional stand structure". All references and data sources that were used in the dissertation have been appropriately acknowledged. I furthermore declare that this work has not been submitted elsewhere in any form as part of another dissertation procedure.

Frankfurt am Main, 14.10.2020

(Julia Juchheim) 